\title{
Experimental and Modeling Study of the Phase Behavior of Synthetic Crude Oil $+\mathrm{CO}_{2}$
}

\author{
Saif Z. Al Ghafri, Geoffrey C. Maitland, and J. P. Martin Trusler* \\ Qatar Carbonates and Carbon Storage Research Centre, Department of Chemical \\ Engineering, Imperial College London, South Kensington Campus, London SW7 2AZ \\ * Corresponding author e-mail: m.trusler@imperial.ac.uk.
}

\begin{abstract}
A full understanding of the phase behavior of $\mathrm{CO}_{2}$-hydrocarbon mixtures at reservoir conditions is essential for the proper design, construction and operation of carbon capture and storage (CCS) and enhanced oil recovery (EOR) processes. While equilibrium data for binary $\mathrm{CO}_{2}$-hydrocarbon mixtures are plentiful, equilibrium data and validated equations of state having reasonable predictive capability for multi-component $\mathrm{CO}_{2}$-hydrocarbon mixtures are limited. In this work, a new synthetic apparatus was constructed to measure the phase behavior of systems containing $\mathrm{CO}_{2}$ and multicomponent hydrocarbons at reservoir temperatures and pressures. The apparatus consisted of a thermostated variable-volume view cell driven by a computer-controlled servo motor system, and equipped with a sapphire window for visual observation. Two calibrated syringe pumps were used for quantitative fluid injection. The maximum operating pressure and temperature were $40 \mathrm{MPa}$ and $473.15 \mathrm{~K}$, respectively. The apparatus was validated by means of isothermal vapor-liquid equilibrium measurement on $\left(\mathrm{CO}_{2}+\right.$ heptane), the results of which were found to be in good agreement with literature data.
\end{abstract}

In this work, we report experimental measurements of the phase behaviour and density of $\left(\mathrm{CO}_{2}+\right.$ synthetic crude oil) mixtures. The 'dead' oil contained a total of 17 components including alkanes, branched-alkanes, cyclo-alkanes, and aromatics. Solution gas $(0.81$ methane +0.13 ethane +0.06 propane $)$ was added to obtain live synthetic crudes with gas-oil ratios of either 58 or 160 . Phase equilibrium and density measurements are reported for the 'dead' oil and the two 'live' oils under the addition of $\mathrm{CO}_{2}$. The measurements were carried out at temperatures of $(298.15,323.15,373.15$ and 423.15$) \mathrm{K}$ and at pressures up to $36 \mathrm{MPa}$, and included vapor-liquid, liquid-liquid and vapor-liquid-liquid equilibrium conditions. The results are qualitatively similar to published data for mixtures of $\mathrm{CO}_{2}$ with both real crude oils or and simple hydrocarbon mixtures containing both light and heavy components. The present experimental data have been compared with results calculated with two predictive 
models, PPR78 and PR 2 SRK, based on the Peng-Robinson 78 (PR78) and Soave-RedlichKwong (SRK) equations of state with group-contribution formulae for the binary interaction parameters. Careful attention was paid to the critical constants and acentric factor of high molar-mass components. Since the mixture also contained several light substances with critical temperatures below some or all experimental temperatures, we investigated the use of the Boston-Mathias modification of the PR78 and SRK equations. The results showed that these models can predict with reasonable accuracy the vapor-liquid equilibria of systems containing $\mathrm{CO}_{2}$ and complex hydrocarbon mixtures without the need to regress multiple binary parameters against experimental data.

Keywords: Phase behavior; modeling; $\mathrm{CO}_{2}$; Hydrocarbon; Predictive Peng Robinson PPR78; $\mathrm{PR}_{2} \mathrm{SRK}$; Variable Volume Cell; Peng Robinson; Soave Redlich Kwong; Density; Prediction 


\section{Introduction}

Phase behavior data at relevant conditions of temperature, pressure and chemical composition are extremely valuable to engineers in the design of numerous industrial processes. Typically, these data are computed during process design calculations from thermodynamic models. However, an underlying database of experimental phase equilibria results is essential for the optimization and/or validation of such models. Typically, data relating to pure components and binary mixtures are used in the optimization of thermodynamic models, while results for multi-component mixtures are used to validate their predictive capabilities.

In the case of hydrocarbon mixtures, knowledge of the phase behavior is fundamental to reservoir engineering and management. Phase behavior data are key inputs to reservoir simulations that are used for evaluating reservoir development plans, interpreting well test data, and designing surface facilities and processing plants [1]. Knowledge of the phase behavior of mixtures containing both $\mathrm{CO}_{2}$ and hydrocarbons plays a major role in carbon capture and storage (CCS) and enhanced oil recovery (EOR) processes [2-6]. For example, the phase behavior of such systems is fundamental in the design of $\mathrm{CO}_{2}$-EOR projects in which the minimum miscibility pressure (MMP) for the $\mathrm{CO}_{2}$-crude oil system at the actual reservoir temperature is required in order to determine whether or not the $\mathrm{CO}_{2}$-flooding process will be immiscible or miscible at the actual reservoir pressure. In the petroleum industry, the determination of the MMP between the $\mathrm{CO}_{2}$ and crude oils is usually accomplished by techniques such as the slim tube method [7], rising bubble method [8], of the vanishing interfacial tension technique [9]. Numerous MMP studies have been published, such as those in references [10-12].

High-pressure phase equilibria of systems containing hydrocarbons and $\mathrm{CO}_{2}$ are also of interest in a wide range of industrial processes such as hydro-treatment of aqueous waste streams [13], production of coal liquids and petroleum processing [14], separation processes [15], and supercritical fluid extraction [16, 17]. In addition, supercritical $\mathrm{CO}_{2}$ is used as a solvent on both laboratory and industrial scales [18] for reactions such as hydrogenation [19] hydroformylation [20] and polymerization [21, 22]. Therefore, phase equilibrium data for mixtures containing carbon dioxide and hydrocarbons is significant in many industrial and scientific fields. In fact, large amounts of such data exist in the literature. However, most of the reported studies relate to binary systems of which $\mathrm{CO}_{2}$-alkane mixtures are the moststudied; fewer data exist for $\mathrm{CO}_{2}$ with branched alkanes, naphthenes or aromatics.

Several review articles have been published covering both experimental methods and the available high-pressure high-temperature phase behavior data in general: Fornari [23] 
reviewed the data published between 1978 and 1987; Dohrn and Brunne [24] covered the period 1988 to 1993; Christov and Dohrn [25] covered the data published between 1994 and 1999; and recently Dohrn, Peper, and Fonseca reviewed the published data from 2000 to 2004 [26] and from 2005 to 2008 [27]. In these articles, high-pressure experimental data from the 17 most relevant journals in the field were reviewed. The phase equilibria studied included vapor-liquid equilibria, liquid-liquid equilibria, vapor-liquid-liquid equilibria, solid-liquid equilibria, solid-vapor equilibria, solid-vapor-liquid equilibria, critical points, the solubility of high-boiling substances in supercritical fluids, the solubility of gases in liquids, and the solubility (sorption) of volatile components in polymers.

Based on the aforementioned reviews and our own literature searches, it can be concluded that phase equilibrium data for ternary and compositionally-characterized multi-component $\mathrm{CO}_{2}$-hydrocarbon mixtures are limited, especially for systems containing heavy hydrocarbons and/or hydrocarbons other than alkanes. Nevertheless, a few such studies have been published. An example is the study of Vitue et al. [28] in which a high-pressure variable-volume cell was used to measure bubble- and dew-points of a five-component synthetic oil mixture in the presence of $\mathrm{CO}_{2}$. The gravimetrically-prepared mixture contained octane, hexadecane, methylcyclohexane, cis-decalin, and methylbenzene (toluene) and bubble- and dew-points were measured at temperatures ranging from (292.95 to 373.35) $\mathrm{K}$ and at pressures between (2 and 16.5) MPa. Shariati et al. [29] studied the bubble points of some selected synthetic $\mathrm{C}_{6+}$ mixtures in the presence of carbon dioxide. In their study, the mole fraction of $\mathrm{CO}_{2}$ was kept close to 0.25 and the measurements were carried out in the Cailletet apparatus in a temperature range of (312 to 470 ) $\mathrm{K}$ at pressures up to $6.2 \mathrm{MPa}$. In addition to these studies, a few experimental data sets pertaining to $\left(\mathrm{CO}_{2}+\right.$ crude oils $)$ have been published in the open literature. The crude oils investigated range from black oil, through volatile oils, to gas condensates. Even though modern analysis methods can resolve much information about the composition of the crude oil, it is still extremely difficult to characterize the composition of the oil in a fully-satisfactory way. In the published studies, the reported oil composition was usually given up to $\mathrm{C}_{7}$ with the components heavier than heptane typically lumped into as single pseudo-component, the properties of which were not well known. From a modeling prospective, this limited composition analysis restricts the usefulness of the data. For example, to use cubic equations of state, one needs to know (or estimate) the mole fraction, critical temperature, critical pressure and acentric factor of each component. Examples of phase equilibria studies on ( $\mathrm{CO}_{2}+$ crude oils) can be found in the work of Orr et al. [30], Gardner et al. [31], Rathmell et al. [32], Turek et al. [33], and Simon et al. [34]. 
In summary, the available phase-equilibrium data for mixtures of $\mathrm{CO}_{2}$ with compositionallycharacterized multi-component hydrocarbons is limited in terms of the diversity of the hydrocarbons, and the ranges of temperature and pressure investigated. Meanwhile, the few available data for $\mathrm{CO}_{2}$ with crude oils are of restricted generic value because of the imperfect compositional analysis of the oil. Thus, one objective of the present work was to provide new experimental data suitable for testing thermodynamic models rigorously under representative conditions of temperature, pressure and composition.

We remark in passing that, in addition to the phase equilibrium conditions, it is also very useful to know the coexisting phase densities. In the case of $\mathrm{CO}_{2}+$ crude oil mixtures, the saturated phase densities are necessary for calculating the crude-oil swelling during $\mathrm{CO}_{2}$ reservoir flooding and for other reservoir and process engineering calculations associated with fluids having an appreciable $\mathrm{CO}_{2}$ content. Thus, a second objective of the present work was to provide experimental data for saturated phase densities, albeit with modest accuracy.

The development of reliable models for the phase behavior and thermophysical properties of multi-component mixtures is a continuing effort in which experimental data play a vital role. A wide variety of modeling approaches has been developed, ranging from empirical and semiempirical correlations, to molecular-based theories. Cubic equations of states (EoS) are widely used in the oil and gas industries for the calculations of phase equilibria and other properties of complex petroleum fluids over wide range of pressure and temperature. Since the introduction of the van der Waals equation of state in 1873 [35], great effort has been expended in developing cubic equations of state that can be used to describe the phase behaviour of pure fluids and mixtures. In most cases, such models rely in the determination of model parameters upon the availability of certain experimental data for each pure component in the mixture and, crucially, for all possible binary pairs, usually over a range of temperatures. However, such reliance upon experimental data is of concern in the case of multicomponent mixtures as the amount of information required becomes very large. Hence, for such systems, more predictive approaches are sought. Molecular-based approaches, such as the Statistical Associating Fluid Theory (SAFT) may be useful in this context but cubic equations of state remain popular because they are simple, reasonably-reliable for systems encountered in the petroleum industry, and capable of fast calculations.

Two cubic equations that have enjoyed widespread acceptance are the Soave-Redlich-Kwong (SRK) EoS [36] and the Peng-Robinson (PR) EoS [37]. However, in their standard form, these models still require determination of a temperature-dependent interaction parameter for each possible binary combination of the mixture components. Recently, Jaubert and coworkers developed a group contribution method allowing the estimation of the temperature-dependent 
binary interaction parameters $k_{i j}(T)$ in the PR EoS, thereby creating a predictive model that they designated PPR78 [28, 38-44]. To date, 21 functional groups have been defined including those necessary to describe alkanes, aromatics, naphthenic components as well as light gases such as $\mathrm{CO}_{2}$ and $\mathrm{CH}_{4}$. The PPR78 model was tested against data for many binary and multi-component mixtures and generally showed good agreement with experiment. In addition, Jaubert and coworkers also proposed a method to transform binary interaction parameters calculated for the PPR78 EoS to other equation of states. For example, the $\mathrm{PR}_{2} \mathrm{SRK}$ model uses this approach with the standard SRK EoS $[38,39]$. Since these predictive EoS models have not yet been extensively tested against multicomponent mixture data, one of the objectives of the present study was to facilitate such comparisons for the case of $\left(\mathrm{CO}_{2}\right.$ + hydrocarbon) systems.

The present work called for the study of a synthetic hydrocarbon mixture with properties similar to a crude oil. Based on this, a synthetic oil was designed to match the physical and chemical properties of a bottom-hole crude oil sample from a Qatari field. The synthetic 'dead' oil contained 17 components; 'live' oils were also obtained by adding a 3-component solutions gas $\left(0.81 \mathrm{CH}_{4}+0.13 \mathrm{C}_{2} \mathrm{H}_{6}+0.06 \mathrm{C}_{3} \mathrm{H}_{8}\right)$.

For the light substances considered in this study, the pure-component properties (critical temperature, critical pressure and acentric factor) needed for modeling with e.g. the PPR-78 are readily available in the literature. There also exists abundant binary vapor-liquid equilibrium data for their mixtures with $\mathrm{CO}_{2}$ that can be used to validate such predictive models for particular pairs of components. However, such data for the three heaviest components (squalane, tetracosane and phenylhexadecane) are scarce. Thus, the estimation of the critical temperature, critical pressure and acentric factor for these components, and the validation of the model for binary (hydrocarbon $+\mathrm{CO}_{2}$ ) systems, was an important precursor to the modeling aspects of the present study. Regarding the binary system $\left(\mathrm{CO}_{2}+\right.$ squalane $)$, three authors have reported VLE data. Brunner et al. [45] used a static-analytical method for the measurements at $T=(313.15$ to 426.0$) \mathrm{K}, p=(3.50$ to 35.0$) \mathrm{MPa}$, and $x_{\mathrm{CO}_{2}}=(0.122$ to 0.884$)$. They also correlated the data with SRK equation of state with Mathias-Klotz-Prausnitz (MKP) mixing rule. Liphard and Schneider [46] used a high-pressure view cell at $T=(273$ to 423$) \mathrm{K}$, $p=(5$ to 100$) \mathrm{MPa}$ and $w_{\mathrm{CO}_{2}}=(0.070$ to 0.931$)$, where $w$ denotes mass fraction. Sovova et al. [47] measured the solubility of squalane in $\mathrm{CO}_{2}$ using a flow type apparatus at temperatures $T=$ (303 to 328$) \mathrm{K}$ and $p=(7.9$ to 27.5$) \mathrm{MPa}$. For the binary system $\left(\mathrm{CO}_{2}+\right.$ tetracosane $)$, there are also three reported VLE data sets. Tsai and Yau [48] measured the solubility of $\mathrm{CO}_{2}$ in ntetracosane at $T=(373.15$ to 573.15$) \mathrm{K}, p=(1$ to 5$) \mathrm{MPa}$ and $x_{\mathrm{CO}_{2}}=(0.0819$ to 0.3531$)$ using a semi-flow apparatus. Kordikowski and Schneider [49] measured the VLE of this system at $T$ 
$=(353.15$ and 393.15) $\mathrm{K}$ and $p \leq 47.5 \mathrm{MPa}$ using an analytical apparatus. Sato et al. [50] measured the solubility of $\mathrm{CO}_{2}$ in tetracosane at $T=(373.15$ to 473.15$) \mathrm{K}$ and $p \leq 40 \mathrm{MPa}$ using a synthetic method with a variable-volume view cell. Unfortunately, there appear to be no available experimental data for the binary system $\left(\mathrm{CO}_{2}+\right.$ phenylhexadecane $)$.

The objectives of this work were divided into three major areas: first, to construct and validate a new experimental apparatus to measure the phase equilibria of systems containing $\mathrm{CO}_{2}$ and hydrocarbons at reservoir conditions; second, to study experimentally the phase behavior of $\left(\mathrm{CO}_{2}+\right.$ synthetic crude oil) over wide ranges of temperature, pressure and gas-oil ratio; and third, to compare the results of these experiments with predictive models such as the PPR78 EoS. The phase behavior studied in this work includes vapor-liquid, liquid-liquid and vaporliquid-liquid equilibrium conditions observed at temperatures of $(298.15,323.15,373.15$ and 423.15) $\mathrm{K}$ and at pressures up to $36 \mathrm{MPa}$. We also report the experimental and modeling of mixture density at each measured bubble- or dew-point, and measurements of the vapor-liquid critical points.

\section{Experimental}

\subsection{Apparatus Design}

Various techniques have been employed to determine the phase behavior of multicomponent mixtures under high-pressure and high-temperature conditions. The classification of these techniques depends mainly on how composition is determined. In the analytical method, the compositions of the coexisting bulk phases are determined (often by sampling and chromatographic analysis) whereas, in the synthetic method, only the overall composition is determined experimentally (usually by metering the amounts of each pure substance introduced into the apparatus). Multi-component mixtures, especially those containing heavy components, can be difficult to analyze and so in the present work we have used a synthetic method in which mixtures of precisely known composition were prepared and their phase behavior observed visually in a variable-volume cell. The technique permits the determination of various types of phase boundary including vapor-liquid, liquid-liquid and vapor-liquid-liquid loci, critical curves of mixtures, solid-fluid equilibria, and cloud curves. The apparatus, shown schematically in figure 1 , was designed for a maximum working pressure and temperature of $40 \mathrm{MPa}$ and $473.15 \mathrm{~K}$ respectively. The main parts are the variable volume cell, high pressure syringe pumps, electrically actuated valves, servo-control system, and heating system. Wetted metallic parts were made from either Hastelloy C276 or titanium, both of which are resistant to corrosion under the conditions studied here. 
The core of the apparatus was the variable volume equilibrium cell (Sitec-Sieber, model 759.1061) in which one end of the equilibrium cell was fitted with a movable piston while the other end was closed by a sapphire window allowing visual observation of the interior of the cell. Figure 2 is an isometric view of the variable volume cell assembly. The cell was a horizontally-orientated cylindrical vessel of $26.5 \mathrm{~mm}$ internal diameter, $85 \mathrm{~mm}$ external diameter, and volume variable from (11 to 67$) \mathrm{cm}^{3}$. A blind axial hole in the vessel wall $(5 \mathrm{~mm}$ diameter $\times 80 \mathrm{~mm}$ long) accommodated a Pt100 sensor for temperature measurements. The cell and piston were made of Hastelloy C-276. The end of the hollow piston was closed with an $8.2 \mathrm{~mm}$ diameter sapphire window that permitted back illumination of the cell contents, while a CCD camera fitted with a LED ring was used for visual observation with front illumination.

A bushed DC servomotor (Hardmeier control, model MT30U4-36), connected through a 66:1 right-angled reduction gearbox to a $6 \mathrm{~mm}$-pitch ball screw, was used to drive the piston. The piston speed and position were determined by means of a rotary encoder (Hardmeier control, model E 260-6-1000 HV) and the servo motor was also fitted with a tacho-generator for speed/acceleration control. Limit switches (Burgess, model V3S) were used to detect the ends of travel. The control system consisted of a Trio MC302X motion controller and a Parker RTS DC servo drive, programmed to allow simple operation of the machine via a host PC. Using software running on the host $\mathrm{PC}$, the drive system could easily be instructed to find its home position, to move an incremental distance, or move to an absolute distance from the home position. The software was also used to implement constant-pressure and volume-ramping modes of operations.

The cell was equipped with four high pressure ports: two, fitted with reducing unions, were used for the fluid inlet and outlet; a third was closed by a rupture-disc safety device (SitecSieber, model 728.0500-HC276, 500 bar); and the fourth was plugged. The main sapphire window assembly was sealed to the cell body by means of a solid PTFE o-ring. The piston was sealed by means of a proprietary gland fitted an annular PTFE sealing ring between two PEEK guide rings that served both to avoid seal extrusion and to protect the polished surface of the piston. The axial compression on the seal was adjustable by means of a threaded ring. The gland itself was sealed to the body of the cell by means of two additional PTFE o-rings.

Mixing of the cell contents was accomplished by means of an PTFE-coated magnetic follower of ellipsoidal shape (10 mm long x $6 \mathrm{~mm}$ diameter) placed inside the cell. An external magnet driven by a variable-speed motor was used to rotate the follower, typically at a rotational speed of about $30 \mathrm{~s}^{-1}$. An optical rail located below the cell was used to mount the CCD camera, front and back illumination devices and also the stirrer motor. It was therefore possible to adjust the 
position of the stirrer back or forth after movement of the piston by sliding the motor along the rail.

A pair of high-pressure syringe pumps (Chandler Engineering, Quizix model Q5210) were used to inject the components of interest into the equilibrium cell. One pump was used for liquid injections while the other for both $\mathrm{CO}_{2}$ and hydrocarbon gas injections. These pumps provided precise pressure control, flow rate and volume displacements. The wetted parts were made of Hastelloy C-276. The pumps were thermostated by means of cooling jackets through which water from a chiller (Huber, model HB3006.0015.99) was passed at $T=283.15 \mathrm{~K}$. The temperature and pressure of the fluid in each pump cylinder were monitored for purposes of determining the density of the fluid from an equation of state and hence determining the mass of fluid injected from the calibrated volumetric displacement. Flexible surface-mounted Pt100 temperature sensors affixed to the wall of the cylinders were used to measure the temperature, while a calibrated pressure transducer attached to each pump was used to obtain the pressure. The pumps were connected to the cell through Hastelloy C276 or titanium tubing of $1.6 \mathrm{~mm}$ o.d. and $0.5 \mathrm{~mm}$ i.d., chosen to minimize dead volumes in the injection line.

The pressure transducer (DJ Instruments, model DF2) was inserted in this line between valve V-20 and the equilibrium cell. This two-port transducer had titanium wetted parts, an internal volume of only $12 \mu \mathrm{L}$, and a full-scale range of $40 \mathrm{MPa}$. Its position was such that it was always in communication with the interior of the cell. The pressure transducer and the line between the cell and V-20 amounted to a volume of about $0.1 \mathrm{~cm}^{3}$ that remained at or near ambient temperature. The way in which components were injected into the cell ensured that this section contained single-phase gas or liquid which, as described below, was accounted for in the calculation of the composition. Reflux in this $0.5 \mathrm{~mm}$ bore tube was never observed.

The cell temperature was measured using a calibrated 4-wire Pt100 sensor (Sensing Device Ltd, model SD01168, $4.8 \mathrm{~mm}$ o.d. x $75 \mathrm{~mm}$ length) inserted into an axial hole in the cell body. This was connected to a data acquisition unit fitted with a high-precision multimeter for fourwire resistance measurements.

Two five-way electrically-actuated valves (Swagelok, model SS-43ZFS2-049-42DCZ, V-9 and $\mathrm{V}$-10 in figure 1) were installed in the inlet streams of the syringe pumps. The main port was connected to the syringe pump inlet valves ( $\mathrm{V}-13$ and $\mathrm{V}-14)$ through a $3.2 \mathrm{~mm}$ o.d. stainless steel tube. The other ports were connected with $3.2 \mathrm{~mm}$ o.d tubing to the $\mathrm{CO}_{2}$ and gas systems (through valves $\mathrm{V}-1$ and $\mathrm{V}-6$ respectively), liquid/solvent system, vent system (through the union cross $\mathrm{V}-11$ ) and vacuum system (through the union cross $\mathrm{V}-12$ ). A normally-closed air operated valve (Sitec-Sieber, model 610.3224-HC276, V-22) could be used to discharge fluid 
from the cell. The air supplied to this valve was controlled by a solenoid valve which was actuated electrically. Fluid could also be vented slowly from the cell through the three-port valve V-20 (Sitec-Sieber, model 610.3240-HC276), via a small-bore restrictor tube and valve V-19 (Sitec-Sieber, model 610.3220-HC276) to waste.

The equilibrium cell was encased in a $10 \mathrm{~mm}$-thick aluminum heating jacket which was used to control the temperature. The jacket was fitted with axial holes to accommodate four cartridge heaters and two Pt100 temperature sensors. A PID process controller (Eurotherm, model $2216 \mathrm{E}$ ) was used to regulate the temperature within $\pm 0.01 \mathrm{~K}$, while a second supervisory controller was used for over-temperature protection. In order to suppress axial temperature gradients, the heating jacket extended over more than twice the maximum length of the experimental volume and was insulated with a $20 \mathrm{~mm}$ thick layer of silicone-rubber sponge.

All aspects of experiment control, except for fluid injection, and data acquisition were computer controlled using software written in Agilent VEE. The controller system included overtemperature and over-pressure cut-out functions interlocked to the servomotor and heating systems.

Prior to use, the system was thoroughly leak tested in the whole pressure range with both helium and water; it exhibited a high-level of integrity. The system was also checked for leakage during the course of measurements. The piston sealing system required periodic adjustments, and eventually seals replacement, to maintain leak-free performance.

\subsection{Calibration and Uncertainty}

The Pt100 thermometer used to measure the cell temperature was calibrated at temperatures in the range (273 to 473 ) $\mathrm{K}$ by comparison in a constant-temperature bath with a standard platinum resistance thermometer having an expanded uncertainty of $2 \mathrm{mK}$ in the present temperature range. The extent of axial temperature gradients in the phase-equilibrium cell was checked by locating the sensor at different depths inside the thermowell: the differences were within $\pm 0.03 \mathrm{~K}$. Taking calibration uncertainty, sensor drift, fluctuations and temperature gradients across the equilibrium cell into account, we estimate that the overall standard uncertainty of the cell temperature measurements was $0.04 \mathrm{~K}$. The Pt100 sensors used to measure the temperature of the fluid in the syringe pumps was not calibrated. Based on the manufacturing tolerance, the standard uncertainty of the pump temperature was taken to be $0.25 \mathrm{~K}$. 
The pressure transducers fitted to the syringe pumps were calibrated at pressures in the range (1 to 70) MPa by comparison with a quartz pressure sensor in a pneumatic calibrator (Fluke$\mathrm{DHI}$ model PPCH-G-70M). It is estimated that the standard uncertainty of the pressure transducer after calibration was $17.5 \mathrm{kPa}(0.025 \%$ of the full scale reading). The pressure transducer used to measure the sample pressure was calibrated against a hydraulic pressure balance (DH-Budenberg model 580EHX) having standard relative uncertainty of $0.004 \%$. In the calibration, the transducer exhibited good linearity and a lack of hysteresis, leading to a standard uncertainty of $6 \mathrm{kPa}$. However, this sensor did drift over time and corrections were required. For this purpose, the reading was checked at ambient pressure prior to each experiment and any difference was applied as a constant offset to correct subsequent readings in that run. Taking all factors into account, the standard uncertainty of the experimental pressure was estimated to be $35 \mathrm{kPa}$.

Since the syringe pumps were used for quantitative injections of the components, they were carefully calibrated using deionised and degassed water. The water displaced by the syringe at a referenced pressure and temperature was collected and weighed on an analytical balance with a resolution of $0.001 \mathrm{~g}$. The mass collected in this way was compared with that calculated from the displaced volume recorded by the syringe pump using water densities $\rho_{\mathrm{w}}$ computed from the IAPWS-95 equation of state developed by Pruss and Wagner [51]. The calibration was broken down into several steps for a full cycle of each syringe and the whole process was repeated two or more times. A linear relationship between volume displaced and actual volume was established for the liquid and gas syringes, respectively, as follows:

$$
\begin{aligned}
& V_{\text {inj }}=0.9982 \cdot V_{\text {dis }} \\
& V_{\text {inj }}=0.9977 \cdot V_{\text {dis }}
\end{aligned}
$$

Here, subscripts "inj" and "dis" refers to the actual volume injected into the cell and the displaced volume indicated by the pump respectively.

Throughout this article, standard uncertainties for experimental quantities are determined using the Guide to the Expression of Uncertainty in Measurements (GUM) [52], according to which the standard uncertainty $u(f)$ of a quantity $f\left(x_{1}, x_{2}, \cdots x_{n}\right)$ is obtained from

$$
u^{2}(f)=\sum_{i=1}^{n} \sum_{j=1}^{n} \frac{\partial f}{\partial x_{i}} \frac{\partial f}{\partial x_{j}} u^{2}\left(x_{i}, x_{j}\right)
$$


Here, $x_{i}$ and $x_{j}$ represent pairs of input variables from which $f$ is to be evaluated, $\left(\partial f / \partial x_{i}\right)$ is the sensitivity coefficient of $f$ with respect to $x_{i}$, and $u^{2}\left(x_{i}, x_{j}\right)$ is the covariance $(i \neq j)$ or the variance $(i=j)$ for variables $x_{i}, x_{j}$. Usually, only the diagonal terms in Eq. (3) are $(i=j)$ retained and we abbreviate $u^{2}\left(x_{i}, x_{i}\right)$ as $u^{2}\left(x_{i}\right)$. Where appropriate, expanded uncertainties are obtained by multiplying the standard uncertainty $u(f)$ by a coverage factor $k$.

In the case of the calibrated volume injected from a syringe pump, the combined standard uncertainty $u\left(V_{\text {inj }}\right)$ is given by

$$
u^{2}\left(V_{\mathrm{inj}}\right)=\left[\left(\frac{1}{\rho_{\mathrm{w}}\left(T_{\mathrm{inj}}, p_{\mathrm{inj}}\right)}\right)^{2} u^{2}(m)+\left(\frac{-\Delta m}{\rho_{\mathrm{w}}^{2}\left(T_{\mathrm{inj}}, p_{\mathrm{inj}}\right)}\right)^{2} u^{2}\left(\rho_{\mathrm{w}}\left(T_{\mathrm{inj}}, p_{\mathrm{inj}}\right)\right)\right]
$$

where

$$
u^{2}\left(\rho_{\mathrm{w}}\left(T_{\text {inj }}, p_{\text {inj }}\right)\right)=\left[\left(\frac{\partial \rho}{\partial T}\right)^{2} u^{2}\left(T_{\text {inj }}\right)+\left(\frac{\partial \rho}{\partial p}\right)^{2} u^{2}\left(p_{\text {inj }}\right)+u^{2}(\text { EoS })\right] .
$$

The uncertainty of the water density is determined by the uncertainties of the syringe temperature and pressure (given above) and, in principle, by the uncertainty $u(E o S)$ associated with the equation of state of water; however, the latter is negligible under the conditions of our calibration. From equation 5 , the standard relative uncertainty of $\rho_{\mathrm{w}}$ was found to be $0.01 \%$. The uncertainty of the weighing itself was very small $(<1 \mathrm{mg}$ ) but the true uncertainty of the mass $m$ of collected water is larger because of the drop-wise nature of the flow. The uncertainty in the mass was therefore taken to be the mass of one collected drop (estimated as $5 \mathrm{mg}$ ) and, from equation 4 , the final standard relative uncertainty of the volumes was found to be $0.1 \%$ for both cylinders.

The volume of the equilibrium cell was also calibrated using deionised and degassed water, in this case making use of one of the calibrated syringe pumps to inject known amounts. The lines from the syringe pumps were first filled up to the closed valve $\mathrm{V}-20$, and the branch to $\mathrm{V}$ 19 was plugged at this time. Thus the dead volumes associated with the calibration were those in the filling line beyond $\mathrm{V}-20$, including the pressure transducer, and in the discharge line as far as $V$-22. These volumes combined amounted to $V_{\text {dead }}=(0.18 \pm 0.01) \mathrm{cm}^{3}$. The cell was calibrated at different temperatures and positions of the piston to establish a relationship between piston position and total cell volume. At each calibration point, the cell was filled with water injected from a syringe pump held at a reference pressure of $1 \mathrm{MPa}$ and a reference temperature of $283.15 \mathrm{~K}$ and the cell volume was calculated as follows: 


$$
V_{\text {cell }}=\frac{\rho_{\mathrm{w}}\left(T_{\text {inj }}, p_{\text {inj }}\right) V_{\text {inj }}-\rho_{\mathrm{w}}\left(T_{\text {dead }}, p_{\text {dead }}\right) V_{\text {dead }}}{\rho_{\mathrm{w}}\left(T_{\text {cell }}, p_{\text {cell }}\right)}
$$

From these calibration measurements, a linear relationship was established between cell volume and the piston displacement $L$ measured from the home position (maximum retraction) at each temperature. The effect of temperature was also found to be linear the calibration data were fitted by the following simple equation

$$
V_{\text {cell }}=V_{0}(1-C L)\left[1+\alpha_{V}\left(T-T_{0}\right)\right]
$$

in which $T_{0}=323.15 \mathrm{~K}$ and $\alpha_{V}=36 \cdot 10^{-6} \mathrm{~K}^{-1}$ was assumed equal the mean volumetric expansivity of Hastelloy HC-276 [53]. The fitted parameters were $V_{0}=67.19 \mathrm{~cm}^{3}$ and $c=0.007414 \mathrm{~mm}^{-1}$, and the standard deviation of Eq. (7) was $0.029 \mathrm{~cm}^{3}$ or $0.13 \%$ of the minimum cell volume. The extent of mechanical backlash was also considered by repeating calibration measurements at the same temperature and theoretical volume with the piston extending and retracting; the volumes were found to be repeatable to within $\pm 0.02 \mathrm{~cm}^{3}$, which is within the standard deviation of Eq. (7).

To estimate the uncertainty of the calibrated cell volume at constant temperature, the contribution associated with each input quantity appearing in equations (6) was determined as follows:

$$
u^{2}\left(V_{\text {cell }}\right)=\left[\left(\frac{1}{\rho_{\mathrm{w}}\left(T_{\text {cell }}, p_{\text {cell }}\right)}\right)^{2} u^{2}\left(m_{\text {total }}\right)+\left(\frac{-m_{\text {total }}}{\rho_{w}^{2}\left(T_{\text {cell }}, p_{\text {cell }}\right)}\right)^{2} u^{2}\left(\rho_{\mathrm{w}}\left(T_{\text {cell }}, p_{\text {cell }}\right)\right],\right.
$$

where the standard uncertainty of the total mass of water inside the cell was given by

$$
\begin{aligned}
u^{2}\left(m_{\text {total }}\right)= & V_{\text {inj }}^{2} \cdot u^{2}\left(\rho_{\mathrm{w}}\left(T_{\text {inj }}, p_{\text {inj }}\right)\right)+\left[\rho_{\mathrm{w}}\left(T_{\text {inj }}, p_{\text {inj }}\right)\right]^{2} u^{2}\left(V_{\text {inj }}\right) \\
& +V_{\text {dead }}^{2} \cdot u^{2}\left(\rho_{\mathrm{w}}\left(T_{\text {dead }}, p_{\text {dead }}\right)\right)+\left[\rho_{\mathrm{w}}\left(T_{\text {dead }}, p_{\text {dead }}\right)\right]^{2} u^{2}\left(V_{\text {dead }}\right)
\end{aligned}
$$

The standard relative uncertainty of $m_{\text {total }}$ was found from Eq. (9) to be $0.15 \%$ and the standard relative uncertainty of the cell volume was then determined to be $0.18 \%$ from Eq. (8). Taking into account also an estimated $20 \%$ relative uncertainty in the volumetric expansivity, we obtain an overall relative standard uncertainty in the cell volume of $0.2 \%$.

The uncertainty of the mass of fluid injected into the cell from syringe $i$ depends on the uncertainty of the mass expelled from the syringe pump and the uncertainty of any dead volume correction required. The calculation of the dead volume correction for each fluid 
depends on the mode of operation, the order in which fluids were injected, and the pressure and temperature conditions. The following equation was used to calculate the combined standard uncertainty of the calculated mass $m_{i}$ of the fluid injected from syringe $i$ :

$$
\begin{aligned}
u^{2}\left(m_{i}\right)= & V_{i, \text { inj }}^{2} \cdot u^{2}\left(\rho_{i, \text { inj }}\left(T_{i, \text { inj }}, p_{i, \text { inj }}\right)\right)+\left[\rho_{i, \text { inj }}\left(T_{i, \text { inj }}, p_{i, \text { inj }}\right)\right]^{2} u^{2}\left(V_{i, \text { inj }}\right) \\
& +V_{i, \text { dead }}^{2} \cdot u^{2}\left(\rho_{i, \text { dead }}\left(T_{i, \text { dead }}, p_{i, \text { dead }}\right)\right)+\left[\rho_{i, \text { dead }}\left(T_{i, \text { dead }}, p_{i, \text { dead }}\right)\right]^{2} u^{2}\left(V_{i, \text { dead }}\right)
\end{aligned}
$$

The uncertainty of the density varies widely depending on the fluid and the available data at the pump conditions. For $\mathrm{CO}_{2}$, the density was obtained from the equation of state of Span and Wagner [54] with an estimated relative uncertainty of between $0.03 \%$ to $0.05 \%$ (which we interpret as an expanded uncertainty with coverage factor $k=2$ ). For the sake of simplicity, we ascribe the value $0.025 \%$ to the standard relative uncertainty of the $\mathrm{CO}_{2}$ density. The density of the gas mixture was obtained from the GERG-2008 model of Kunz and Wagner [55] with an estimated standard relative uncertainty of $0.05 \%$. The densities of the synthetic dead oil liquid was measured at ambient pressure and different temperatures using an Anton Paar DMA 5000 densimeter calibrated at that temperature with ambient air and pure water. The relative estimated uncertainty was estimated to be $0.001 \%$. This measured density was applied, without correction for pressure changes, in the calculation of the amount of liquid injected. The syringe pump was operated at a reference pressure of $1 \mathrm{MPa}$ and so the effect of compressibility would have been small. For example, if the liquid were heptane then the density change between pressures of $0.1 \mathrm{MPa}$ and $1.0 \mathrm{MPa}$ would be $0.8 \mathrm{~kg} \cdot \mathrm{m}^{-3}$ [56]. Since the dead volume filled by the synthetic oil was very small, we also applied the same density there with a negligible effect on the final mole fraction uncertainty. Considering all factors, the standard relative uncertainty of the mass injected from each syringe varied from $0.11 \%$ to $0.15 \%$ depending on the fluid injected. For the sake of simplicity, we ascribe the larger value of $0.15 \%$ to all cases. The mole fraction $x_{\mathrm{CO}_{2}}$ of $\mathrm{CO}_{2}$ in the system was calculated from the simple expression:

$$
x_{\mathrm{CO}_{2}}=\frac{n_{\mathrm{CO}_{2}}}{n_{\mathrm{CO}_{2}}+n_{\mathrm{HC}}}
$$

where $n$ denotes amount of substance and subscripts $\mathrm{CO}_{2}$ and $\mathrm{HC}$ denote $\mathrm{CO}_{2}$ and total hydrocarbons. The standard uncertainty of $x_{\mathrm{CO}_{2}}$ which follows from this expression is

$$
u^{2}\left(x_{\mathrm{CO}_{2}}\right)=\left[x_{\mathrm{CO}_{2}}\left(1-x_{\mathrm{CO}_{2}}\right)\right]^{2}\left[u_{\mathrm{r}}^{2}\left(n_{\mathrm{CO}_{2}}\right)+u_{\mathrm{r}}^{2}\left(n_{\mathrm{HC}}\right)\right],
$$


where $u_{\mathrm{r}}$ denotes relative standard uncertainty. With $u_{\mathrm{r}}\left(x_{\mathrm{CO}_{2}}\right)=u_{\mathrm{r}}\left(x_{\mathrm{HC}}\right)=0.0015$, identical with the standard relative uncertainty of the masses, the standard uncertainty of the mole fraction turns out to be $0.0021 x_{\mathrm{CO}_{2}}\left(1-x_{\mathrm{CO}_{2}}\right)$.

The uncertainty of the bubble- and dew-pressures depends on both the subjective uncertainty in observing the bubble- or dew-point condition and the uncertainty of the pressure measurement itself. Except in the critical region, bubble points were easily observed visually during isothermal compression and these observations also coincided closely with an abrupt change in slope of pressure against volume. Dew points were generally more difficult to observe by this method and were only measured at high pressures. Close to the critical point, it became more difficult to detect bubble- or dew-point conditions. Nevertheless, the repeatability of the bubble- and dew-pressures was found to be within (0.05 to 0.1) MPa. Considering both this and the uncertainty of the pressure measurements, the standard uncertainty of the bubble pressures $p_{\mathrm{b}}$ were estimated to be $0.05 \mathrm{MPa}$ for $p_{\mathrm{b}} \leq 25 \mathrm{MPa}$ and $0.075 \mathrm{MPa}$ for $p_{\mathrm{b}}>25 \mathrm{MPa}$ at all temperatures, while the standard uncertainties of the critical pressure and of dew pressures $p_{\mathrm{d}}$ were estimated to be $0.075 \mathrm{MPa}$ at $T \leq 373.15 \mathrm{~K}$ and 0.1 $\mathrm{MPa}$ at $T>373.15 \mathrm{~K}$.

Finally, the standard relative uncertainty of the homogeneous phase density, deduced from the relation

$$
u^{2}\left(\rho_{\mathrm{m}}\right)=\left(\frac{1}{V_{\text {cell }}}\right)^{2} u^{2}\left(m_{\text {total }}\right)+\left(\frac{-m_{\text {total }}}{V_{\text {cell }}^{2}}\right)^{2} u^{2}\left(V_{\text {cell }}\right)
$$

was found to be $0.4 \%$.

\subsection{Materials}

Pure deionised and degassed water (electrical resistivity $>18 \mathrm{M} \Omega \cdot \mathrm{cm}$ at $T=298.15 \mathrm{~K}$ ) was used. Carbon dioxide was supplied by BOC with a mole fraction purity higher than 0.99995 , and was used as supplied. All liquid hydrocarbon components were supplied by Sigma-Aldrich and were used as supplied. Table 1 details the mole fraction purities specified by the supplier. The hydrocarbon gas mixture $\left(0.813 \mathrm{CH}_{4}+0.126 \mathrm{C}_{2} \mathrm{H}_{6}+0.061 \mathrm{C}_{3} \mathrm{H}_{8}\right)$ was supplied by BOC who prepared it from gases having a minimum mole-fraction purity of 0.99 . No analysis or purification was attempted. Table 1 also details the mole fraction purities of these gases. 


\subsection{Selection of the Synthetic crude Oil}

The synthetic liquid oil was identified and selected based on available literature data to match the physical and chemical properties of a crude oil sample from a Qatari field [57]. The properties of the oil sample used in this analysis are given in table 2 . These include properties of the whole sample, such as density and kinematic viscosity, and properties of different cuts obtained by fractional distillation. Overall, 8 cuts were reported and for each cut, certain properties such as boiling temperature range, cumulative volume, density, and ratios of paraffins, naphthenes, and aromatics (PNA) were given.

In order to find a representative synthetic mixture, the properties of the whole dead oil and of the 8 cuts were analyzed with the aid of the Oil Manager function in Aspen Hysys simulation software [58]. This resulted in the identification of a mixture of hypothetical components that best represented the known physical properties of each cut. The hypothetical components were identified by molar mass, density and normal boiling temperature. We then selected real components with properties chosen to approximate those of the hypothetical components. In making this match we considered also the availability and cost of potential real components and the desired PNA ratios that we also wished to match. Once real components were selected, the simulation software was run again with a fixed component slate and the composition optimized to best match the boiling curve and densities of the fractions. Initially, polycyclic components (such as chrysene and anthracene) and long-chain normal alkanes (such as $n-\mathrm{C}_{30} \mathrm{H}_{62}$ ) were considered but these were found not to be soluble in the rest of the mixture. Consequently, polycyclics were abandoned, and normal alkanes longer than $\mathrm{C}_{24}$ were replaced with the $\mathrm{C}_{30}$ isomer 2,6,10,15,19,23-hexamethyltetracosane (squalane). Finally, 17 components were selected to represent the dead oil, including alkanes, branched- and cycloalkanes, and aromatics as detailed in Table 1. The PNA ratio of the synthetic dead oil was $72.7 \%, 4.9 \%$ and $22.4 \%$ respectively. These values lie within the ranges found in the literature. A comparison between the experimental true boiling curve of the original dead crude oil and that simulated for the synthetic mixture is shown in figure 3. Good agreement was achieved for approximately $80 \%$ of the boiling range but deviations are observed at the heavy end due to the elimination of heavy polycyclic components.

In order to generate so-called live oils, a three-component solution gas $\left(0.813 \mathrm{CH}_{4}+0.126\right.$ $\mathrm{C}_{2} \mathrm{H}_{6}+0.061 \mathrm{C}_{3} \mathrm{H}_{8}$ ) mixture was added to obtain two different gas-oil ratios (GOR), ${ }^{1}$ leading

\footnotetext{
${ }^{1}$ The GOR is defined as the ratio of the volumes of gas and liquid obtained when the mixtures is flashed at standard conditions of $T=288.15 \mathrm{~K}$ and $p=0.1013 \mathrm{MPa}$.
} 
to a live oil containing 20 components in total. The solution gas composition was identified and characterized based on the properties of gas from a Qatari field [59].

Table 1 list all components and gives their mole fractions in the dead oil and in the live oil with both low and high GOR. Also given are the values of the normal boiling temperatures $\left(T_{\mathrm{b}}\right)$, molar mass $(M)$, and density at standard conditions $\left(\rho_{\text {std }}\right)$ obtained from the National Institute of Standard and Technology (NIST) Thermodata Engine (TDE) software [60, 61].

\subsection{Experimental Procedure and Calculations}

The synthetic dead oil mixture was prepared gravimetrically at ambient pressure and temperature and in a sufficient quantity for the entire study. Some heavy components, such as hexadecylbenzene, were solid at ambient temperature but the entire mixture formed a stable homogenous liquid after mixing at ambient temperature. Aliquots of the liquid mixture were degassed immediately prior to use by stirring under partial vacuum but this operation was kept brief to avoid stripping of volatile components. Starting from a clean and evacuated system, gases and liquids were introduced into the syringe pumps through valves V-9 and V10 respectively. The pump cylinders were maintained at constant temperature, usually $T=$ $283.15 \mathrm{~K}$. The liquid or gas inside each pump was pressurized to a reference pressure, the value of which depended upon the experimental conditions, both before and after the injection of fluid into the equilibrium cell. In this way, the mass of fluid introduced in each injection step could be obtained from the syringe displacement and knowledge of the density at the pump temperature and pressure. For the synthetic dead oil, the reference pressure was always $1 \mathrm{MPa}$. The reference pressure for the solution gas was $10 \mathrm{MPa}$, while the reference pressure for $\mathrm{CO}_{2}$ was adjusted as needed to match the experimental conditions.

Initially, a measured amount of liquid was injected into the cell through valve V-20. For the studies of live synthetic oil, this was followed by: (a) injection of the desired amount of solution gas; and (b) replacement of solution gas in the relevant syringe pump by pure $\mathrm{CO}_{2}$. Next, measured amounts of $\mathrm{CO}_{2}$ was introduced into the cell and, after each injection of $\mathrm{CO}_{2}$, valve $\mathrm{V}$-20 was closed. Each injection had the effect of pushing the fluid previously in the connecting tubing into the cell. In order to achieve high mole fractions of $\mathrm{CO}_{2}$, it was sometimes necessary to expel some of the mixture and to replace it by additional $\mathrm{CO}_{2}$. In these cases, the mixture was first brought into a measured homogeneous state and the desired amount pushed out by driving the piston forward while allowing sample to flow out through $\mathrm{V}-20$ and $\mathrm{V}-19$. The amount expelled in this way was calculated from the swept volume. The overall composition of the system could be calculated at every stage of the experiment from the cumulative amounts of liquid, solution gas and $\mathrm{CO}_{2}$ introduced from the pumps, the amounts and 
composition of homogenous mixture expelled from the system, and the amount and composition of the fluid remaining in the connecting tubing.

The dead volumes considered were those in the tubing between syringe pumps and the cell, and between the cell and valve $\mathrm{V}-22$, as well as the volumes within $\mathrm{V}-19, \mathrm{~V}-20, \mathrm{~V}-22$, and the pressure transducer. The safety head ( $\mathrm{V}-21)$ was considered as part of the cell volume as it communicated reasonably freely with the interior of the cylinder. The amounts $n_{\mathrm{CO}_{2}}$ of $\mathrm{CO}_{2}$ and $n_{\mathrm{HC}}$ of total hydrocarbons prior to expulsion of any material were determined from the following relations:

$$
\begin{gathered}
n_{\mathrm{CO}_{2}}=M_{\mathrm{CO}_{2}}^{-1}\left[\sum_{k=1}^{N_{k}} \rho_{\mathrm{CO}_{2}}\left(T_{\text {inj }}, p_{\text {inj }}\right) V_{k}-\sum_{l=1}^{N_{l}} \rho_{\mathrm{CO}_{2}}\left(T_{\text {dead }}, p_{\text {dead }}\right) V_{l}\right] \\
n_{\mathrm{HC}}=M_{\mathrm{L}}^{-1}\left[\sum_{k=1}^{N_{k}} \rho_{\mathrm{L}}\left(T_{\text {inj }}, p_{\text {inj }}\right) V_{k}-\sum_{l=1}^{N_{l}} \rho_{\mathrm{L}}\left(T_{\text {dead }}, p_{\text {dead }}\right) V_{l}\right]+M_{\mathrm{G}}^{-1}\left[\sum_{k=1}^{N_{k}} \rho_{\mathrm{G}}\left(T_{\text {inj }}, p_{\text {inj }}\right) V_{k}-\sum_{l=1}^{N_{l}} \rho_{\mathrm{G}}\left(T_{\text {dead }}, p_{\text {dead }}\right) V_{l}\right]
\end{gathered}
$$

Here, the summations over $k$ refer to $N_{k}$ sequential injections from the syringe pumps and the summations over $k$ refer to the $N_{\text {l }}$ sections into which the dead volume was divided; these sections may contain different fluids at different times depending upon the sequence of injections. Additionally, subscripts "inj" and "dead" refers to the conditions in the syringe pumps and the dead volumes respectively, and subscripts $L$ and $G$ refer to the hydrocarbon liquid and gas mixtures, respectively, that were injected into the cell. Based on the compositions, $M_{\mathrm{L}}=220.40 \mathrm{~g} \cdot \mathrm{mol}^{-1}$ and $M_{\mathrm{G}}=19.52 \mathrm{~g} \cdot \mathrm{mol}^{-1}$. Following the expulsion of volume $\Delta V$, starting from an initial cell volume of $V_{0}$, the amounts of $\mathrm{CO}_{2}$ and hydrocarbon present in the cell were both modified by the factor $\left(1-\Delta V / V_{0}\right)$ and equations (14) and (15) were used to obtain the additional amounts of $\mathrm{CO}_{2}$ and hydrocarbon (if any) following subsequent injections.

Following the injection of components, V-20 was closed and the pressure inside the cell was adjusted by moving the piston until one homogenous phase was obtained. The system was then left to equilibrate under stirring. The time required to achieve thermodynamic equilibrium, as determined from pressure measurements at constant temperature and volume, was typically about one hour under continuous stirring. The pressure was then decreased in small decrements, each followed by a further equilibration period, while simultaneously recording temperature, pressure and volume, and observing the state of the system. This process continued until the appearance of a second phase. If necessary, the pressure was raised again and the phase boundary approached in smaller decrements. In some cases, the 
disappearance of a phase was measured during isothermal compression steps. It was found that bubble- or dew-points determined with increasing or decreasing pressure agreed to within about $0.05 \mathrm{MPa}$, which is within the uncertainty of the measurements. Usually, after observing a bubble- or dew-point, additional $\mathrm{CO}_{2}$ was injected and a new measurement initiated.

Visual observation through the CCD camera was the primary means of detecting phase changes. The large sapphire window permitted a clear view of the interior of the cell. Bubbles were observed to form in the bulk of the fluid during pressure reduction and to disappear along the top of the cell during compression. At low pressures, there was also an abrupt change in slope of pressure versus volume when passing through a bubble point and this coincided closely with the results of visual observations. The sensitivity of the pressure-volume plot became unfavorable at high pressures and, especially, close to a critical point.

\subsection{Validation}

Several validation experiments were conducted to test the apparatus. Figure $4(a)$ is a pressure-volume diagram measured for pure $\mathrm{CO}_{2}$ at $T=298.15 \mathrm{~K}$. It shows the expected plateau in the two-phase region from which the vapor pressure was determined to be 6.394 $\mathrm{MPa}$, which is $0.04 \mathrm{MPa}$ below the value obtained from the equation of state of Span and Wagner [54]. The vapor pressure of pentane was measured in a similar way at temperatures from ( 353.13 to 466.45 ) $\mathrm{K}$. Pentane was chosen as its critical temperature of $470 \mathrm{~K}$ almost coincides with the maximum operating temperature of the apparatus. The results are shown as deviations from the equation of state of Span and Wagner [56] in Figure 4(b) and the deviations do not exceed $0.01 \mathrm{MPa}$ in magnitude. Thus, for both substances, the measured vapor pressures agree with the reference data to within the experimental uncertainty of the pressure measurements. This good agreement also confirms that the experimental volume was sufficiently isothermal, even at high temperatures.

The phase behavior of the binary mixture $\left(\mathrm{CO}_{2}+\right.$ heptane $)$ was measured at $T=394.15 \mathrm{~K}$. The density of $\mathrm{CO}_{2}$ was obtained as described above while the density of heptane was obtained using the equation of state of by Span and Wagner [56] which is associated with a relative uncertainty of $0.2 \%$ at the injection conditions. The results obtained are presented in table 3 and figure 5 . The results were compared with the available literature data reported by Mutelet et al. [62], Kalra et al. [63], and Inomata et al. [64] at this temperature and they are in good agreement with all available data.

The saturated liquid density of pentane was also measured and compared with the equation of state of Span and Wagner [56] and the absolute relative deviations were less than $0.3 \%$ at 
$T \leq 413$, the highest temperature at which the equation of state was constrained by experimental data.

\section{Experimental Results and Discussion}

Phase equilibrium measurements are reported for the 'dead' synthetic oil, and for two 'live' synthetic oil with GORs of 58 and 160, and under the addition of $\mathrm{CO}_{2}$. The measurements were carried out at temperatures of $(298.15 \mathrm{~K}, 323.15 \mathrm{~K}, 373.15 \mathrm{~K}$ and $423.15 \mathrm{~K})$ and at pressures up to $36 \mathrm{MPa}$ and include vapor-liquid equilibrium (VLE), vapor-liquid-liquid equilibrium (VLLE) and liquid-liquid equilibrium (LLE) conditions. The results, in the form of isothermal $\left(p, x_{\mathrm{CO}_{2}}\right)$ data, are given in Tables 4,5 and 6 for the measurements of $\left(\mathrm{CO}_{2}+\right.$ dead oil), $\left(\mathrm{CO}_{2}\right.$ + live oil 1$)$, and $\left(\mathrm{CO}_{2}+\right.$ live oil 2$)$ respectively. In the tables, some experimentally determined critical points are also given. Typically, when approaching the critical point, the sample appeared as a white cloud, with color changes and darkening. At this condition, retracting the piston yielded two phases of equal volume. Generally speaking, at high pressures, phase separation was harder to spot because the two phases had only slightly different densities and therefore separated more slowly. Because of this, and as indicated in the uncertainty calculations, the high pressure portions of the phase boundaries are known less precisely than the portions at low pressures.

The $\left(p, x_{\mathrm{CO}_{2}}\right)$ data at $T=(323.15,373.15$, and 423.15$) \mathrm{K}$ are plotted in Figures $6 \mathrm{a}, 6 \mathrm{~b}$, and $6 \mathrm{c}$ for the dead oil, live oil 1 , and live oil 2 respectively. Under these conditions, only vapor-liquid equilibria were found. The $\left(p, x_{\mathrm{CO}_{2}}\right)$ data are plotted for the same systems in Figures $7 \mathrm{a}, 7 \mathrm{~b}$, and $7 \mathrm{c}$ at $T=298.15 \mathrm{~K}$, at which temperature vapor-liquid, vapor-liquid-liquid and liquid-liquid equilibria were observed.

We first discuss the system $\left(\mathrm{CO}_{2}+\right.$ dead oil). At low temperatures, this system behaves as a pseudo-binary mixture of $\left(\mathrm{CO}_{2}+\right.$ hydrocarbon). The VLLE observed at the lowest temperature is typical of type III phase behavior in the classifications of Scott and van Konynenburg for a binary system [65]. This is expected due to the presence of heavy components which exhibit only partially miscibility with $\mathrm{CO}_{2}$-rich liquid due to the large differences in molecular size and volatility. The three-phase VLLE region at fixed temperature in a multi-component system is, in principle, delimited by lower and upper pressure loci that vary with composition. However, for $\left(\mathrm{CO}_{2}+\right.$ dead oil), the upper and lower bounds were almost indistinguishable and we found the horizontal three-phase line at $p=6.06 \mathrm{MPa}$, as shown in Figure $7 \mathrm{a}$. The $T$ - $p$ projection of this three-phase line was measured from $T=298.15 \mathrm{~K}$ to the upper critical end point, which was found to be at $T=316.3 \mathrm{~K}$, and the data are given in table 7 and plotted in Figure 8 in 
comparison with the vapor-pressure curve of $\mathrm{CO}_{2}$. Thus, the three-phase behavior in the $\left(\mathrm{CO}_{2}\right.$ + dead oil) system is essentially that of a type III binary system in the classification of Scott and van Konynenburg. The same behavior is observed in binary $\left(\mathrm{CO}_{2}+\right.$ alkane $)$ systems when the alkane contains more than 13 carbon atoms. For example, in the system $\left(\mathrm{CO}_{2}+\right.$ hexadecane) at temperatures of $294.15 \mathrm{~K}$ and $305.15 \mathrm{~K}$, the three-phase line has been measured at $p=5.5 \mathrm{MPa}$ and $p=5.8 \mathrm{MPa}$ respectively with $x_{\mathrm{CO}_{2}} \geq 0.75[66,67]$. It was also observed in the same binary system that the LLE region separated from the VLE region as temperature increased. Similar VLLE behavior has also been observed for $\mathrm{CO}_{2}$ with either multicomponent hydrocarbon mixtures or real crude oils, as in the studies reported by Orr et al. [30], Gardner et al. [31], Rathmell et al. [32], Turek et al. [33], and Simon et al. [34]. Although limited to $T \leq 316.3 \mathrm{~K}$ in the present work, it is likely that the three phase region can extend into the temperature range of $\mathrm{CO}_{2}$ reservoir-flooding processes because of multiple contacts between $\mathrm{CO}_{2}$ and hydrocarbons during $\mathrm{CO}_{2}$ injection [68].

Returning to Figure $7 \mathrm{a}$, we see that there is a change in slope where the bubble-curve meets the three-phase line at $x_{\mathrm{CO}_{2}}=0.68$, above which the system is characterized by LLE. While mapping the boundary between the $L_{1}$ and $L_{1}+L_{2}$ regions, where $L_{1}$ is hydrocarbon-rich liquid and $L_{2}$ is $\mathrm{CO}_{2}$-rich liquid, it was observed that there was a density inversion at a pressure of approximately $12 \mathrm{MPa}$ above which $\mathrm{L}_{2}$ was the more dense phase. Experimentally, we were not able to reach a sufficiently high mole fraction of $\mathrm{CO}_{2}$ to observe the boundary between the $\left(L_{1}+L_{2}\right)$ the $L_{2}$ regions in the $\left(C_{2}+\right.$ dead oil $)$ system. This boundary is predicted in our modeling, as discussed below, to occur at around $x_{\mathrm{CO}_{2}}=0.98$ and to be bounded at low pressures by a small VLE region that terminates at the vapor pressure of $\mathrm{CO}_{2}$. The dew curve, expected at very high $\mathrm{CO}_{2}$ concentrations and at pressures below the three-phase pressure, was also not observed in our experiments on $\left(\mathrm{CO}_{2}+\right.$ dead oil). Figure $6 \mathrm{a}$ shows that, at the higher temperatures investigated, only VLE conditions were observed for $\left(\mathrm{CO}_{2}+\right.$ dead oil) with the bubble- and dew-curves meeting at a vapor-liquid critical point. At $T=323.15 \mathrm{~K}$, the $(p$, $x_{\mathrm{CO}_{2}}$ ) loci are steeper to either side of the critical point than at higher temperatures, and this behavior may be identified as a precursor of the appearance of LLE at lower temperatures.

We now consider the systems $\left(\mathrm{CO}_{2}+\right.$ live oil 1$)$ and $\left(\mathrm{CO}_{2}+\right.$ live oil 2$)$, where live oil 1 contained 40 mol\% solution gas (GOR of 58) and live oil 2 contained 65 mol\% solution gas (GOR of 160). The addition of solution gas raises the pressure of the VLE loci relative to that observed for $\left(\mathrm{CO}_{2}+\right.$ dead oil). For $T=323.15 \mathrm{~K}$ and higher temperatures, Figures $6 \mathrm{~b}$ and $6 \mathrm{c}$ show that only VLE conditions were observed while, as shown in figures $7 \mathrm{~b}$ and $7 \mathrm{c}$, VLE, VLLE and LLE were all observed at $T=298.15 \mathrm{~K}$. Due to the presence of the light components in the solution gas, the VLLE region is observed at increasing pressures as the GOR is increased and we 
also observe a narrow loop in the $\left(p, x_{\mathrm{CO}_{2}}\right)$ diagram instead of the horizontal three-phase line found in the absence of solution gas. It can also be seen that the VLLE region does not intersect the VLE/LLE locus. This is because the hydrocarbon mixture is rich in methane (33 mol\% in live oil 1). If the oil had a lower methane content then the three phase region could extend to the intersection of the VLE and LLE curves. Such behavior was observed in $\left(\mathrm{CO}_{2}+\right.$ crude oil) systems and in simple ternary mixtures containing $\left(\mathrm{CO}_{2}+\mathrm{CH}_{4}+\right.$ heavy alkanes) such as the ternary mixture $\left(\mathrm{CO}_{2}+\mathrm{CH}_{4}+\mathrm{C}_{16} \mathrm{H}_{34}\right)$ reported by Orr et al. [69] in which the methane represents the solution gas and hexadecane represents the synthetic dead oil. It worth mentioning here that knowing the pressure at which LLE behavior occurs provides an indication of the pressure required to make the $\mathrm{CO}_{2}$ rich phase behave as a dense, relatively incompressible liquid that could offer better displacement of oil during EOR processes. Turek et al. [33] studied mixtures of $\mathrm{CO}_{2}$ with crude oils. For the crude oils containing $27 \mathrm{~mol} \%$ and $69 \mathrm{~mol} \% \mathrm{C}_{7+}$ components, the VLLE region at $T=313.7 \mathrm{~K}$ occurred for $x_{\mathrm{CO}_{2}} \geq 0.60$ with an envelope that was qualitatively similar to that observed for our $\left(\mathrm{CO}_{2}+\right.$ live oil) systems, while for an oil with 95 mol\% $\mathrm{C}_{7+}$ components the behavior was similar to our $\left(\mathrm{CO}_{2}+\right.$ dead oil) system.

The two liquid-liquid curves usually meet at a critical point, the position of which is mainly determined by whether the light components partition strongly into the lower or upper phase. This point will lie to the right of the maximum pressure if the light hydrocarbons partition more strongly into the lower phase while it will lie to the left of the maximum pressure if they partition more strongly into the upper phase. This was not experimentally determined as this critical pressure is much higher than the maximum working pressure of our apparatus ( $p=40 \mathrm{MPa})$.

Finally, in Figures $9 \mathrm{a}$ and $9 \mathrm{~b}$, we show the saturated phase densities measured in the $\left(\mathrm{CO}_{2}+\right.$ dead oil) and $\left(\mathrm{CO}_{2}+\right.$ live oil 2$)$ systems at $T=(323.15,373.15$, and 423.15$) \mathrm{K}$. In each case, the density increased slightly with increasing $\mathrm{CO}_{2}$ content along the bubble curve but then fell sharply along the dew curve. As expected, the saturated phase densities declined with increase of either temperature or GOR.

\section{Modelling}

\subsection{PPR78 and PR 2 SRK}

As explained in the Introduction, two predictive cubic equations of state were considered in this work: the PPR78 and PR ${ }_{2}$ SRK models. These are based on the PR78 [37] and SRK [36] equations, respectively. The SRK EoS is given by 


$$
p(T, v)=\frac{R T}{v-b}-\frac{a(T)}{v(v+b)}
$$

where $p$ is pressure, $T$ is temperature, $v$ is the molar volume, and $a$ and $b$ are the energy and co-volume parameters of the mixture, respectively. These are calculated for individual components by the following equations

$$
\left.\begin{array}{rl}
a_{i} & =0.42740\left(R^{2} T_{\mathrm{c}, i}^{2} / p_{\mathrm{c}, i}\right) \alpha(T) \\
\alpha_{i}(T) & =\left[1+m_{i}\left(1-\sqrt{T / T_{\mathrm{c}, i}}\right)\right]^{2} \\
m_{i} & =0.480+1.574 \omega_{i}-0.176 \omega_{i}^{2} \\
b_{i} & =0.08664\left(R T_{\mathrm{c}, i} / p_{\mathrm{c}, i}\right)
\end{array}\right\},
$$

where subscript $i$ denotes properties of the $i^{\text {th }}$ component, subscript $c$ denotes critical properties and $\omega_{i}$ is the acentric factor of component $i$. The SRK EoS is normally applied to mixtures by means of conventional van der Waals one-fluid mixing rules:

$$
\left.\begin{array}{l}
a=\sum_{i=1}^{N} \sum_{j=1}^{N} x_{i} x_{j} \sqrt{a_{i} a_{j}}\left[1-k_{i j}(T)\right] \\
b=\sum_{i=1}^{N} x_{i} b_{i}
\end{array}\right\},
$$

where $\mathrm{x}_{i}$ denotes mole fraction of component $i, N$ is the total number of components and $k_{i j}(T)$ is a temperature-dependent binary interaction parameter pertaining to components $i$ and $j$ with the properties that $k_{i i}=1$ and $k_{i j}=k_{j i}$.

The PR78 equation is given by

$$
p(T, v)=\frac{R T}{v-b}-\frac{a(T)}{v(v+b)+b(v-b)}
$$

where

$$
\begin{array}{rlr}
a_{i} & =0.457236\left(R^{2} T_{\mathrm{c}, i}^{2} / p_{\mathrm{c}, i}\right) \alpha(T) & \\
\alpha_{i}(T) & =\left[1+m_{i}\left(1-\sqrt{T / T_{\mathrm{c}, i}}\right)\right]^{2} & \\
m_{i} & =0.37464+1.54226 \omega_{i}-0.26992 \omega_{i}^{2} & \left(\omega_{i} \leq 0.491\right) \\
& =0.379642+1.48503 \omega_{i}-0.164423 \omega_{i}^{2}+0.016666 \omega_{i}^{3} & \left(\omega_{i}>0.491\right) \\
b_{i} & =0.077796\left(R T_{\mathrm{c}, i} / p_{\mathrm{c}, i}\right) &
\end{array}
$$


and Eqs (17) are the conventional mixing rules.

The so-called Soave alpha function $\alpha_{i}(T)$ [36], which appears in both (16) and (19), determines the temperature dependency of the parameter a and was optimized so as to obtain a good representation of the vapor pressure curves of pure, mainly non-polar, substances. It does not necessarily work well for polar substances or for very light components with $T_{\mathrm{c}, i} \ll T$ and/or very heavy components with $T_{\mathrm{c}, i} \gg T$. In order to deal with some such cases, alternative alpha functions have been proposed such as the Mathias and Copeman function [70] (for polar substances with the PR EoS) and the Boston-Mathias alpha function [71] (for mixtures containing supercritical components). The latter, which we make use of below, is identical to the Soave alpha function at $T \leq T_{\mathrm{c}, i}$ but, for higher reduced temperatures, asserts that

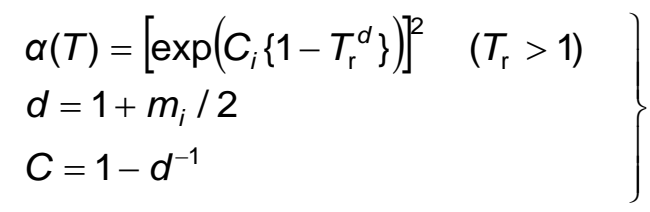

where $T_{\mathrm{r}}=T / T_{\mathrm{c}, i}$. Alternatives to the conventional mixing rules have also been widely studied. A good review of non-conventional alpha functions and mixing rules in the context of the PR and SRK EoS was given by Ghosh [72].

The binary interaction parameter $k_{i j}$ for a pair of components is usually, by observation, a function of temperature and depends on the EoS model and the alpha function used. These binary interaction parameters are typically fitted to VLE data spanning the temperature range of interest. Unfortunately, the number of possible binary pairs in a complex multi-component mixture is large and binary VLE data are not necessarily available for all combinations. There has therefore been a great deal of interest in predictive models from which the $k_{i j}$ parameters in a particular EoS model may be estimated without the need to fit any experimental VLE data. The predictive models considered in this work use the group-contribution approach of Jaubert and coworkers $[28,38-44]$ to achieve this. In this method, the binary interaction parameter $k_{i j}$ is given by

$$
k_{i j}(T)=\left[\left\{-\frac{1}{2} \sum_{k=1}^{N_{g}} \sum_{l=1}^{N_{g}}\left(a_{i k}-\alpha_{j k}\right)\left(\alpha_{i l}-\alpha_{j l}\right) A_{k l}\left(T_{0} / T\right)^{\left(B_{k l} / A_{k l}-1\right)}\right\}-\left\{\frac{\sqrt{a_{i}(T)}}{b_{i}}-\frac{\sqrt{a_{j}(T)}}{b_{j}}\right\}^{2}\right] \times\left[\frac{2 \sqrt{a_{i}(T) a_{j}(T)}}{b_{i} b_{j}}\right]^{-1}
$$

Here, $N_{\mathrm{g}}$ is the number of distinct functional groups present in the molecule, $\alpha_{i k}$ is the occurrence of group $k$ in component $i$ divided by the total number of groups present in that component, and $A_{k l}$ and $B_{k l}$ are group parameters. Jaubert and coworkers [28, 38-44] defined 
21 functional groups and determined the group parameters $A_{k l}$ and $B_{k l}$ by fitting a very large database of experimental binary VLE using the PR78 EoS with the Soave alpha function. The resulting model is the PPR78 EoS. With this model, the properties of arbitrary mixture containing any number of components may be computed knowing only the critical temperature, critical pressure and acentric factor of each component, provided that the components may be represented in terms of the 21 elementary groups.

The parameters appearing in Eq. (21) cannot be applied directly to other equations of state or other alpha functions. However, Jaubert and coworkers proposed a method to transform the binary interaction parameters calculated using the PPR78 EoS model for use with other equation of states (such as SRK EoS) or alternative different alpha functions. The proposed relationship is given by the following equations [39]

$$
\left.\begin{array}{rl}
k_{i j}^{E O S 2} & =\frac{2 \xi_{1 \rightarrow 2} k_{i j}^{E O S 1} \delta_{i}^{E O S 1} \delta_{j}^{E O S 1}+\xi_{1 \rightarrow 2}\left(\delta_{i}^{E O S 1}-\delta_{j}^{E O S 1}\right)^{2}-\left(\delta_{i}^{E O S 2}-\delta_{j}^{E O S 2}\right)^{2}}{2\left(\delta_{i}^{E O S 2} \delta_{j}^{E O S 2}\right)} \\
\delta_{i}^{E O S} & =\frac{\sqrt{a_{i}^{E O S}}}{b_{i}^{E O S}}
\end{array}\right\} .
$$

In these equations, superscripts EoS1 and EoS2 refer to the two EoS models, and $\xi_{1 \rightarrow 2}$ is a parameter linking the two. The binary parameter is assumed to be known for EoS1; $\xi_{1 \rightarrow 2}$ is unity when EoS1 and EoS2 differ only in their alpha functions, but generally takes a constant value other than unity when the EoS model differ in other respects. The parameter value linking the PPR78 EoS (EOS1) with the SRK EoS (EOS2) is $\xi_{1 \rightarrow 2}=0.807341$. When applied in this way to the SRK equation, the resulting model was called the $\mathrm{PR}_{2} \mathrm{SRK}$ EoS $[38,39]$.

Finally, the saturated density is calculated using PPR78 EoS with the Soave alpha function and predicted binary interactions from the group contribution scheme. The saturated density is also calculated using the volume translation method introduced by Peneloux [73] to minimize the deviation between the predicted liquid molar volume and the experimental data. In his approach, the translated molar volume $v^{\prime}$ is calculated from the following relations



Here, $v$ is the mixture molar volume calculated from the equation of state, $c$ is the volume translation parameter, $x_{i}$ is the mole fraction of component $i$, and $Z_{c, i}$ is the compressibility 
factor for component $i$ at its critical point. The values of $Z_{\mathrm{c}, i}$ used are those obtained from the NIST Thermodata Engine (TDE) software $[60,61]$ and tabulated in Table 8.

\subsection{Modeling Procedure}

Phase equilibrium calculations were performed using the PR78 EoS, with binary parameters from Eq. (21), using the Aspen Properties software package [74]. The model was applied first to the binary mixture $\left(\mathrm{CO}_{2}+\right.$ heptane $)$ at $T=394.15 \mathrm{~K}$ and the predicted bubble- and dewcurves are compared with our experimental data in Figure 5 . The binary interaction value found at this temperature for the PR78 EoS was then transformed with Eq. (22) for use with the SRK EoS and the results of that model are also shown in Figure 5. The comparison shows small differences between PPR78 and $\mathrm{PR}_{2}$ SRK but both are in quite good agreement with the experimental data.

The same procedure was applied to calculate the phase equilibria of $\left(\mathrm{CO}_{2}+\right.$ synthetic oils $)$. In these calculations, the mole ratios of all hydrocarbon components were fixed at the relevant experimental values while the mole fraction of $\mathrm{CO}_{2}$ was adjusted to find the bubble- or dew points at given temperature and pressure. Overall, 210 binary interaction parameters were required to describe the $\left(\mathrm{CO}_{2}+\right.$ live oil) systems.

\subsection{Evaluation of the critical properties}

In order to apply the predicitive EoS models, it is necessary to know the critical temperature, critical temperature and acentric factor of each substance. The latter was defined by Pitzer [75] as

$$
\omega=\log _{10}\left[p_{\mathrm{c}} / p_{\mathrm{s}}\left(T=0.7 T_{\mathrm{c}}\right)\right]-1
$$

where $p_{\mathrm{s}}$ denoted the saturated vapor pressure. For most of the components present in our mixtures, the critical constants and acentric factor are readily available and are associated with small uncertainties. However, some of the heavier components are not chemically stable at their critical points and there exists uncertainty about the correct values of $T_{\mathrm{c}}$ and $p_{\mathrm{c}}$, and consequently about $\omega$.

We have carefully reviewed the available pure-component data in order to arrive at the critical constants and acentic factors listed in Table 7. For light components, the values were taken from available experimental data. Generaly speaking, experimental vapor pressure data exists for all components of interest, with the light components having the largest and most-reliable 
amount data. The acentric values obtained are the same as or similar to with those avaiabale from the NIST Thermodata Engine (TDE) software [60, 61]. The heavier components required more-careful consideration. In the case of the n-alkanes up to octadecane, we used the critical constants measured by Rosenthal and Teja [76] using a low-residence-time flow method. The critical temperature and pressure of nonadecane were obtained from the study of Nikitin et al. [77], who used the method of pulse heating to measure the critical properties of $n$-alkanes with $n=5,6,7,17$ and 19 to 24 . The critical temperature of tetracosane was also obtained from this work but, to reduce the uncertainty, the critical pressure was adjusted to fit the available binary VLE data for $\left(\mathrm{CO}_{2}+\right.$ tetracosane) at $T=353.15 \mathrm{~K} \mathrm{[49]}$ and (ethane + tetracosane) at $T$ $=352.7 \mathrm{~K}$ [78]. To accomplish this, a trial value of the critical pressure for tetracosane was adopted, the acentric factor was evaluated from Eq. (23) and the available vapor-pressure data, and binary VLE data were simulated with the PPR78 EoS model. The value of the critical pressure was adjusted to minimize the combined absolute average pressure deviations from the two experimental data sets.

Nikitin et al. [79] measured the critical temperature and critical pressure of ten phenylalkanes, $\mathrm{C}_{6} \mathrm{H}_{5} \mathrm{C}_{n} \mathrm{H}_{2 n+1}$ with $n=1$ to 11 , and 13 , using the method of pulse heating. We took $T_{\mathrm{c}}$ and $p_{\mathrm{c}}$ for 1-phenylhexane and 1-phenyloctane from this study. Nikitin et al. also reported correlations for the critical constants of phenylalkanes as functions of $n$ and compared their values with those calculated by the group contribution methods of Lydersen [80], Joback and Reid [81], and Constantinou and Gani [82]. We used these to obtain $T_{\mathrm{c}}$ and $p_{\mathrm{c}}$ for 1-phenylhexadecane. The critical pressures of ethylcyclohexane and propylcyclohexane were obtained from the work of Nikitin et al. [83] which is associated with an uncertainty of $0.1 \mathrm{MPa}$. However, the critical temperatures reported in that study have an uncertainty of $6 \mathrm{~K}$ and we preferred instead the values of Morton et al. [84], who used a conventional sealed-ampoule method with an uncertainty in $T_{\mathrm{c}}$ of $1 \mathrm{~K}$.

The case of squalane, which is a major component in this work, was considered in some detail. To our knowledge, only two studies of the critical constants of squalane have been published. Von Niederhausern et al. [85] employed a flow method and reported $T_{\mathrm{c}}=(795.9 \pm 2.0) \mathrm{K}$ and $p_{\mathrm{c}}=(0.59 \pm 0.02) \mathrm{MPa}$. Nikitin and Popov [86] used the pulse heating method and obtained $T_{\mathrm{c}}=(822 \pm 12) \mathrm{K}$ and $p_{\mathrm{c}}=(0.70 \pm 0.03) \mathrm{MPa}$. They compared their measurements with the results obtained by Von Niederhausern et al. [85], computer-simulation data [87-90], and the values predicted by group-contribution methods [81, 82, 91]. Clearly, these experimental determinations are not in mutual agreement. Zhuravlev et al. [90] used Monto Carlo simulations to estimate the critical properties of squalane and concluded that a critical temperature of between $820 \mathrm{~K}$ and $830 \mathrm{~K}$ was most likely. They observed that a value in this 
range would also yield a relative difference in the critical temperatures between $n$-triacontane and squalane in good agreement with experimental data for low-molecular-weight analogues (e.g. n-octane versus 2,5-dimethylhexane or n-nonane versus 2,6-dimethylheptane) in which the critical temperatures of the dimethyl-branched isomers are about 3\% lower than those of the linear isomers. In view of the lack of agreement, we again resorted to binary VLE data to arrive at optimized critical constants. In this case, both $T_{\mathrm{c}}$ and $p_{\mathrm{c}}$ were adjusted, starting from trial values in the range of the reported experimental data. For every trial pair, $T_{\mathrm{c}}$ and $p_{\mathrm{c}}$, the corresponding value of $\omega$ was determined from vapor pressure data of Mokbel et al. [92] and Von Niederhausern et al. [85] together with Eq. (24). Binary VLE data were then simulated using the PPR78 EoS and compared with experiment. The experimental values considered were bubble-curve data for both $\left(\mathrm{CO}_{2}+\right.$ squalane $)$ at $T=343.15 \mathrm{~K}$, from the study of Brunner et al. [45], and $\left(\mathrm{CH}_{4}+\right.$ squalane $)$ at $T=370 \mathrm{~K}$, from the study of Marteau et al. [93]. Figure 10 shows the combined absolute average relative deviations, $\Delta_{\mathrm{AAD}}$, between the simulated and experimental data for the two binary systems considered. The optimal critical constants determined from this were $T_{\mathrm{c}}=820 \mathrm{~K}$ and $p_{\mathrm{c}}=0.90 \mathrm{MPa}$; the corresponding acentric factor was found to be $\omega=1.2436$.

Figure 11 illustrates the important role of the critical constants and acentric factor of squalane in the context of the present study. Here we compare our experimental VLE data for $\left(\mathrm{CO}_{2}+\right.$ dead oil) at $T=373.15 \mathrm{~K}$ with simulations based on the PPR78 EoS with different values of $T_{\mathrm{c}}, p_{\mathrm{c}}$ and $\omega$ for squalane. The values considered are those fitted in this work $\left(T_{\mathrm{c}}=820 \mathrm{~K}, p_{\mathrm{c}}\right.$ $=0.90 \mathrm{MPa}, \omega=1.2436)$, those measured experimentally by Nikitin and Popov [86] $\left(T_{\mathrm{c}}=822\right.$ $\mathrm{K}, p_{\mathrm{c}}=0.70 \mathrm{MPa}$ with $\left.\omega=1.075\right)$, and those fitted to VLE data using the SRK EoS by Brunner and coworkers [45] $\left(T_{\mathrm{c}}=822.89 \mathrm{~K}, p_{\mathrm{c}}=1.13 \mathrm{MPa}\right.$ and $\left.\omega=1.1515\right)$. The calculated binary interaction parameters between $\mathrm{CO}_{2}$ and squalane in the PPR78 model corresponding to these choices are $0.0409,-0.0234$, and 0.0680 . We observe that, of the three cases plotted, our fitted critical constants and acentric factor provide the best predictions when using PPR78 for the $\left(\mathrm{CO}_{2}+\right.$ dead oil $)$ system.

\subsection{Comparison with Experiment}

Figure 6a compares our experimental results for $\left(\mathrm{CO}_{2}+\right.$ dead oil $)$ at $T=(323.15,373.15$, and 423.15) $\mathrm{K}$ with the predictions of the PPR78 EoS with the 'standard' Soave alpha function. The bubble curves are generally in reasonably good agreement with experiment, especially considering the fact that no parameters were tuned to fit these data. The deviations increase in the critical regions and are more pronounced for the dew curves. When considering the two live oils, we found that the PPR78 EoS provided an excellent prediction of the bubble pressure 
in the absence of $\mathrm{CO}_{2}$ as shown by the dotted lines in figure $6 \mathrm{~b}$ and $6 \mathrm{c}$. However, the model was much less successful when $\mathrm{CO}_{2}$ was introduced, mainly at high pressures in the critical and dew regions. This suggests that at least some of the binary parameters involving $\mathrm{CO}_{2}$ are not well predicted by the model of Jaubert and coworkers [28, 38-44] for $T \geq 323.15 \mathrm{~K}$. In our opinion, this problem is most significant for the $\left(\mathrm{CO}_{2}+\mathrm{CH}_{4}\right)$ system because no binary VLE data exist for that mixture at temperatures above the critical temperature of $\mathrm{CO}_{2}$ and hence the group parameters between these components were not constrained by experimental data at higher temperatures. The good agreement seen in Figure 5 for the $\left(\mathrm{CO}_{2}+\right.$ heptane $)$ system lends weight to the idea that it is the interactions between $\mathrm{CO}_{2}$ and the lightest components that need to be adjusted. Consequently, it was decided to proceed by fitting the binary interaction parameter between $\mathrm{CO}_{2}$ and $\mathrm{CH}_{4}$ at each temperature. The results obtained after this one-parameter optimization at each temperature are shown in Figures $6 b$ and $6 c$ as solid lines for the two $\left(\mathrm{CO}_{2}+\right.$ live oil $)$ systems. The agreement, after fitting, with the experimental data is reasonably good along the bubble curves but less good on the dew curves, especially at $T=323.15 \mathrm{~K}$ where the predicted dew pressures drop too rapidly with increasing $x_{\mathrm{CO}_{2}}$.

Figure 7 compares the experimental data with the predictions of the PPR78 EoS with the Soave alpha function at $T=298.15 \mathrm{~K}$. Again, the binary parameter between $\mathrm{CO}_{2}$ and $\mathrm{CH}_{4}$ was adjusted (based on the bubble-curve data). It is interesting to note that the model is in qualitative agreement with experiment in respect of the appearance of VLE, VLLE and LLE regions. The bubble pressures and three-phase pressure of the $\left(\mathrm{CO}_{2}+\right.$ dead oil $)$ system are well predicted, although the predicted LLE region is too narrow. For the $\left(\mathrm{CO}_{2}+\right.$ live oil) systems, the predictions of the PPR78 EoS are good for the bubble pressure at $\mathrm{XCO}_{2}=0$, but less good for the VLE, VLLE and LLE data at finite $x_{\mathrm{CO}_{2}}$. At this temperature, the model also predicts for the $\left(\mathrm{CO}_{2}+\right.$ live oil) systems a second small VLE region in the region $0.995 \leq x_{\mathrm{CO} 2}$ $\leq 1$ joining the VLLE region to the vapor pressure of pure $\mathrm{CO}_{2}$.

In view of the fact that several components, especially $\mathrm{CH}_{4}$, are supercritical under the conditions investigated here, we explored the effect of replacing the Soave alpha function with the Boston-Mathias alpha function. All predicted binary parameters in the PPR78 EoS were transformed using Eq. (4.8) and, initially, no terms were fitted. We found good agreement for the $\left(\mathrm{CO}_{2}+\right.$ dead oil) system at all mole fractions of $\mathrm{CO}_{2}$, as can be seen in Figure 12a. However, for the live oils, significant deviations from experiment of up to $3.6 \mathrm{MPa}$ were observed for the bubble pressures at $x_{\mathrm{CO}_{2}}=0$ as shown by the dotted lines in figure $12 \mathrm{~b}$ and 12c. These discrepancies suggested that the transformed binary interaction parameters between $\mathrm{CH}_{4}$ and some of the heavy components, especially squalane, might be inaccurate. To explore this, we compared the predictions of the PPR78 EoS model using both the Soave 
and the Boston-Mathias alpha functions, the latter with transformed $k_{i j}$, with the experimental data of Marteau et al. [93] at $T=370 \mathrm{~K}$. With the Soave alpha function, the average absolute relative deviation of bubble pressure was $5.5 \%$, while for the Boston-Mathias function it was $17 \%$. We note that the former was the model used in the tuning of the squalane critical constants, and so it might be that better results could be obtained with the Boston-Mathias alpha function if the critical constants of squalane were re-optimized. However, we decided to address the problem instead by adjusting the binary interaction parameter between $\mathrm{CH}_{4}$ and squalane at each temperature. Figure 12 compares the results obtained in this way with experiment at $T \geq 323.15 \mathrm{~K}$. We see for all three systems a noticeable improvement in agreement with experiment compared with the results seen in Figure 6 for the case of the Soave alpha function. The improvement is more marked at high temperatures, as expected, because the Soave and Boston-Mathias functions differ increasingly as the temperature increases above the critical. However, it worth mentioning that in this case two parameters were fitted while only one parameter was adjusted with the Soave alpha function.

Figure 13 shows the VLE predictions of the $\mathrm{PR}_{2} \mathrm{SRK}$ EoS model with the Soave alpha function. Better agreement was observed in the critical and dew region (figure 13a) for the $\left(\mathrm{CO}_{2}+\right.$ dead oil) compared with PPR78 EoS prediction (figure $6 \mathrm{a})$. For the $\left(\mathrm{CO}_{2}+\right.$ live oil) systems, less deviation, as shown by the dotted lines, was observed in comparison with PPR78 EoS. However, the model is still less successful when $\mathrm{CO}_{2}$ was introduced. Hence, again the $\mathrm{CO}_{2}$ $\mathrm{CH}_{4}$ binary interaction parameters were subjected to optimization. The results for $T=(373.15$ and 423.15) $\mathrm{K}$ provide an excellent representation of both the bubble- and dew-curve experimental data. Unfortunately, the $\mathrm{PR}_{2} \mathrm{SRK}$ model predicts three-phase equilibria extending up to at least $T=323.15 \mathrm{~K}$, at which temperature the model fails qualitatively for all three systems investigated. For this reason, the $\mathrm{PR}_{2} \mathrm{SRK}$ predictions are not compared with experiment in Figures 13. Figure 14 compares the $\mathrm{PR}_{2} \mathrm{SRK}$ EoS with the Boson-Mathias model with experiment at $T=(373.15$ and 423.15$) \mathrm{K}$. As with the PPR78-Boston-Mathias combination, significant discrepancies were found in the bubble pressures of the live oils at $x_{\mathrm{CO}_{2}}=0$ and these were addressed by adjusting the $\mathrm{CO}_{2}$-squalane binary interaction parameter at each temperature. The results are slightly less good than those obtained with $\mathrm{PR}_{2} \mathrm{SRK}$ and the Soave alpha function.

Finally, in Figures $9 \mathrm{a}$ and $9 \mathrm{~b}$, we show the experimental and predicted saturated phase densities measured in the $\left(\mathrm{CO}_{2}+\right.$ dead oil $)$ and $\left(\mathrm{CO}_{2}+\right.$ live oil 2$)$ systems at $T=(323.15$, 373.15 , and 423.15) $\mathrm{K}$. The solid lines corresponds to the values obtained using the volume translation correction while the dotted lines corresponds to values obtained without the use of this correction. The agreement, while not perfect, is good for the liquid densities with 
noticeable deviation in the critical and dew regions. Without the use of volume translation, the density values are under predicted by an average of approximately $10 \%$ in most of the cases. Better agreements were observed with the use of volume correction. The density values are under predicted by amount varying from less than $1 \%$ at around zero $\mathrm{CO}_{2}$ to around $10 \%$ in the critical and dew regions. The use of volume correction is only effective for the saturated liquid densities. The predicted saturated vapour densities are almost the same in both cases.

The binary parameters for $\mathrm{CO}_{2}-\mathrm{CH}_{4}$ according to the prediction from PPR78 with the Soave alpha function and our optimized values are presented in figure 15. It seems that the two curves intersect at lower temperatures, where large amount of $\mathrm{CO}_{2}-\mathrm{CH}_{4} \mathrm{VLE}$ data exists. This suggests that extrapolating at high temperatures using equation (21) does not give good predictions. The optimized binary interactions for $\mathrm{CO}_{2}-\mathrm{CH}_{4}$ and squalane- $\mathrm{CH}_{4}$ are summarized in table 9. It was found that the optimized $\mathrm{CO}_{2}-\mathrm{CH}_{4}$ binary interactions for a given temperature did not change much when the Soave and Boston-Mathias alpha functions were interchanged.

\section{Conclusion}

A new experimental apparatus has been designed and constructed to measure the phase behavior of systems containing $\mathrm{CO}_{2}$ and multicomponent hydrocarbons at reservoir temperatures and pressures. The apparatus was validated by comparison with published isothermal VLE data for the binary system $\left(\mathrm{CO}_{2}+\right.$ heptane). Experimental measurements of the phase behavior of $\left(\mathrm{CO}_{2}+\right.$ synthetic crude oil) mixtures were completed. The composition of the synthetic oil was chosen to match the physical and chemical properties of a bottom-hole crude oil sample from a Qatari field. The 'dead' oil contained a total of 17 components and live oils were created by adding a three-component solution gas. Experimental results are reported for the dead oil and for two live oils under the addition of $\mathrm{CO}_{2}$ at temperatures of (298.15, $323.15,373.15$ and 423.15$) \mathrm{K}$ and at pressures up to $36 \mathrm{MPa}$. VLE conditions were observed at all temperatures; additionally, VLLE and LLE conditions were measured at the lowest temperature.

The experimental results are compared with two predictive equations of state: the PPR78 and PR2SRK models. In making this comparison, careful attention was paid to the critical constants and acentric factors of the heavy components in the mixture. The two EoS models were considered in combination with either the 'standard' Soave alpha function or the BostonMathias alpha function. It was found that the PPR78, in combination with either alpha function and with no parameters adjusted, generally provided a good description of the bubble pressures for the $\left(\mathrm{CO}_{2}+\right.$ dead oil) system. The same model predicted well the pressure at which VLLE occurred at $T=298.15 \mathrm{~K}$. The PPR78 with the Soave alpha function also 
predicted well the bubble pressures of the live oils in the absence of $\mathrm{CO}_{2}$. However, discrepancies were found at finite $x_{\mathrm{CO}_{2}}$ which suggested that the binary parameter between $\mathrm{CO}_{2}$ and $\mathrm{CH}_{4}$ should be adjusted. After optimizing that single parameter at each temperature, quite good agreement was observed with the experimental bubble points, while some discrepancies remained with the dew points. When the Boston-Mathias alpha function was used, it was necessary to adjust the $\mathrm{CO}_{2}-\mathrm{CH}_{4}$ and the $\mathrm{CH}_{4}$-squalane parameters. The agreement, after adjusting these two parameters, is better than the previous agreement using the Soave alpha function but this comes with the cost of an additional adjustable parameter.

The $\mathrm{PR}_{2} \mathrm{SRK}$ model was found to predict qualitatively incorrect phase behavior at $T=323.15$ $\mathrm{K}$ but, in combination with the standard Soave alpha function, it gave a superior account of the experimental VLE data, including dew points, at $T=(373.15$ and 423.15$) \mathrm{K}$ when the $\mathrm{CO}_{2}$ $\mathrm{CH}_{4}$ binary parameter was optimized. Use of the Boston-Mathias alpha function resulted in some deterioration in comparison with experiment.

Overall, the PPR78 model with the Boston-Mathias alpha function performed best in qualitative and quantitative predictions of the phase behavior observed experimentally. However, this model requires the adjustment of two binary interaction parameters and hence, on a purely predictive basis, it seems that the PPR78 EoS with the Soave alpha function performed best compared to the other options investigated.

We can draw several conclusions in relation to modeling the phase behavior of $\mathrm{CO}_{2}+$ multicomponent hydrocarbon mixtures with predictive cubic equation of state. First, very careful attention must be paid to the critical constants and acentric factors of heavy components. We suggest that comparisons of experimental and simulated binary VLE data for such substances with light components, such as $\mathrm{CO}_{2}$ and/or $\mathrm{CH}_{4}$, may be a good way of discriminating between discrepant critical-point data. Second, we note that the binary interaction parameters between two supercritical components may not be predicted well by group contribution methods that were developed by fitting binary phase-equilibrium data only. Such binary parameters may require adjustment. Finally, the transformation of binary parameters to account for different alpha functions may result in erroneous results for pairs of components that differ greatly in volatility. It seems that there is scope for further improvement in the performance of predictive cubic equations of state in relation to the class of mixtures considered in this work. 


\section{Acknoledgment}

This work was carried out as part of the activities of the Qatar Carbonates \& Carbon Storage Research Centre (QCCSRC). We gratefully acknowledge the funding of QCCSRC provided jointly by Qatar Petroleum, Shell, and the Qatar Science and Technology Park, and their permission to publish this research. 


\section{References}

[1] N.R. Nagarajan, M.M. Honarpour, K. Sampath, Reservoir-Fluid Sampling and Characterization - Key to Efficient Reservoir Management, J. Pet. Technol., 59 (2007) 8091.

[2] J.-N. Jaubert, L. Avaullee, J.-F. Souvay, A crude oil data bank containing more than 5000 PVT and gas injection data, J. Pet. Sci. Eng., 34 (2002) 65-107.

[3] J.-N. Jaubert, L. Avaullee, C. Pierre, Is It Still Necessary to Measure the Minimum Miscibility Pressure?, Ind. Eng. Chem. Res., 41 (2001) 303-310.

[4] J.-N. Jaubert, L. Arras, E. Neau, L. Avaullee, Properly Defining the Classical Vaporizing and Condensing Mechanisms When a Gas Is Injected into a Crude Oil, Ind. Eng. Chem. Res., 37 (1998) 4860-4869.

[5] E. Neau, L. Avaullée, J.N. Jaubert, A new algorithm for enhanced oil recovery calculations, Fluid Phase Equilib., 117 (1996) 265-272.

[6] J.-N. Jaubert, E. Neau, L. Avaullee, G. Zaborowski, Characterization of Heavy Oils. 3. Prediction of Gas Injection Behavior: Swelling Test, Multicontact Test, Multiple-Contact Minimum Miscibility Pressure, and Multiple-Contact Minimum Miscibility Enrichment, Ind. Eng. Chem. Res., 34 (1995) 4016-4032.

[7] A.M. Elsharkawy, F.H. Poettmann, R.L. Christiansen, Measuring Minimum Miscibility Pressure: Slim-Tube or Rising-Bubble Method?, in: SPE/DOE Enhanced Oil Recovery Symposium, 1992 Copyright 1992, Soc Petrol Eng Inc., Tulsa, Oklahoma, 1992.

[8] R.L. Christiansen, H.K. Haines, Rapid Measurement of Minimum Miscibility Pressure With the Rising-Bubble Apparatus, SPE Resev Eng, 2 (1987) 523-527.

[9] D.N. Rao, A New Technique of Vanishing Interfacial Tension for Miscibility Determination, Fluid Phase Equilib., 139 (1997) 311.

[10] M. Nobakht, S. Moghadam, Y. Gu, Determination of $\mathrm{CO}_{2}$ Minimum Miscibility Pressure from Measured and Predicted Equilibrium Interfacial Tensions, Ind. Eng. Chem. Res., 47 (2008) 8918-8925.

[11] E.M.E.-M. Shokir, $\mathrm{CO}_{2}$-Oil Minimum Miscibility Pressure Model For Impure And Pure $\mathrm{CO}_{2}$ Streams, in, Offshore Mediterranean Conference, 2007.

[12] M. Dong, S. Huang, R. Srivastava, Effect of Solution Gas in Oil on $\mathrm{CO}_{2}$ Minimum Miscibility Pressure, J. Can. Pet. Technol., 39 (2000). 
[13] G. Brunner, J. Teich, R. Dohrn, Phase equilibria in systems containing hydrogen, carbon dioxide, water and hydrocarbons, Fluid Phase Equilib., 100 (1994) 253-268.

[14] E. Neau, J.N. Jaubert, M. Rogalski, Characterization of heavy oils, Ind. Eng. Chem. Res., 32 (1993) 1196-1203.

[15] J.-N. Jaubert, P. Borg, L. Coniglio, D. Barth, Phase equilibria measurements and modeling of EPA and DHA ethyl esters in supercritical carbon dioxide, J. Supercrit. Fluids, 20 (2001) 145-155.

[16] H.-Y. Chiu, R.-F. Jung, M.-J. Lee, H.-M. Lin, Vapor-liquid phase equilibrium behavior of mixtures containing supercritical carbon dioxide near critical region, J. Supercrit. Fluids, 44 (2008) 273-278.

[17] R. Eustaquio-Rincón, A. Trejo, Solubility of n-octadecane in supercritical carbon dioxide at $310,313,333$, and $353 \mathrm{~K}$, in the range 10-20 MPa, Fluid Phase Equilib., 185 (2001) 231239.

[18] E.J. Beckman, Supercritical and near-critical $\mathrm{CO}_{2}$ in green chemical synthesis and processing, J. Supercrit. Fluids, 28 (2004) 121-191.

[19] P.G. Jessop, Y. Hsiao, T. Ikariya, R. Noyori, Homogeneous Catalysis in Supercritical Fluids: Hydrogenation of Supercritical Carbon Dioxide to Formic Acid, Alkyl Formates, and Formamides, JACS, 118 (1996) 344-355.

[20] I. Bach, Hydroformylation of hex-1-ene in supercritical carbon dioxide catalysed by rhodium trialkylphosphine complexes, Chem. Commun., 0 (1998) 1463-1464.

[21] T.J. Romack, E.E. Maury, J.M. DeSimone, Precipitation Polymerization of Acrylic Acid in Supercritical Carbon Dioxide, Macromolecules, 28 (1995) 912-915.

[22] M. Haruki, K. Sato, S.-i. Kihara, S. Takishima, High pressure phase behavior for the supercritical ethylene + cyclohexane + hexane + polyethylene systems, J. Supercrit. Fluids, 49 (2009) 125-134.

[23] R.E. Fornari, P. Alessi, I. Kikic, High pressure fluid phase equilibria: experimental methods and systems investigated (1978-1987), Fluid Phase Equilib., 57 (1990) 1-33.

[24] R. Dohrn, High-pressure fluid-phase equilibria: Experimental methods and systems investigated (1988-1993), Fluid Phase Equilib., 106 (1995) 213-282.

[25] M. Christov, R. Dohrn, High-pressure fluid phase equilibria: Experimental methods and systems investigated (1994-1999), Fluid Phase Equilib., 202 (2002) 153-218. 
[26] R. Dohrn, High-pressure fluid-phase equilibria: Experimental methods and systems investigated (2000-2004), Fluid Phase Equilib., 288 (2010) 1-54.

[27] J.M.S. Fonseca, R. Dohrn, S. Peper, High-pressure fluid-phase equilibria: Experimental methods and systems investigated (2005-2008), Fluid Phase Equilib., 300 (2011) 1-69.

[28] S. Vitu, J.-N. Jaubert, J. Pauly, J.-L. Daridon, D. Barth, Bubble and Dew Points of Carbon Dioxide + a Five-Component Synthetic Mixture: Experimental Data and Modeling with the PPR78 Model, J. Chem. Eng. Data, 52 (2007) 1851-1855.

[29] A. Shariati, C.J. Peters, M. Moshfeghian, Bubble Point Pressures of Some Selected Carbon Dioxide + Synthetic C6+ Mixtures, J. Chem. Eng. Data, 43 (1998) 785-788.

[30] F.M. Orr Jr., A.D. Yu, C.L. Lien, Phase Behavior of $\mathrm{CO}_{2}$ and Crude Oil in LowTemperature Reservoirs, Soc Petrol Eng J, 21 (1981) 480-492.

[31] J.W. Gardner, F.M. Orr, P.D. Patel, The Effect of Phase Behavior on $\mathrm{CO}_{2}$-Flood Displacement Efficiency, J Petrol Technol, 33 (1981) 2067-2081.

[32] J.J. Rathmell, F.I. Stalkup, R.C. Hassinger, A Laboratory Investigation of Miscible Displacement by Carbon Dioxide, in: Fall Meeting of the Society of Petroleum Engineers of AIME, 1971 Copyright 1971, New Orleans, Louisiana, 1971.

[33] E.A. Turek, R.S. Metcalfe, R.E. Fishback, Phase Behavior of Several CO2/ West TexasReservoir-Oil Systems, SPE Reserv Eng, 3 (1988) 505-516.

[34] R. Simon, A. Rosman, E. Zana, Phase-Behavior Properties of CO2 - Reservoir Oil Systems, Soc Petrol Eng J, 18 (1978) 20-26.

[35] J.D.v.d. Waals, Ph. D. Thesis, PhD Thesis, University of Leiden, 1873.

[36] G. Soave, Equilibrium constants from a modified Redlich-Kwong equation of state, Chem. Engng Sci., 27 (1972) 1197-1203.

[37] D.-Y. Peng, D.B. Robinson, A New Two-Constant Equation of State, Ind. Eng. Chem. Fun, 15 (1976) 59-64.

[38] J.-N. Jaubert, J. Qian, R. Privat, C.F. Leibovici, Reliability of the correlation allowing the $k_{\mathrm{ij}}$ to switch from an alpha function to another one in hydrogen-containing systems, Fluid Phase Equilib., 338 (2013) 23-29.

[39] J.-N. Jaubert, R. Privat, Relationship between the binary interaction parameters $\left(k_{\mathrm{ij}}\right)$ of the Peng-Robinson and those of the Soave-Redlich-Kwong equations of state: Application to the definition of the PR2SRK model, Fluid Phase Equilib., 295 (2010) 26-37. 
[40] S. Vitu, J.-N. Jaubert, J. Pauly, J.-L. Daridon, D. Barth, Phase equilibria measurements of $\mathrm{CO}_{2}+$ methyl cyclopentane and $\mathrm{CO}_{2}+$ isopropyl cyclohexane binary mixtures at elevated pressures, The Journal of Supercritical Fluids, 44 (2008) 155-163.

[41] S. Vitu, J.-N. Jaubert, J. Pauly, J.-L. Daridon, High-pressure phase behaviour of the binary system $\mathrm{CO}_{2}+$ cis-decalin from (292.75 to 373.75$) \mathrm{K}$, J. Chem. Thermodyn., 40 (2008) 13581363.

[42] S. Vitu, J.-N. Jaubert, F. Mutelet, Extension of the PPR78 model (Predictive 1978, PengRobinson EOS with temperature dependent $k_{\mathrm{ij}}$ calculated through a group contribution method) to systems containing naphtenic compounds, Fluid Phase Equilib., 243 (2006) 9-28. [43] J.-N. Jaubert, S. Vitu, F. Mutelet, J.-P. Corriou, Extension of the PPR78 model (predictive 1978, Peng-Robinson EOS with temperature dependent $k_{\mathrm{ij}}$ calculated through a group contribution method) to systems containing aromatic compounds, Fluid Phase Equilib., 237 (2005) 193-211.

[44] J.-N. Jaubert, F. Mutelet, VLE predictions with the Peng-Robinson equation of state and temperature dependent $k_{\mathrm{ij}}$ calculated through a group contribution method, Fluid Phase Equilib., 224 (2004) 285-304.

[45] G. Brunner, C. Saure, D. Buss, Phase Equilibrium of Hydrogen, Carbon Dioxide, Squalene, and Squalane, J. Chem. Eng. Data, 54 (2009) 1598-1609.

[46] K.G. Liphard, G.M. Schneider, Phase equilibria and critical phenomena in fluid mixtures of carbon dioxide $+2,6,10,15,19,23$-hexamethyltetracosane up to $423 \mathrm{~K}$ and $100 \mathrm{MPa}, \mathrm{J}$. Chem. Thermodyn., 7 (1975) 805.

[47] H. Sovova, J. Jez, M. Khachaturyan, Solubility of squalane, dinonyl phthalate and glycerol in supercritical $\mathrm{CO}_{2}$, Fluid Phase Equilib., 137 (1997) 3762.

[48] F.N. Tsai, J.S. Yau, Solubility of carbon dioxide in n-tetracosane and in n-dotriacontane, J. Chem. Eng. Data, 35 (1990) 43-45.

[49] A. Kordikowski, G.M. Schneider, Fluid phase equilibria of binary and ternary mixtures of supercritical carbon dioxide with low-volatility organic substances up to $100 \mathrm{MPa}$ and $393 \mathrm{~K}$ : c, Fluid Phase Equilib., 90 (1993) 149-162.

[50] Y. Sato, Y. Tagashira, D. Maruyama, S. Takishima, H. Masuoka, Solubility of carbon dioxide in eicosane, docosane, tetracosane, and octacosane at temperatures from 323 to 473 $\mathrm{K}$ and pressures up to $40 \mathrm{MPa}$, Fluid Phase Equilib., 147 (1998) 181-193. 
[51] W. Wagner, A. Pruss, The IAPWS Formulation 1995 for the Thermodynamic Properties of Ordinary Water Substance for General and Scientific Use, J. Phys. Chem. Ref. Data, 31 (2002) 387.

[52] JCGM 100:2008, Evaluation of measurement data - guide to the expression of uncertainty in measurement., (2008).

[53] S.L. Hoyt, ASME Handbook on Metal Properties, in, McGraw-Hill, New York, 1956.

[54] R. Span, W. Wagner, A New Equation of State for Carbon Dioxide Covering the Fluid Region from the Triple-Point Temperature to $1100 \mathrm{~K}$ at Pressures up to $800 \mathrm{MPa}$, J. Phys. Chem. Ref. Data, 25 (1996) 1509-1596.

[55] O. Kunz, W. Wagner, The GERG-2008 Wide-Range Equation of State for Natural Gases and Other Mixtures: An Expansion of GERG-2004, J. Chem. Eng. Data, 57 (2012) 3032-3091.

[56] R. Span, W. Wagner, Equations of State for Technical Applications. II. Results for Nonpolar Fluids, Int. J. Thermophys., 24 (2003) 41-109.

[57] Maersk Oil Qatar AS, Crude Assay Report: AL SHAHEEN CRUDE OIL, in, www.maerskoil.com, 2006.

[58] A. Technology, Aspen Hysys, version 7.3, in, 2011.

[59] D.K. Gupta, J. Lawrence, M.N.A. Majid, T.A. Wahlheim, Fluid Characterization and Modeling of Compositional Variation, Dukhan Field, Qatar, in: International Petroleum Technology Conference, 2009, International Petroleum Technology Conference, Doha, Qatar, 2009.

[60] V. Diky, C.D. Muzny, E.W. Lemmon, R.D. Chirico, M. Frenkel, ThermoData Engine (TDE): Software Implementation of the Dynamic Data Evaluation Concept. 2. Equations of State on Demand and Dynamic Updates over the Web, J. Chem. Inf. Model., 47 (2007) 17131725.

[61] M. Frenkel, R.D. Chirico, V. Diky, X. Yan, Q. Dong, C. Muzny, ThermoData Engine (TDE): Software Implementation of the Dynamic Data Evaluation Concept, J. Chem. Inf. Model., 45 (2005) 816-838.

[62] F. Mutelet, S. Vitu, R. Privat, J.-N. Jaubert, Solubility of $\mathrm{CO}_{2}$ in branched alkanes in order to extend the PPR78 model (predictive 1978, Peng-Robinson EOS with temperaturedependent $k_{\mathrm{ij}}$ calculated through a group contribution method) to such systems, Fluid Phase Equilib., 238 (2005) 157-168. 
[63] H. Kalra, H. Kubota, D.B. Robinson, H.-J. Ng, Equilibrium phase properties of the carbon dioxide-n-heptane system, J. Chem. Eng. Data, 23 (1978) 317-321.

[64] H. Inomata, K. Arai, S. Saito, Measurement of vapor-liquid equilibria at elevated temperatures and pressures using a flow type apparatus, Fluid Phase Equilib., 29 (1986) 225232.

[65] P.H.V.K.a.R.L. Scott, Critical Lines and Phase Equilibria in Binary Van Der Waals Mixtures Philos T Roy Soc A, 298 (1980) 495-540.

[66] W.C. Stewart, Phase Equilibria for Mixtures of Carbon Dioxide and Several Normal Saturated Hydrocarbons, Pennsylvania State College.

[67] G. Schneider, Z. Alwani, W. Heim, E. Horvath, E.U. Franck, Phasengleichgewichte und kritische Erscheinungen in binären Mischsystemen bis 1500 bar, $\mathrm{CO}_{2}$ mit n-Octan, $\mathrm{n}$ Undecan, n-Tridecan und n-Hexadecan, Chem. Ing. Tech., 39 (1967) 649-656.

[68] R.L. Henry, R.S. Metcalfe, Multiple-Phase Generation During Carbon Dioxide Flooding, Soc Petrol Eng J, 23 (1983) 595-601.

[69] F.M. Orr Jr., C.M. Jensen, Interpretation of Pressure-Composition Phase Diagrams for $\mathrm{CO}_{2} /$ Crude-Oil Systems, Soc Petrol Eng J, 24 (1984) 485-497.

[70] P.M. Mathias, T.W. Copeman, Extension of the Peng-Robinson equation of state to complex mixtures: Evaluation of the various forms of the local composition concept, Fluid Phase Equilib., 13 (1983) 91-108.

[71] E. Neau, O. Hernández-Garduza, J. Escandell, C. Nicolas, I. Raspo, The Soave, Twu and Boston-Mathias alpha functions in cubic equations of state: Part I. Theoretical analysis of their variations according to temperature, Fluid Phase Equilib., 276 (2009) 87-93.

[72] P. Ghosh, Prediction of Vapor-Liquid Equilibria Using Peng-Robinson and Soave-RedlichKwong Equations of State, Chem. Eng. Technol., 22 (1999) 379-399.

[73] A. Péneloux, E. Rauzy, R. Fréze, A consistent correction for Redlich-Kwong-Soave volumes, Fluid Phase Equilib., 8 (1982) 7-23.

[74] Aspen Technology, Aspen Properties, version 7.3, in, 2011.

[75] K.S. Pitzer, D.Z. Lippmann, R.F. Curl, C.M. Huggins, D.E. Petersen, The Volumetric and Thermodynamic Properties of Fluids. II. Compressibility Factor, Vapor Pressure and Entropy of Vaporization1, JACS, 77 (1955) 3433-3440.

[76] D.J. Rosenthal, A.S. Teja, The critical properties of n-alkanes using a low-residence time flow apparatus, AIChE J., 35 (1989) 1829-1834. 
[77] E.D. Nikitin, P.A. Pavlov, N.V. Bessonova, Critical constants of n-alkanes with from 17 to 24 carbon atoms, J. Chem. Thermodyn., 26 (1994) 177-182.

[78] M. du Rand, I. Nieuwoudt, Measurement of phase equilibria of supercritical ethane and paraffins, The Journal of Supercritical Fluids, 21 (2001) 181-193.

[79] E.D. Nikitin, A.P. Popov, N.S. Bogatishcheva, Y.G. Yatluk, Vapor-Liquid Critical Properties of n-Alkylbenzenes from Toluene to 1-Phenyltridecane, J. Chem. Eng. Data, 47 (2002) 1012-1016.

[80] K.E. Starling, The properties of gases and liquids, AIChE J., 24 (1978) 1142-1142.

[81] K.G. Joback, R.C. Reid, Estimation of Pure Component Properties from Group Contributions, Chem. Eng. Commun., 57 (1987) 233-243.

[82] L. Constantinou, R. Gani, New group contribution method for estimating properties of pure compounds, AlChE J., 40 (1994) 1697-1710.

[83] E.D. Nikitin, A.P. Popov, N.S. Bogatishcheva, Critical Point Measurements for Five nAlkylcyclohexanes (C6 to C10) by the Pulse-Heating Method, J. Chem. Eng. Data, 48 (2003) 1137-1140.

[84] D.W. Morton, M.P.W. Lui, C.A. Tran, C.L. Young, Gas-Liquid Critical Temperatures of Some Alkenes, Amines, and Cyclic Hydrocarbons, J. Chem. Eng. Data, 49 (2003) 283-285.

[85] D.M. VonNiederhausern, G.M. Wilson, N.F. Giles, Critical Point and Vapor Pressure Measurements at High Temperatures by Means of a New Apparatus with Ultralow Residence Times, J. Chem. Eng. Data, 45 (2000) 157-160.

[86] E.D. Nikitin, A.P. Popov, Vapor-liquid critical properties of squalane measured by the pulse-heating technique, Fluid Phase Equilib., 237 (2005) 16-20.

[87] N.D. Zhuravlev, J. Ilja Siepmann, Exploration of the vapour-liquid phase equilibria and critical points of triacontane isomers, Fluid Phase Equilib., 134 (1997) 55-61.

[88] S.T. Cui, P.T. Cummings, H.D. Cochran, Configurational bias Gibbs ensemble Monte Carlo simulation of vapor-liquid equilibria of linear and short-branched alkanes, Fluid Phase Equilib., 141 (1997) 45-61.

[89] B. Neubauer, J. Delhommelle, A. Boutin, B. Tavitian, A.H. Fuchs, Monte Carlo simulations of squalane in the Gibbs ensemble, Fluid Phase Equilib., 155 (1999) 167-176.

[90] N.D. Zhuravlev, M.G. Martin, J. Ilja Siepmann, Vapor-liquid phase equilibria of triacontane isomers: Deviations from the principle of corresponding states, Fluid Phase Equilib., 202 (2002) 307-324. 
[91] J. Marrero, R. Gani, Group-contribution based estimation of pure component properties, Fluid Phase Equilib., 183-184 (2001) 183-208.

[92] I. Mokbel, A. Blondel-Telouk, D. Vellut, J. Jose, Vapor-liquid equilibria of two binary mixtures: benzene+n-tetradecane and benzene+squalane, Fluid Phase Equilib., 149 (1998) 287-308.

[93] P. Marteau, P. Tobaly, V. Ruffier-Meray, J.C. de Hemptinne, High-Pressure Phase Diagrams of Methane + Squalane and Methane + Hexatriacontane Mixtures, J. Chem. Eng. Data, 43 (1998) 362-366.

[94] J.M. Genco, A.S. Teja, W.B. Kay, Study of the critical and azeotropic behavior of binary mixtures. 2. PVT-x data and azeotropic states of perfluoromethylcyclohexane-isomeric hexane systems, J. Chem. Eng. Data, 25 (1980) 355-360.

[95] M.T.T. Gude, A.S, The Critical Properties of Several n-Alkanals, Tetralin and NMP, Experimental Results for DIPPR 1990-91 Projects on Phase Equilibria and Pure Component Properties, DIPPR Data Series, 2 (1994) 174-183.

[96] W.V. Steele, R.D. Chirico, S.E. Knipmeyer, A. Nguyen, Vapor Pressure, Heat Capacity, and Density along the Saturation Line, Measurements for Cyclohexanol, 2-Cyclohexen-1-one, 1,2-Dichloropropane, 1,4-Di-tert-butylbenzene, ( \pm -2-Ethylhexanoic Acid, 2(Methylamino)ethanol, Perfluoro-n-heptane, and Sulfolane, J. Chem. Eng. Data, 42 (1997) 1021-1036.

[97] R. Kleinrahm, W. Wagner, Measurement and correlation of the equilibrium liquid and vapour densities and the vapour pressure along the coexistence curve of methane, J. Chem. Thermodyn., 18 (1986) 739-760.

[98] D.E. Matschke, G. Thodos, Vapor-Liquid Equilibria for the Ethane-Propane System, J. Chem. Eng. Data, 7 (1962) 232-234.

[99] Y. Honda, T. Sato, M. Uematsu, Critical parameters for propane determined by the image analysis, J. Chem. Thermodyn., 40 (2008) 208-211.

[100] A. Diefenbacher, M. Crone, M. Türk, Critical properties of CO2, CHF3, SF6, (CO2+ CHF3), and (CHF3+ SF6), J. Chem. Thermodyn., 30 (1998) 481-496. 


\section{Table 1}

List of components used in this work with mole fraction $x$, normal boiling temperature $T_{\mathrm{b}}$, molar mass $M$, and mole-fraction purity $x .^{a}$

\begin{tabular}{|c|c|c|c|c|c|c|}
\hline Component & $x_{1}$ & $x_{2}$ & $x_{3}$ & $\begin{array}{l}T_{\mathrm{b}} \\
(\mathrm{K})\end{array}$ & $\begin{array}{c}M \\
\left(\mathrm{~g} \cdot \mathrm{mol}^{-1}\right)\end{array}$ & $\begin{array}{c}x \\
\text { (purity) }\end{array}$ \\
\hline 2,2-dimethylbutane & 0.1192 & 0.0715 & 0.0417 & 322.88 & 86.18 & 0.99 \\
\hline n-heptane & 0.1047 & 0.0628 & 0.0366 & 371.58 & 100.21 & 0.99 \\
\hline ethylcyclohexane & 0.0621 & 0.0373 & 0.0217 & 404.94 & 112.21 & 0.99 \\
\hline n-nonane & 0.0503 & 0.0302 & 0.0176 & 423.97 & 128.26 & 0.99 \\
\hline propylcyclohexane & 0.0301 & 0.0181 & 0.0105 & 429.89 & 126.24 & 0.99 \\
\hline $\begin{array}{c}1,2,3,4- \\
\text { tetrahydronaphthalene }\end{array}$ & 0.0454 & 0.0272 & 0.0159 & 480.77 & 132.21 & 0.99 \\
\hline 1,3,5-triethylbenzene & 0.0666 & 0.0400 & 0.0233 & 489.20 & 162.27 & 0.97 \\
\hline 1-phenylhexane & 0.0379 & 0.0227 & 0.0133 & 499.30 & 162.27 & 0.97 \\
\hline n-tridecane & 0.0127 & 0.0076 & 0.0044 & 508.58 & 184.37 & 0.99 \\
\hline 1-phenyloctane & 0.0638 & 0.0383 & 0.0223 & 537.54 & 190.32 & 0.98 \\
\hline n-pentadecane & 0.0310 & 0.0186 & 0.0109 & 543.77 & 212.41 & 0.99 \\
\hline n-hexadecane & 0.0131 & 0.0079 & 0.0046 & 559.94 & 226.43 & 0.99 \\
\hline octadecane & 0.0420 & 0.0252 & 0.0147 & 589.86 & 254.48 & 0.99 \\
\hline nonadecane & 0.0365 & 0.0219 & 0.0128 & 603.80 & 268.51 & 0.99 \\
\hline 1-phenylhexadecane & 0.0449 & 0.0269 & 0.0157 & 662.15 & 316.57 & 0.97 \\
\hline tetracosane & 0.0066 & 0.0040 & 0.0023 & 664.43 & 338.64 & 0.99 \\
\hline squalane & 0.2331 & 0.1399 & 0.0816 & 720.00 & 422.82 & 0.99 \\
\hline methane & 0.0000 & 0.3252 & 0.5285 & 111.63 & 16.04 & 0.995 \\
\hline ethane & 0.0000 & 0.0504 & 0.0819 & 184.55 & 30.07 & 0.99 \\
\hline propane & 0.0000 & 0.0244 & 0.0397 & 231.05 & 44.10 & 0.99 \\
\hline
\end{tabular}

${ }^{a} x_{1}$ is the mole fraction of the components present in the synthetic dead oil mixture, $x_{2}$ is the mole fraction of the components present in the synthetic live oil mixture with low gas oil ratio, $x_{3}$ is the mole fraction of the components present in the synthetic live oil mixture with high gas oil ratio. The normal boiling point temperatures $T_{\mathrm{b}}$ and molar mass $M$ were obtained from the NIST Thermodata Engine (TDE) software. 


\section{Table 2}

Properties of Qatari crude oil sample: density $\rho$, relative density $\rho_{\mathrm{r}}$, API gravity, kinematic viscosity $\mu$, PNA ratios, asphaltene mass fraction and boiling-range analysis.

\begin{tabular}{|c|c|c|c|c|c|}
\hline \multirow{2}{*}{\multicolumn{2}{|c|}{$\begin{array}{c}\rho(T=283.15 \mathrm{~K})\left(\mathrm{kg} \cdot \mathrm{m}^{-3}\right) \\
\rho_{\mathrm{r}}(T=288.7 \mathrm{~K})^{a}\end{array}$}} & 886.5 & \multicolumn{2}{|c|}{ Paraffins volume fraction ${ }^{c}$} & $69.19 \%$ \\
\hline & & 0.8873 & \multicolumn{2}{|c|}{ Naphthenes volume fraction ${ }^{c}$} & $23.41 \%$ \\
\hline \multicolumn{2}{|c|}{ API gravity ${ }^{b}$} & 27.97 & \multicolumn{2}{|c|}{ Aromatics volume fraction ${ }^{c}$} & $7.40 \%$ \\
\hline \multicolumn{2}{|c|}{$\mu(T=293.15 \mathrm{~K})\left(\mathrm{mm}^{2} \cdot \mathrm{s}^{-1}\right)$} & 44.06 & \multicolumn{2}{|c|}{ Asphaltenes mass fraction } & $1.7 \%$ \\
\hline \multicolumn{2}{|c|}{$\mu(T=313.15 \mathrm{~K})\left(\mathrm{mm}^{2} \cdot \mathrm{s}^{-1}\right)$} & 13.32 & & & \\
\hline $\begin{array}{c}\text { Boiling range } \\
\left({ }^{\circ} \mathrm{C}\right)\end{array}$ & $\begin{array}{l}\text { Cumulative } \\
\text { volume fraction }\end{array}$ & $\begin{array}{c}\rho(T=283.15 \mathrm{~K}) \\
\left(\mathrm{kg} \cdot \mathrm{m}^{-3}\right)\end{array}$ & $\begin{array}{c}\text { Boiling range } \\
\left({ }^{\circ} \mathrm{C}\right)\end{array}$ & $\begin{array}{l}\text { Cumulative } \\
\text { volume fraction }\end{array}$ & $\begin{array}{c}\rho(T=283.15 \mathrm{~K}) \\
\left(\mathrm{kg} \cdot \mathrm{m}^{-3}\right)\end{array}$ \\
\hline $5-65$ & $5.7 \%$ & 646.4 & $250-300$ & $39.48 \%$ & 857.8 \\
\hline $65-150$ & $14.47 \%$ & 731.6 & $300-350$ & $48.92 \%$ & 880.3 \\
\hline $150-200$ & $21.66 \%$ & 789.7 & $350-420$ & $60.69 \%$ & 905.2 \\
\hline $200-250$ & $29.89 \%$ & 825.5 & $420-560$ & $80.5 \%$ & 944.9 \\
\hline
\end{tabular}

a Relative density $\rho_{\mathrm{r}}=\rho / \rho\left(\mathrm{H}_{2} \mathrm{O}\right)$

${ }^{b} \mathrm{API}$ (American Petroleum Institute) gravity $=\left(141.5 / \rho_{\mathrm{r}}\right)-131.5$ at $T=288.7 \mathrm{~K}$

${ }^{c}$ PNA ratios refer to the boiling range up to $200^{\circ} \mathrm{C}$ only. 


\section{Table 3}

Bubble and dew experimental points obtained in this work for the binary mixture $\left(\mathrm{CO}_{2}+\right.$ heptane) at $T=394.15 \mathrm{~K}^{\mathrm{a}}$

\begin{tabular}{cclccc}
\hline$p(\mathrm{MPa})$ & $x_{\mathrm{CO} 2}$ & Status & $p / \mathrm{MPa}$ & $x_{\mathrm{cO} 2}$ & Status \\
\hline 0.56 & 0.0230 & bubble & 13.45 & 0.8042 & bubble \\
1.87 & 0.1121 & bubble & 13.48 & 0.8314 & bubble \\
3.59 & 0.2136 & bubble & 13.11 & 0.8873 & $\mathrm{dew}$ \\
6.34 & 0.3711 & bubble & 12.63 & 0.9043 & $\mathrm{dew}$ \\
9.02 & 0.5153 & bubble & 11.82 & 0.9213 & $\mathrm{dew}$ \\
10.85 & 0.6120 & bubble & 11.09 & 0.9336 & $\mathrm{dew}$ \\
12.90 & 0.7256 & bubble & 10.02 & 0.9400 & $\mathrm{dew}$ \\
13.29 & 0.7710 & bubble & & & \\
\hline
\end{tabular}

a Expanded uncertainties are $U(T)=0.08 \mathrm{~K}, U(p)=0.2 \mathrm{MPa}$ and $U\left(x_{\mathrm{CO}_{2}}\right)=0.0042 x_{\mathrm{CO}_{2}}\left(1-x_{\mathrm{CO}_{2}}\right)$, with coverage factor $k=2$. 


\section{Table 4}

Experimentally determined VLE, LLE, VLLE pressures $p$ and densities $\rho$ for the $\left(\mathrm{CO}_{2}+\right.$ synthetic dead oil) mixture at temperatures of $T$ and $\mathrm{CO}_{2}$ mole fractions $\mathrm{X}_{\mathrm{CO}_{2}}$. ${ }^{\text {a }}$

\begin{tabular}{|c|c|c|c|c|c|c|c|}
\hline$p(\mathrm{MPa})$ & $x_{\mathrm{CO}_{2}}$ & Status & $\rho\left(\mathrm{kg} \cdot \mathrm{m}^{-3}\right)$ & $p(\mathrm{MPa})$ & $x_{\mathrm{CO}_{2}}$ & Status & $\rho\left(\mathrm{kg} \cdot \mathrm{m}^{-3}\right)$ \\
\hline \multicolumn{4}{|c|}{$T=298.15 \mathrm{~K}$} & 25.350 & 0.9393 & Critical & 870 \\
\hline 0.011 & 0.0000 & $\mathrm{~L}_{1}-\mathrm{V}$ & 801 & 25.850 & 0.9473 & dew & 874 \\
\hline 0.465 & 0.0662 & $\mathrm{~L}_{1}-\mathrm{V}$ & 795 & 25.750 & 0.9601 & dew & 863 \\
\hline 1.450 & 0.1843 & $\mathrm{~L}_{1}-\mathrm{V}$ & 798 & 24.650 & 0.9678 & dew & 858 \\
\hline 2.740 & 0.3266 & $\mathrm{~L}_{1}-\mathrm{V}$ & 802 & 23.950 & 0.9732 & dew & 853 \\
\hline 4.050 & 0.4954 & $\mathrm{~L}_{1}-\mathrm{V}$ & 807 & 23.050 & 0.9798 & dew & 845 \\
\hline 5.450 & 0.6458 & $L_{1}-V$ & 818 & \multicolumn{4}{|c|}{$T=373.15 \mathrm{~K}$} \\
\hline 5.950 & 0.6749 & $\mathrm{~L}_{1}-\mathrm{V}$ & 825 & 0.205 & 0.0000 & bubble & 735 \\
\hline 8.030 & 0.7332 & $L_{1}-L_{2}$ & 836 & 3.550 & 0.2211 & bubble & 741 \\
\hline 11.150 & 0.7791 & $L_{1}-L_{2}$ & 850 & 5.850 & 0.3517 & bubble & 742 \\
\hline 13.150 & 0.7929 & $\mathrm{~L}_{1}-\mathrm{L}_{2}$ & 856 & 8.150 & 0.4560 & bubble & 750 \\
\hline 17.850 & 0.8158 & $L_{1}-L_{2}$ & 870 & 11.150 & 0.5745 & bubble & 753 \\
\hline 24.950 & 0.8438 & $L_{1}-L_{2}$ & 890 & 13.860 & 0.6413 & bubble & 753 \\
\hline 36.052 & 0.8632 & $L_{1}-L_{2}$ & 901 & 16.050 & 0.7011 & bubble & 757 \\
\hline 6.060 & 0.7332 & $L_{1}-L_{2}-V$ & $\mathrm{~N} / \mathrm{A}$ & 20.980 & 0.7927 & bubble & 760 \\
\hline 6.060 & 0.7793 & $L_{1}-L_{2}-V$ & $\mathrm{~N} / \mathrm{A}$ & 23.050 & 0.8315 & bubble & 761 \\
\hline 6.060 & 0.7929 & $L_{1}-L_{2}-V$ & $\mathrm{~N} / \mathrm{A}$ & 24.250 & 0.8588 & bubble & 755 \\
\hline 6.060 & 0.8161 & $L_{1}-L_{2}-V$ & $\mathrm{~N} / \mathrm{A}$ & 25.480 & 0.8844 & bubble & 751 \\
\hline 6.060 & 0.8440 & $L_{1}-L_{2}-V$ & $\mathrm{~N} / \mathrm{A}$ & 27.850 & 0.9261 & bubble & 741 \\
\hline 6.060 & 0.8738 & $L_{1}-L_{2}-V$ & $\mathrm{~N} / \mathrm{A}$ & 28.350 & 0.9469 & critical & 738 \\
\hline 6.060 & 0.9024 & $L_{1}-L_{2}-V$ & $\mathrm{~N} / \mathrm{A}$ & 28.650 & 0.9601 & dew & 731 \\
\hline 6.060 & 0.9500 & $L_{1}-L_{2}-V$ & $\mathrm{~N} / \mathrm{A}$ & 28.450 & 0.9689 & dew & 716 \\
\hline 6.060 & 0.9800 & $L_{1}-L_{2}-V$ & $\mathrm{~N} / \mathrm{A}$ & 27.820 & 0.9762 & dew & 715 \\
\hline 6.060 & 0.9911 & $\mathrm{~L}_{1}-\mathrm{L}_{2}-\mathrm{V}$ & $\mathrm{N} / \mathrm{A}$ & 27.350 & 0.9798 & dew & 705 \\
\hline \multicolumn{4}{|c|}{$T=323.15 \mathrm{~K}$} & 26.350 & 0.9845 & dew & 679 \\
\hline 0.175 & 0.0019 & bubble & 788 & \multicolumn{4}{|c|}{$T=423.15 \mathrm{~K}$} \\
\hline 1.010 & 0.0948 & bubble & 786 & 0.340 & 0.0000 & bubble & 721 \\
\hline 3.075 & 0.2897 & bubble & 796 & 0.796 & 0.0295 & bubble & 723 \\
\hline 4.780 & 0.4113 & bubble & 798 & 3.250 & 0.1522 & bubble & 726 \\
\hline
\end{tabular}




\begin{tabular}{cccccccc}
\hline$p(\mathrm{MPa})$ & $x_{\mathrm{CO}_{2}}$ & Status & $\rho\left(\mathrm{kg} \cdot \mathrm{m}^{-3}\right)$ & $p(\mathrm{MPa})$ & $x_{\mathrm{CO}_{2}}$ & Status & $\rho\left(\mathrm{kg} \cdot \mathrm{m}^{-3}\right)$ \\
\hline 6.820 & 0.5558 & bubble & 806 & 5.350 & 0.2783 & bubble & 726 \\
8.350 & 0.6578 & bubble & 815 & 9.250 & 0.4178 & bubble & 726 \\
11.750 & 0.7796 & bubble & 825 & 14.850 & 0.5742 & bubble & 729 \\
13.230 & 0.8000 & bubble & 828 & 20.620 & 0.7010 & bubble & 729 \\
16.150 & 0.8358 & bubble & 836 & 25.850 & 0.7948 & bubble & 721 \\
18.650 & 0.8694 & bubble & 843 & 29.250 & 0.8588 & bubble & 710 \\
19.100 & 0.8736 & bubble & 843 & 31.950 & 0.9261 & bubble & 659 \\
19.850 & 0.8844 & bubble & 848 & 32.700 & 0.9469 & critical & 645 \\
19.980 & 0.8866 & bubble & 847 & 32.250 & 0.9689 & dew & 612 \\
21.480 & 0.9023 & bubble & 851 & 31.850 & 0.9725 & dew & 602 \\
21.950 & 0.9073 & bubble & 850 & 31.400 & 0.9774 & dew & 590 \\
23.650 & 0.9265 & bubble & 861 & 30.050 & 0.9845 & dew & 578 \\
\hline
\end{tabular}

${ }^{a}$ Expanded uncertainties are $U(T)=0.08 \mathrm{~K}, U\left(p_{\mathrm{b}}\right)=0.2 \mathrm{MPa}$ for $p_{\mathrm{b}} \leq 25 \mathrm{MPa}$ and $0.3 \mathrm{MPa}$ for $p_{\mathrm{b}}>25 \mathrm{MPa}, U\left(p_{\mathrm{d}}\right)=0.3 \mathrm{MPa}$ for $T \leq 373.15 \mathrm{MPa}$ and $0.4 \mathrm{MPa}$ for $T>373.15 \mathrm{~K}$, and $U\left(x_{\mathrm{CO}_{2}}\right)=0.0042 x_{\mathrm{CO}_{2}}\left(1-x_{\mathrm{CO}_{2}}\right)$, with coverage factor $k=2$. 


\section{Table 5}

Experimentally determined VLE, LLE, VLLE pressures $p$ and densities $\rho$ for the $\left(\mathrm{CO}_{2}+\right.$ synthetic live oil) mixture with the low GOR at temperatures of $T$ and $\mathrm{CO}_{2}$ mole fractions $X_{\mathrm{CO}_{2}}$.

\begin{tabular}{|c|c|c|c|c|c|c|c|}
\hline$p(\mathrm{MPa})$ & $x_{\mathrm{CO}_{2}}$ & Status & $\begin{array}{c}\rho\left(\mathrm{kg} \cdot \mathrm{m}^{-}\right. \\
3)\end{array}$ & $p(\mathrm{MPa})$ & $x_{\mathrm{CO}_{2}}$ & Status & $\begin{array}{c}\rho\left(\mathrm{kg} \cdot \mathrm{m}^{-}\right. \\
3)\end{array}$ \\
\hline \multicolumn{4}{|c|}{$T=298.15 \mathrm{~K}$} & 26.450 & 0.9323 & dew & 840 \\
\hline 8.710 & 0.0000 & $L_{1}-V$ & 744 & 25.850 & 0.9453 & dew & 834 \\
\hline 9.800 & 0.0659 & $\mathrm{~L}_{1}-\mathrm{V}$ & 754 & 25.550 & 0.9493 & dew & 826 \\
\hline 10.520 & 0.2208 & $\mathrm{~L}_{1}-\mathrm{V}$ & 765 & 24.500 & 0.9583 & dew & 814 \\
\hline 11.150 & 0.3543 & $\mathrm{~L}_{1}-\mathrm{V}$ & 764 & 24.000 & 0.9618 & dew & 812 \\
\hline 11.640 & 0.4211 & $\mathrm{~L}_{1}-\mathrm{V}$ & 781 & 22.150 & 0.9717 & dew & 810 \\
\hline 12.630 & 0.6000 & $\mathrm{~L}_{1}-\mathrm{V}$ & 796 & 20.220 & 0.9788 & dew & 806 \\
\hline 14.820 & 0.6481 & $\mathrm{~L}_{1}-\mathrm{L}_{2}$ & 800 & 16.650 & 0.9846 & dew & 801 \\
\hline 17.550 & 0.7053 & $\mathrm{~L}_{1}-\mathrm{L}_{2}$ & 818 & 16.230 & 0.9868 & dew & 788 \\
\hline 19.230 & 0.7288 & $\mathrm{~L}_{1}-\mathrm{L}_{2}$ & 836 & 14.920 & 0.9915 & dew & 763 \\
\hline 23.460 & 0.7831 & $\mathrm{~L}_{1}-\mathrm{L}_{2}$ & 848 & \multicolumn{4}{|c|}{$T=373.15 \mathrm{~K}$} \\
\hline 29.350 & 0.8296 & $\mathrm{~L}_{1}-\mathrm{L}_{2}$ & 876 & 12.250 & 0.0000 & bubble & 696 \\
\hline 9.300 & 0.6483 & $L_{1}-L_{2}-V$ & $\mathrm{~N} / \mathrm{A}$ & 13.060 & 0.0648 & bubble & 703 \\
\hline 8.500 & 0.7053 & $L_{1}-L_{2}-V$ & N/A & 15.460 & 0.2200 & bubble & 711 \\
\hline 7.725 & 0.7831 & $\mathrm{~L}_{1}-\mathrm{L}_{2}-\mathrm{V}$ & N/A & 16.450 & 0.2739 & bubble & 716 \\
\hline 7.050 & 0.8296 & $L_{1}-L_{2}-V$ & N/A & 19.550 & 0.4205 & bubble & 722 \\
\hline 6.710 & 0.9164 & $L_{1}-L_{2}-V$ & $\mathrm{~N} / \mathrm{A}$ & 20.050 & 0.4433 & bubble & 727 \\
\hline 6.560 & 0.9725 & $L_{1}-L_{2}-V$ & N/A & 23.560 & 0.5996 & bubble & 732 \\
\hline 6.507 & 0.9803 & $\mathrm{~L}_{1}-\mathrm{L}_{2}-\mathrm{V}$ & $\mathrm{N} / \mathrm{A}$ & 24.370 & 0.6320 & bubble & 738 \\
\hline 6.440 & 0.9850 & $L_{1}-L_{2}-V$ & N/A & 26.750 & 0.7286 & bubble & 742 \\
\hline 6.440 & 0.9880 & $L_{1}-L_{2}-V$ & $\mathrm{~N} / \mathrm{A}$ & 27.340 & 0.7595 & bubble & 743 \\
\hline 6.440 & 0.9890 & $\mathrm{~L}_{1}-\mathrm{L}_{2}-\mathrm{V}$ & $\mathrm{N} / \mathrm{A}$ & 27.920 & 0.7957 & bubble & 741 \\
\hline 6.500 & 0.9910 & $L_{1}-L_{2}-V$ & N/A & 28.280 & 0.8157 & bubble & 747 \\
\hline 9.300 & 0.6483 & $L_{1}-L_{2}-V$ & N/A & 28.750 & 0.8450 & bubble & 744 \\
\hline 8.650 & 0.7053 & $L_{1}-L_{2}-V$ & N/A & 29.060 & 0.8724 & critical & 728 \\
\hline 8.010 & 0.7831 & $L_{1}-L_{2}-V$ & N/A & 29.500 & 0.9164 & dew & 721 \\
\hline 7.850 & 0.8296 & $L_{1}-L_{2}-V$ & $\mathrm{~N} / \mathrm{A}$ & 28.950 & 0.9503 & dew & 709 \\
\hline
\end{tabular}




\begin{tabular}{|c|c|c|c|c|c|c|c|}
\hline$p(\mathrm{MPa})$ & $x_{\mathrm{CO}_{2}}$ & Status & $\begin{array}{c}\rho\left(\mathrm{kg} \cdot \mathrm{m}^{-}\right. \\
3)\end{array}$ & $p(\mathrm{MPa})$ & $x_{\mathrm{CO}_{2}}$ & Status & $\begin{array}{c}\rho(\mathrm{kg} \cdot \mathrm{m} \\
3)\end{array}$ \\
\hline 7.010 & 0.9164 & $L_{1}-L_{2}-V$ & N/A & 28.000 & 0.9613 & dew & 702 \\
\hline 28.250 & 0.9851 & $\mathrm{~L}_{1}-\mathrm{L}_{2}$ & 802 & 27.500 & 0.9678 & dew & 700 \\
\hline 20.550 & 0.9853 & $\mathrm{~L}_{1}-\mathrm{L}_{2}$ & 862 & 26.950 & 0.9725 & dew & 699 \\
\hline 7.400 & 0.9860 & $\mathrm{~L}_{1}-\mathrm{L}_{2}$ & 832 & 25.920 & 0.9788 & dew & 697 \\
\hline 6.850 & 0.9880 & $L_{1}-L_{2}$ & 778 & 25.030 & 0.9827 & dew & 681 \\
\hline 6.730 & 0.9890 & $L_{1}-L_{2}$ & 770 & 24.450 & 0.9846 & dew & 677 \\
\hline 6.500 & 0.9910 & $L_{1}-L_{2}$ & 762 & \multicolumn{4}{|c|}{$T=423.15 \mathrm{~K}$} \\
\hline \multicolumn{4}{|c|}{$T=323.15 \mathrm{~K}$} & 13.200 & 0.0000 & bubble & 666 \\
\hline 10.210 & 0.0000 & bubble & 728 & 14.470 & 0.0643 & bubble & 666 \\
\hline 11.040 & 0.0654 & bubble & 737 & 17.450 & 0.2197 & bubble & 674 \\
\hline 12.480 & 0.2205 & bubble & 747 & 22.460 & 0.4203 & bubble & 681 \\
\hline 14.620 & 0.4208 & bubble & 762 & 27.510 & 0.5995 & bubble & 683 \\
\hline 16.710 & 0.5998 & bubble & 778 & 30.870 & 0.7285 & bubble & 684 \\
\hline 20.240 & 0.7287 & bubble & 800 & 31.960 & 0.7956 & bubble & 675 \\
\hline 22.150 & 0.7957 & bubble & 811 & 33.120 & 0.8724 & Critical & 648 \\
\hline 23.250 & 0.8297 & bubble & 826 & 33.380 & 0.9164 & dew & 628 \\
\hline 24.050 & 0.8494 & bubble & 842 & 32.750 & 0.9503 & dew & 607 \\
\hline 25.050 & 0.8724 & bubble & 846 & 31.500 & 0.9613 & dew & 598 \\
\hline 24.930 & 0.8750 & bubble & 848 & 31.030 & 0.9678 & dew & 593 \\
\hline 26.420 & 0.9041 & bubble & 849 & 30.020 & 0.9725 & dew & 586 \\
\hline 27.050 & 0.9164 & dew & 849 & & & & \\
\hline
\end{tabular}

${ }^{a}$ Expanded uncertainties are $U(T)=0.08 \mathrm{~K}, U\left(p_{\mathrm{b}}\right)=0.2 \mathrm{MPa}$ for $p_{\mathrm{b}} \leq 25 \mathrm{MPa}$ and $0.3 \mathrm{MPa}$ for $p_{\mathrm{b}}>25 \mathrm{MPa}, U\left(p_{\mathrm{d}}\right)=0.3 \mathrm{MPa}$ for $T \leq 373.15 \mathrm{MPa}$ and $0.4 \mathrm{MPa}$ for $T>373.15 \mathrm{~K}$, and $U\left(x_{\mathrm{CO}_{2}}\right)=0.0042 x_{\mathrm{CO}_{2}}\left(1-x_{\mathrm{CO}_{2}}\right)$, with coverage factor $k=2$. 


\section{Table 6}

Experimentally determined VLE, LLE, VLLE pressures $p$ and densities $\rho$ for the $\left(\mathrm{CO}_{2}+\right.$ synthetic live oil) mixture with the high GOR at temperatures of $T$ and $\mathrm{CO}_{2}$ mole fractions $X_{\mathrm{CO}_{2}}$.

\begin{tabular}{|c|c|c|c|c|c|c|c|}
\hline$p(\mathrm{MPa})$ & $x_{\mathrm{CO}_{2}}$ & Status & $\begin{array}{c}\rho\left(\mathrm{kg} \cdot \mathrm{m}^{-}\right. \\
3)\end{array}$ & $p(\mathrm{MPa})$ & $x_{\mathrm{CO}_{2}}$ & Status & $\begin{array}{c}\rho\left(\mathrm{kg} \cdot \mathrm{m}^{-}\right. \\
3)\end{array}$ \\
\hline \multicolumn{4}{|c|}{$T=298.15 \mathrm{~K}$} & 26.000 & 0.8835 & dew & 802 \\
\hline 22.250 & 0.0000 & $L_{1}-V$ & 689 & 25.350 & 0.9226 & dew & 799 \\
\hline 23.780 & 0.1404 & $L_{1}-V$ & 698 & 23.620 & 0.9412 & dew & 797 \\
\hline 24.150 & 0.3428 & $\mathrm{~L}_{1}-\mathrm{V}$ & 724 & 22.050 & 0.9526 & dew & 792 \\
\hline 24.420 & 0.5122 & $L_{1}-V$ & 749 & 21.130 & 0.9594 & dew & 789 \\
\hline 24.750 & 0.6291 & $L_{1}-V$ & 782 & 19.940 & 0.9653 & dew & 783 \\
\hline 25.920 & 0.7078 & $\mathrm{~L}_{1}-\mathrm{L}_{2}$ & 809 & 18.400 & 0.9773 & dew & 778 \\
\hline 27.750 & 0.7605 & $\mathrm{~L}_{1}-\mathrm{L}_{2}$ & 835 & 16.900 & 0.9855 & dew & 762 \\
\hline 33.900 & 0.8432 & $L_{1}-L_{2}$ & 890 & 15.020 & 0.9933 & dew & 726 \\
\hline 36.000 & 0.8600 & $L_{1}-L_{2}$ & 916 & 14.130 & 0.9944 & dew & 708 \\
\hline 6.620 & 0.9774 & $\mathrm{~L}_{1}-\mathrm{L}_{2}-\mathrm{V}$ & N/A & \multicolumn{4}{|c|}{$T=373.15 \mathrm{~K}$} \\
\hline 6.550 & 0.9824 & $\mathrm{~L}_{1}-\mathrm{L}_{2}-\mathrm{V}$ & N/A & 26.280 & 0.0000 & bubble & 637 \\
\hline 6.540 & 0.9855 & $\mathrm{~L}_{1}-\mathrm{L}_{2}-\mathrm{V}$ & N/A & 28.015 & 0.1401 & bubble & 642 \\
\hline 6.410 & 0.9933 & $L_{1}-L_{2}-V$ & $\mathrm{~N} / \mathrm{A}$ & 29.520 & 0.3425 & bubble & 657 \\
\hline 6.407 & 0.9944 & $L_{1}-L_{2}-V$ & $N / A$ & 31.380 & 0.5121 & bubble & 676 \\
\hline 6.780 & 0.9309 & $\mathrm{~L}_{1}-\mathrm{L}_{2}-\mathrm{V}$ & $\mathrm{N} / \mathrm{A}$ & 32.140 & 0.6290 & bubble & 686 \\
\hline 7.000 & 0.8845 & $L_{1}-L_{2}-V$ & N/A & 32.692 & 0.7078 & bubble & 698 \\
\hline 7.363 & 0.8261 & $L_{1}-L_{2}-V$ & N/A & 32.450 & 0.7588 & dew & 704 \\
\hline 8.630 & 0.7539 & $\mathrm{~L}_{1}-\mathrm{L}_{2}-\mathrm{V}$ & N/A & 31.750 & 0.8114 & dew & 705 \\
\hline 11.230 & 0.6857 & $\mathrm{~L}_{1}-\mathrm{L}_{2}-\mathrm{V}$ & $\mathrm{N} / \mathrm{A}$ & 31.100 & 0.8432 & dew & 706 \\
\hline 6.650 & 0.9774 & $L_{1}-L_{2}-V$ & $\mathrm{~N} / \mathrm{A}$ & 29.815 & 0.8923 & dew & 698 \\
\hline 6.550 & 0.9824 & $L_{1}-L_{2}-V$ & N/A & 28.645 & 0.9225 & dew & 688 \\
\hline 6.540 & 0.9855 & $\mathrm{~L}_{1}-\mathrm{L}_{2}-\mathrm{V}$ & $\mathrm{N} / \mathrm{A}$ & 26.215 & 0.9565 & dew & 666 \\
\hline 6.410 & 0.9933 & $L_{1}-L_{2}-V$ & N/A & 25.620 & 0.9624 & dew & 660 \\
\hline 6.407 & 0.9944 & $L_{1}-L_{2}-V$ & $\mathrm{~N} / \mathrm{A}$ & 24.050 & 0.9753 & dew & 648 \\
\hline 7.250 & 0.9309 & $\mathrm{~L}_{1}-\mathrm{L}_{2}-\mathrm{V}$ & N/A & 23.220 & 0.9788 & dew & 647 \\
\hline 7.750 & 0.8845 & $\mathrm{~L}_{1}-\mathrm{L}_{2}-\mathrm{V}$ & $N / A$ & 22.130 & 0.9859 & dew & 631 \\
\hline
\end{tabular}




\begin{tabular}{cccccccc}
\hline$p(\mathrm{MPa})$ & $x_{\mathrm{CO}_{2}}$ & Status & $\begin{array}{c}\rho\left(\mathrm{kg} \cdot \mathrm{m}^{-}\right. \\
3)\end{array}$ & $p(\mathrm{MPa})$ & $x_{\mathrm{CO}_{2}}$ & Status & $\begin{array}{c}\rho\left(\mathrm{kg} \cdot \mathrm{m}^{-}\right. \\
3\end{array}$ \\
\hline 8.270 & 0.8261 & $\mathrm{~L}_{1}-\mathrm{L}_{2}-\mathrm{V}$ & $\mathrm{N} / \mathrm{A}$ & 21.070 & 0.9922 & dew & 580 \\
8.890 & 0.7539 & $\mathrm{~L}_{1}-\mathrm{L}_{2}-\mathrm{V}$ & $\mathrm{N} / \mathrm{A}$ & 20.250 & 0.9933 & dew & 567 \\
11.230 & 0.6857 & $\mathrm{~L}_{1}-\mathrm{L}_{2}-\mathrm{V}$ & $\mathrm{N} / \mathrm{A}$ & & $T=423.15 \mathrm{~K}$ & \\
14.820 & 0.9653 & $\mathrm{~L}_{1}-\mathrm{L}_{2}$ & 852 & 27.500 & 0.0000 & bubble & 605 \\
13.460 & 0.9692 & $\mathrm{~L}_{1}-\mathrm{L}_{2}$ & 845 & 29.580 & 0.1269 & bubble & 606 \\
11.400 & 0.9774 & $\mathrm{~L}_{1}-\mathrm{L}_{2}$ & 826 & 32.450 & 0.3348 & bubble & 615 \\
9.350 & 0.9824 & $\mathrm{~L}_{1}-\mathrm{L}_{2}$ & 807 & 34.280 & 0.5076 & bubble & 622 \\
8.620 & 0.9855 & $\mathrm{~L}_{1}-\mathrm{L}_{2}$ & 797 & 35.100 & 0.6262 & bubble & 623 \\
7.380 & 0.9933 & $\mathrm{~L}_{1}-\mathrm{L}_{2}$ & 766 & 35.300 & 0.6711 & bubble & 624 \\
7.300 & 0.9944 & $\mathrm{~L}_{1}-\mathrm{L}_{2}$ & 744 & 35.200 & 0.7535 & Critical & 613 \\
& $T=323.15 \mathrm{~K}$ & & 35.100 & 0.8230 & dew & 610 \\
23.730 & 0.0000 & bubble & 672 & 34.700 & 0.8608 & dew & 598 \\
25.030 & 0.1403 & bubble & 679 & 34.250 & 0.8837 & dew & 583 \\
25.830 & 0.3426 & bubble & 703 & 33.500 & 0.9010 & dew & 573 \\
26.770 & 0.5122 & bubble & 726 & 32.800 & 0.9220 & dew & 552 \\
27.120 & 0.6291 & bubble & 746 & 31.120 & 0.9503 & dew & 520 \\
26.950 & 0.7078 & bubble & 767 & 29.010 & 0.9695 & dew & 502 \\
26.750 & 0.7605 & bubble & 784 & 25.370 & 0.9902 & dew & 464 \\
26.400 & 0.8432 & bubble & 804 & & & & \\
\hline
\end{tabular}

a Expanded uncertainties are $U(T)=0.08 \mathrm{~K}, U\left(p_{\mathrm{b}}\right)=0.2 \mathrm{MPa}$ for $p_{\mathrm{b}} \leq 25 \mathrm{MPa}$ and $0.3 \mathrm{MPa}$ for $p_{\mathrm{b}}>25 \mathrm{MPa}, U\left(p_{\mathrm{d}}\right)=0.3 \mathrm{MPa}$ for $T \leq 373.15 \mathrm{MPa}$ and $0.4 \mathrm{MPa}$ for $T>373.15 \mathrm{~K}$, and $U\left(x_{\mathrm{CO}_{2}}\right)=0.0042 x_{\mathrm{CO}_{2}}\left(1-x_{\mathrm{CO}_{2}}\right)$, with coverage factor $k=2$. 


\section{Table 7}

Three phases VLLE locus for the $\mathrm{CO}_{2}+$ dead oil mixture. ${ }^{a}$

\begin{tabular}{cccccc}
\hline$T(\mathrm{~K})$ & $p(\mathrm{MPa})$ & $T(\mathrm{~K})$ & $p(\mathrm{MPa})$ & $T(\mathrm{~K})$ & $p(\mathrm{MPa})$ \\
\hline 298.15 & 6.04 & 308.62 & 7.39 & 313.9 & 8.173 \\
300.5 & 6.28 & 310.16 & 7.636 & 314.27 & 8.211 \\
303.02 & 6.62 & 311.2 & 7.749 & 315.28 & 8.311 \\
306.06 & 7.02 & 312.92 & 8.026 & 316.3 & 8.443 \\
\hline
\end{tabular}

${ }^{\text {a }}$ Expanded uncertainties are $U(T)=0.08 \mathrm{~K}$ and $U(p)=0.2 \mathrm{MPa}$ with coverage factor $k=2$. 


\section{Table 8}

Critical pressure $p_{\mathrm{c}}$ and critical temperature $T_{\mathrm{c}}$ (with uncertainties, $u$ ), acentric factor $\omega$ and critical compressibility factor $Z_{c}$ for the components studied in this work.

\begin{tabular}{|c|c|c|c|c|c|c|c|}
\hline Component & Ref & $\omega$ & $\begin{array}{c}p_{\mathrm{C}} \\
(\mathrm{MPa})\end{array}$ & $\begin{array}{c}u\left(p_{\mathrm{c}}\right) \\
(\mathrm{MPa})\end{array}$ & $\begin{array}{l}T_{\mathrm{c}} \\
(\mathrm{K})\end{array}$ & $\begin{array}{c}u(T c) \\
(\mathrm{K})\end{array}$ & $Z_{\mathrm{c}}$ \\
\hline 2,2-dimethylbutane & {$[94]$} & $0.2251^{f}$ & 3.102 & 0.01 & 489.21 & 0.11 & 0.27415 \\
\hline n-heptane & {$[76]$} & $0.3481^{f}$ & 2.734 & 0.02 & 540.30 & 0.6 & 0.26078 \\
\hline ethylcyclohexane & $\begin{array}{l}{[83} \\
84]\end{array}$ & $0.3180^{f}$ & $3.250^{\mathrm{a}}$ & 0.1 & $606.9^{a}$ & 0.4 & 0.26046 \\
\hline n-nonane & {$[76]$} & $0.4409^{f}$ & 2.280 & 0.02 & 594.70 & 0.6 & 0.25451 \\
\hline propylcyclohexane & $\begin{array}{l}{[83} \\
84]\end{array}$ & $0.3149^{f}$ & $2.860^{\mathrm{a}}$ & 0.09 & $630.80^{a}$ & 0.9 & 0.26011 \\
\hline 1,2,3,4-tetrahydronaphthalene & [95] & $0.3318^{f}$ & 3.630 & 0.1 & 719.50 & 2 & 0.26194 \\
\hline 1,3,5-triethylbenzene & {$[96]$} & $0.5070^{f}$ & $2.330^{\mathrm{b}}$ & 0.115 & $679.00^{\mathrm{b}}$ & 2 & 0.24980 \\
\hline 1-phenylhexane & [79] & $0.4498^{f}$ & 2.350 & 0.07 & 695.00 & 7 & 0.25217 \\
\hline n-tridecane & {$[76]$} & $0.6099^{f}$ & 1.679 & 0.02 & 676.00 & 0.6 & 0.24324 \\
\hline 1-phenyloctane & [79] & $0.5845^{f}$ & 1.98 & 0.06 & 725.00 & 7 & 0.24749 \\
\hline n-pentadecane & {$[76]$} & $0.7192^{f}$ & 1.479 & 0.02 & 707.50 & 0.7 & 0.23836 \\
\hline n-hexadecane & {$[76]$} & $0.7442^{f}$ & 1.401 & 0.05 & 722.40 & 1.1 & 0.23659 \\
\hline octadecane & {$[76]$} & $0.8020^{f}$ & 1.292 & 0.11 & 747.70 & 1 & 0.23473 \\
\hline nonadecane & {$[77]$} & $0.8722^{f}$ & 1.160 & 0.023 & 755.30 & 7.6 & 0.23337 \\
\hline 1-phenylhexadecane & [79] & $0.9055^{f}$ & $1.279^{d}$ & 0.06 & $827.35^{d}$ & 7 & 0.23682 \\
\hline tetracosane & {$[77]$} & $1.1840^{f}$ & 1.075 & 0.2 & $799.8^{c}$ & 8 & 0.22839 \\
\hline squalane & & $1.2436^{f}$ & $0.900^{\mathrm{e}}$ & 0.2 & $820.00^{\mathrm{e}}$ & 15 & 0.23296 \\
\hline methane & {$[97]$} & $0.0100^{f}$ & 4.599 & 0.017 & 190.56 & 0.01 & 0.28927 \\
\hline ethane & {$[98]$} & $0.0990^{f}$ & 4.885 & 0.0002 & 305.36 & 0.01 & 0.28085 \\
\hline propane & [99] & $0.1520^{f}$ & 4.260 & 0.005 & 370.01 & 0.03 & 0.27657 \\
\hline carbon Dioxide & [100] & $0.2310^{f}$ & 7.378 & 0.007 & 304.16 & 0.082 & 0.27256 \\
\hline
\end{tabular}

a reference 83 was used for the experimental critical temperature while reference 84 was used for the experimental criticial pressure; ${ }^{\mathrm{b}}$ reference 96 was used for the critical temperature while the critical pressure was calculated using the Ambrose-Walton method; c reference 77 was only used to obtain the critical temperature while the critical pressure was obtained by fitting to match the available binary data of tetraacosane $+\mathrm{CO}_{2}$ and tetracosane + ethane; ${ }^{d}$ calculated using the correlation function given in reference 79; e fitted againet available binary data of squalane $+\mathrm{CO}_{2}$ and squalane + methane; ${ }^{f}$ calculated from the available vapor pressure data with the use of equation 24 for the acentric factor. 
Table 9. Optimized binary interaction values for $\mathrm{CO}_{2}-\mathrm{CH}_{4}$ and squalane- $\mathrm{CH}_{4}$

\begin{tabular}{|c|c|c|c|c|c|c|}
\hline & \multicolumn{3}{|c|}{ PPR78 EoS } & \multicolumn{3}{c|}{$\mathrm{PR}_{2}$ SRK EoS } \\
\hline$T(\mathrm{~K})$ & Soave alpha & \multicolumn{2}{|c|}{$\mathrm{B}-\mathrm{M}$ alpha } & Soave alpha & \multicolumn{2}{c|}{ B-M alpha } \\
\hline & $\mathrm{CO}_{2}-\mathrm{CH}_{4}$ & $\mathrm{CO}_{2}-\mathrm{CH}_{4}$ & $\mathrm{Squ}-\mathrm{CH}_{4}$ & $\mathrm{CO}_{2}-\mathrm{CH}_{4}$ & $\mathrm{CO}_{2}-\mathrm{CH}_{4}$ & Squ-CH \\
\hline 298.15 & -0.01 & $\mathrm{~N} / \mathrm{A}$ & $\mathrm{N} / \mathrm{A}$ & $\mathrm{N} / \mathrm{A}$ & $\mathrm{N} / \mathrm{A}$ & N/A \\
\hline 323.15 & -0.07 & -0.07 & 0.03 & $\mathrm{~N} / \mathrm{A}$ & $\mathrm{N} / \mathrm{A}$ & N/A \\
\hline 373.15 & -0.2 & -0.2 & -0.01 & -0.08 & -0.08 & -0.01 \\
\hline 423.15 & -0.25 & -0.25 & -0.05 & -0.05 & $0.1613^{\mathrm{a}}$ & -0.05 \\
\hline
\end{tabular}

a The fitting of this parameter yielded a value which is almost same as the value predicted by the group contribution method, and hence we used the predicted value 


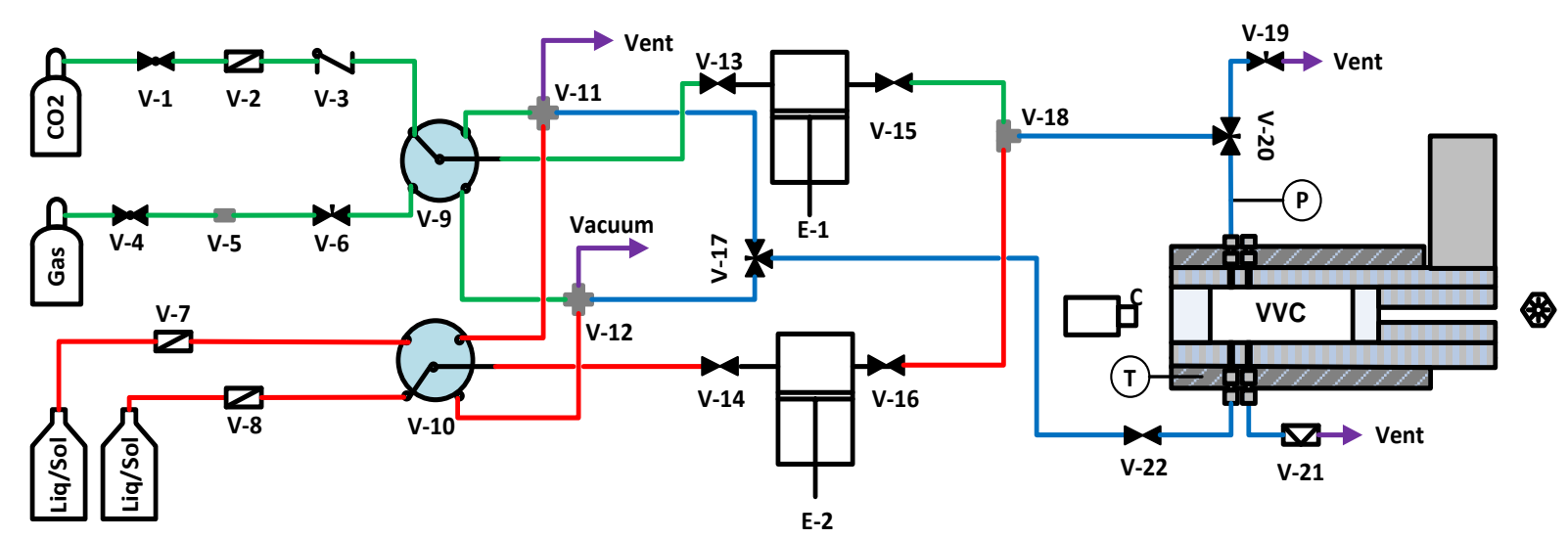

Figure. 1. Schematic diagram of the variable volume cell apparatus: $\vee-1$, on/off valve; $\vee-2$, filter; V-3, check valve; $\mathrm{V}-4$, on/off valve; $\mathrm{V}-5$, reducer; $\mathrm{V}-6$ valve; $\mathrm{V}-7$ and $\mathrm{V}-8$, filter; $\mathrm{V}-9$ and $\mathrm{V}-10,5$ way electrically actuated valves; $\mathrm{V}-11$ and $\mathrm{V}-12$, union crosses; $\mathrm{V} 13$ to $\mathrm{V} 16$, check valves; V17, three way electrically actuated valve; $\mathrm{V}-18$, tee; $\mathrm{V}-19$, two way manual valve; $\mathrm{V}$ 20 , three way manual valve; $\mathrm{V}-21$ safety head; $\mathrm{V}-22$, two way air operated normally closed valve; VVC, variable volume cell; $\mathrm{E}-1$ and $\mathrm{E}-2$, high pressure syringe pumps; notation $\mathrm{P}$ and $T$ indicates pressure transducer and temperature sensors respectively. Green colour indicates gas paths, red colour indicates liquid paths, and blue colour indicates mixture paths 


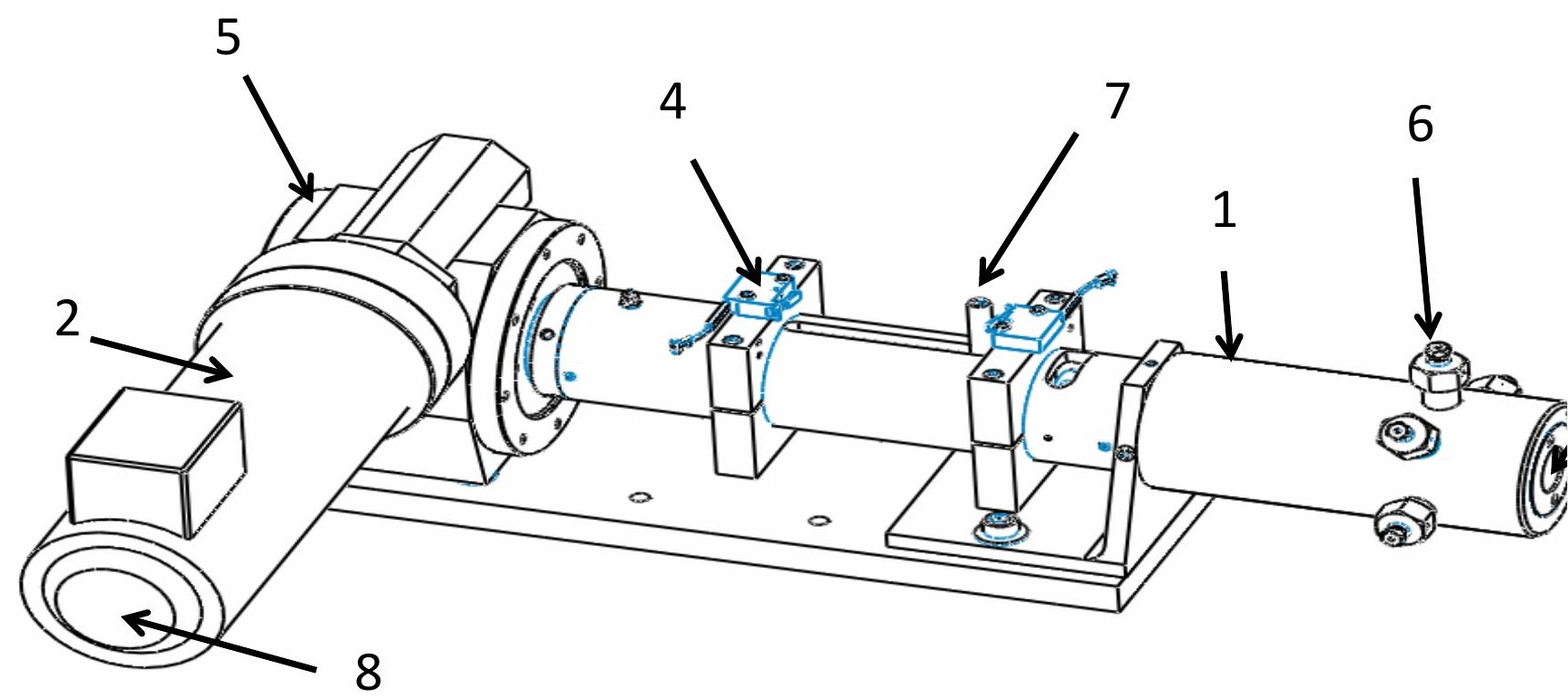

Figure 2. Perspective drawing of the variable volume cell assembly: (1) equilibrium cell; (2) servo motor; (3) sapphire window; (4) limit switches; (5) gear box; (6) high pressure ports; (7) lead screw with position indicator; (8) encoder. 


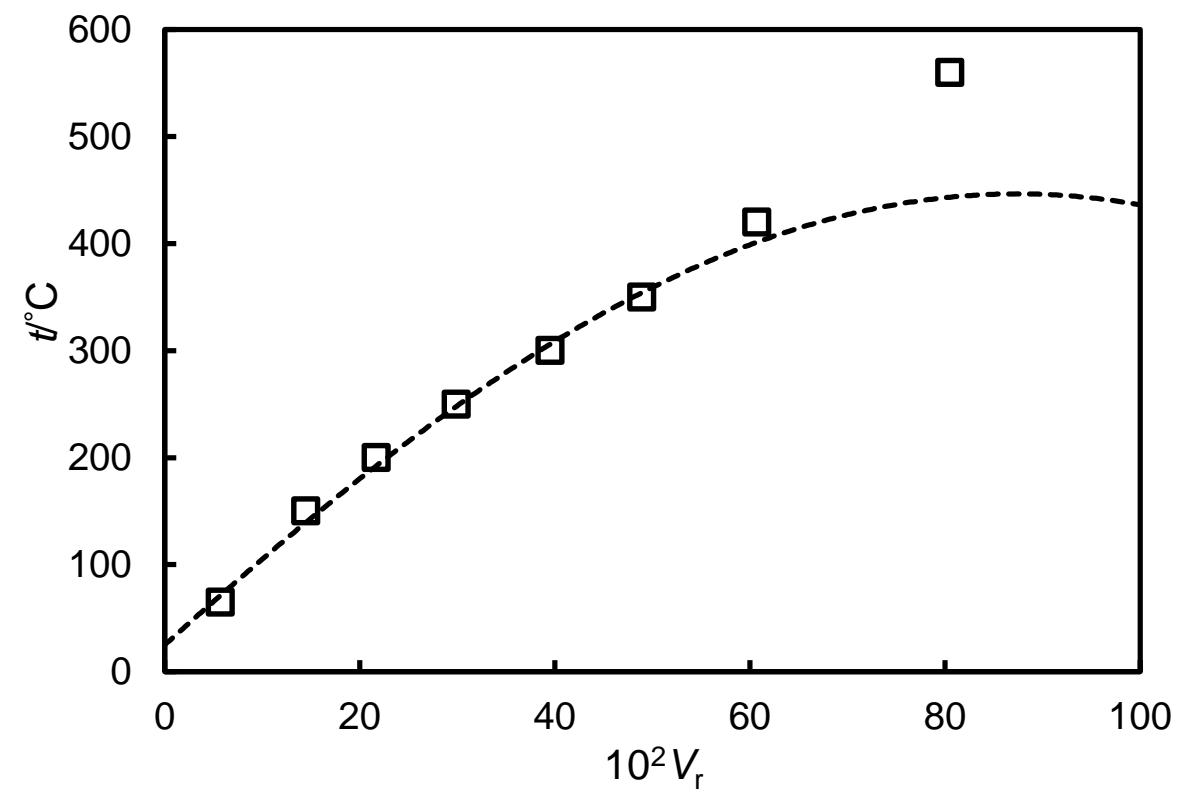

Figure 3. True boiling curve: Celsius boiling temperature $t$ as a function of cumulative volume fraction $V_{\mathrm{r}}$ : $\square$, experimental data from Table 2; dashed curve, simulated for the synthetic dead oil. 

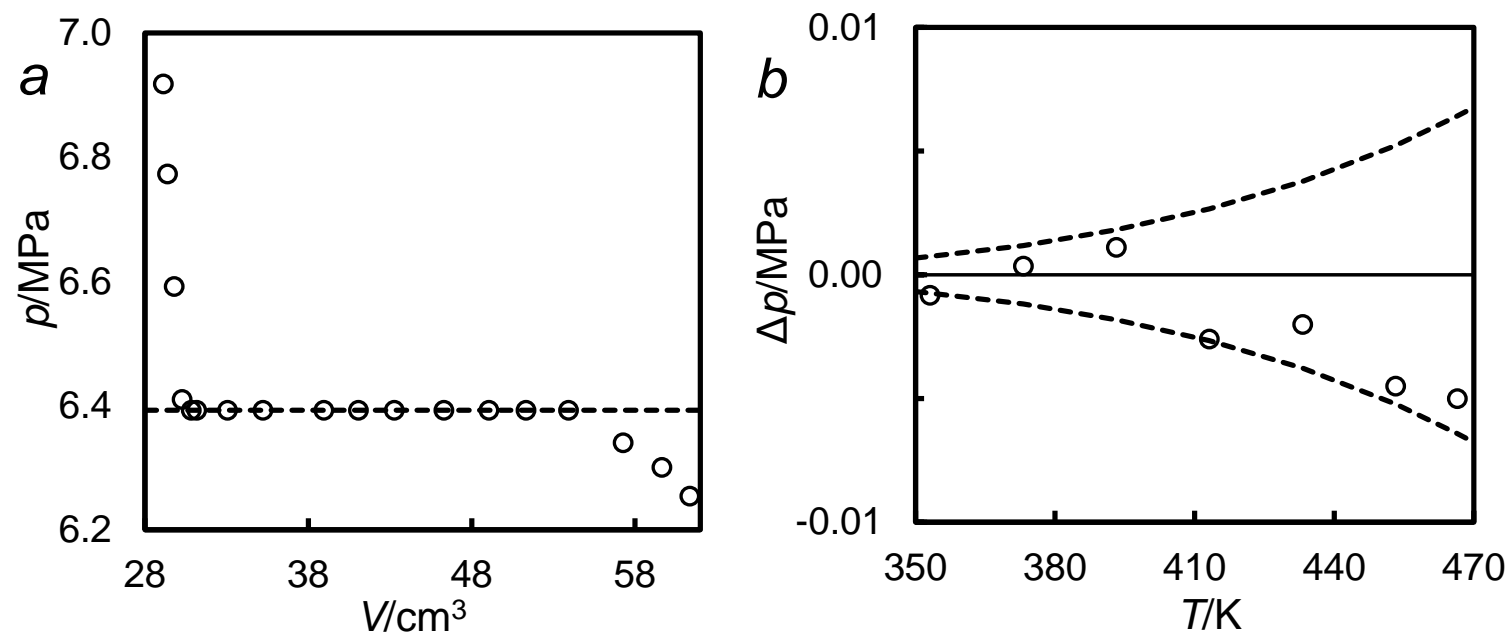

Figure 4. (a) Pressure-volume plot for $\mathrm{CO}_{2}$ at $T=298.15 \mathrm{~K}$ : $\mathrm{O}$, experimental data; - - - - , vapor pressure of $\mathrm{CO}_{2}$ at $T=298.15$ from the equation of state of Span and Wagner. (b) Deviations $\Delta p=p_{\text {exp }}-p_{\text {calc }}$ of experimental vapor pressures $p_{\text {exp }}$ of pentane from the values $p_{\text {calc }}$ calculated from the equation of state of Span: $O$, experimental data; - - - - uncertainty limits of the calculated vapor pressure. 


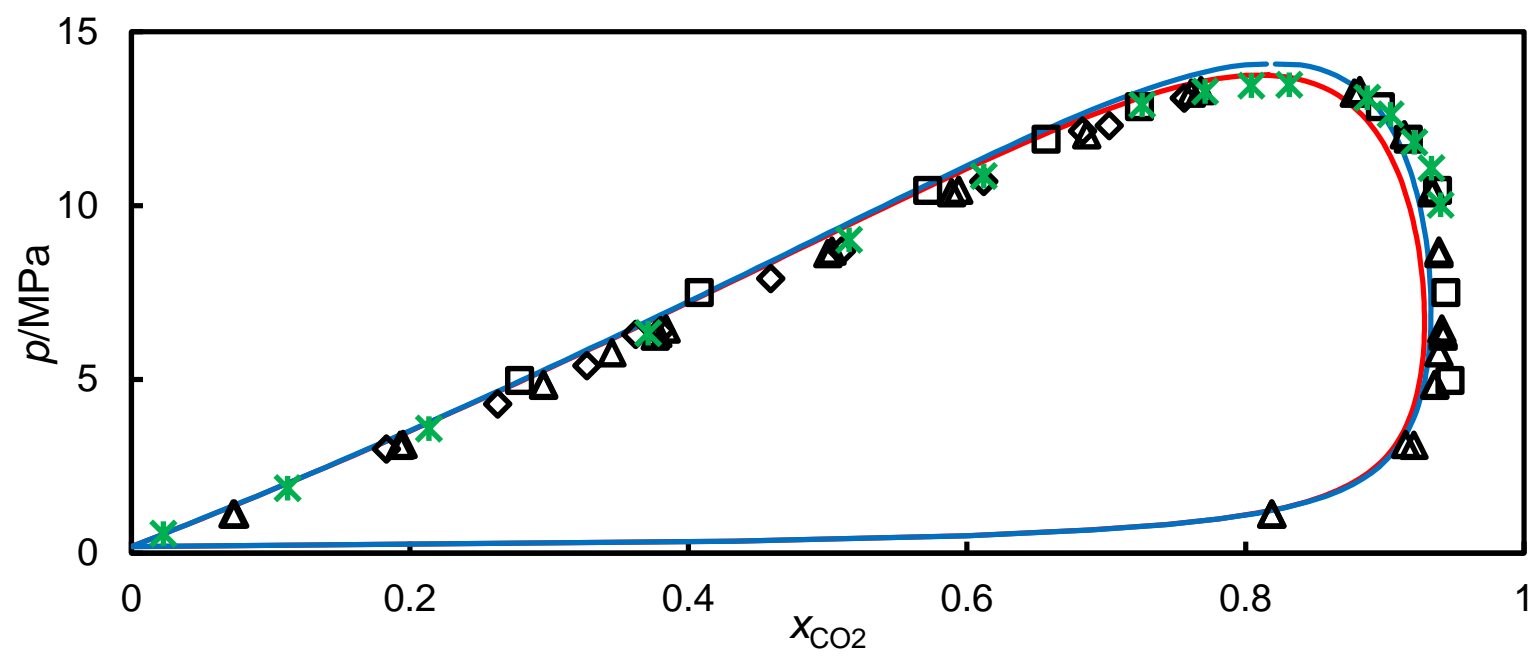

Figure 5. Bubble- and dew-point pressures $p$ for $\left(\mathrm{CO}_{2}+\right.$ heptane) as a function of the mole fraction $x_{\mathrm{CO}_{2}}$ of $\mathrm{CO}_{2}$ at $T=394.15 \mathrm{~K}: *$, this work; $\diamond$, Mutelet et al. [62]; $\triangle$, Kalra et.al [63]; $\square$, Inomata et al. [64]. Curves show the predictions of the PPR78 EoS with $k_{12}=0.1156$ (red) and the $\mathrm{PR}_{2}$ SRK EoS with $k_{12}=0.1356$ (blue). 



Figure 6. Bubble- and dew-point pressures $p$ as a function of the mole fraction $x_{\mathrm{CO}_{2}}$ of $\mathrm{CO}_{2}$ for (a) $\left(\mathrm{CO}_{2}+\right.$ dead oil), (b) $\left(\mathrm{CO}_{2}\right.$ + live oil 1), (c) $\left(\mathrm{CO}_{2}+\right.$ live oil 2$): \triangle, T=323.15 \mathrm{~K} ; \mathrm{O}, T=373.15$ and $\square, T=423.15 \mathrm{~K}$. Curves show the predictions of the PPR78 EoS with the Soave alpha function and either no binary parameters adjusted (dashed curves) or $\mathrm{k}_{\mathrm{CO}_{2}-\mathrm{CH}_{4}}$ fitted to the bubble pressures of the live oil 2 (solid curves). 

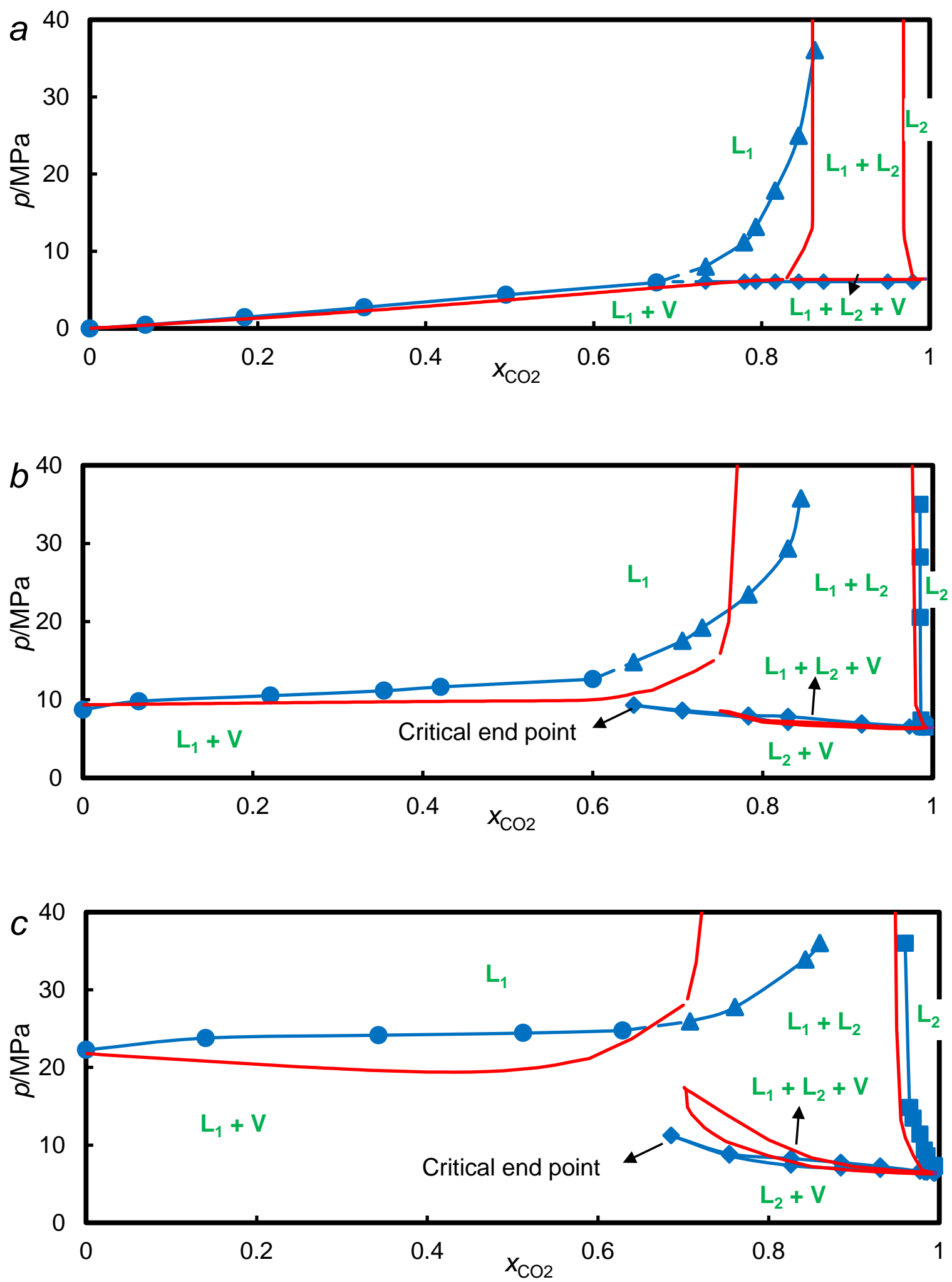

Figure 7. Phase-boundary pressures $p$ as a function of the mole fraction $x_{\mathrm{CO}_{2}}$ of $\mathrm{CO}_{2}$ for (a) ( $\mathrm{CO}_{2}+$ dead oil), (b) $\left(\mathrm{CO}_{2}+\right.$ live oil 1), (c) $\left(\mathrm{CO}_{2}+\right.$ live oil 2$)$ at $T=298.15 \mathrm{~K}: \odot, \mathrm{VLE} ; \boldsymbol{\square}$, LLE; $\diamond$, VLLE. Blue curves connect experimental points. Red curves show the predictions of the PPR78 EoS with the Soave alpha function. 


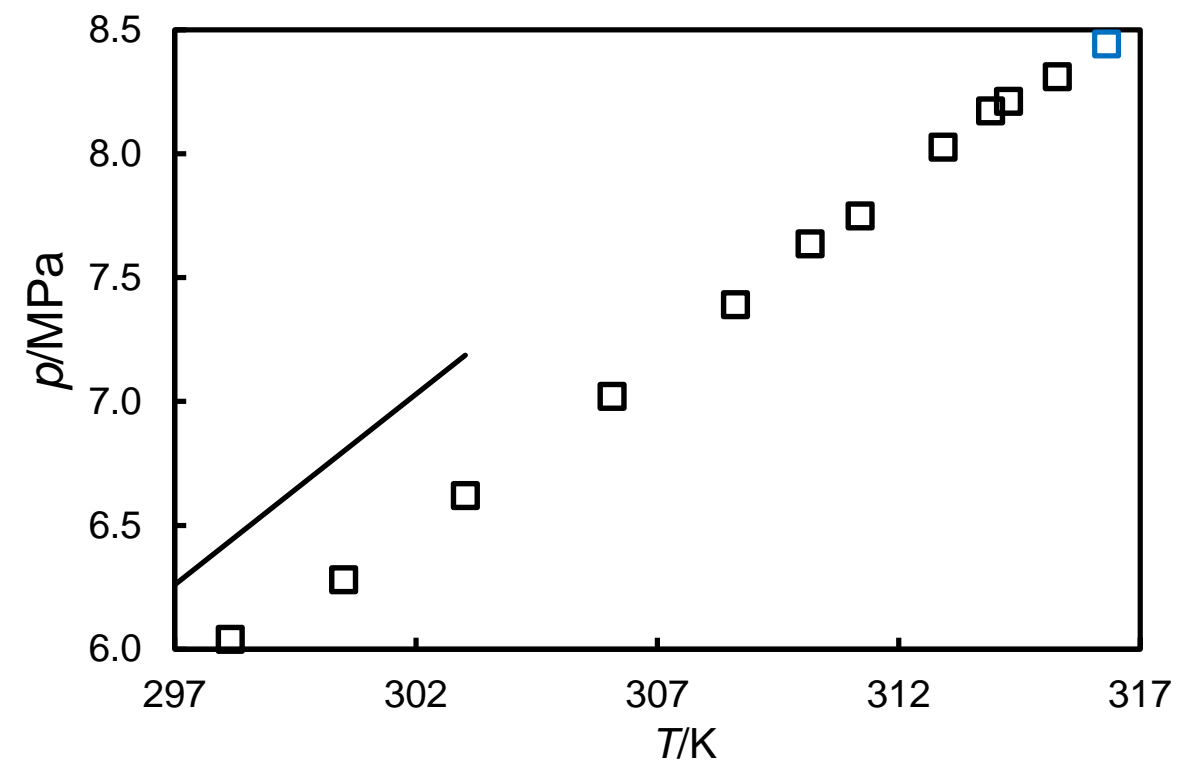

Figure 8. Three-phase VLLE locus for the $\left(\mathrm{CO}_{2}+\right.$ dead oil) mixture: $\square$ three-phase pressure; $\square$ upper critical end point (UCEP); black solid line, vapor pressure of pure $\mathrm{CO}_{2}$. 

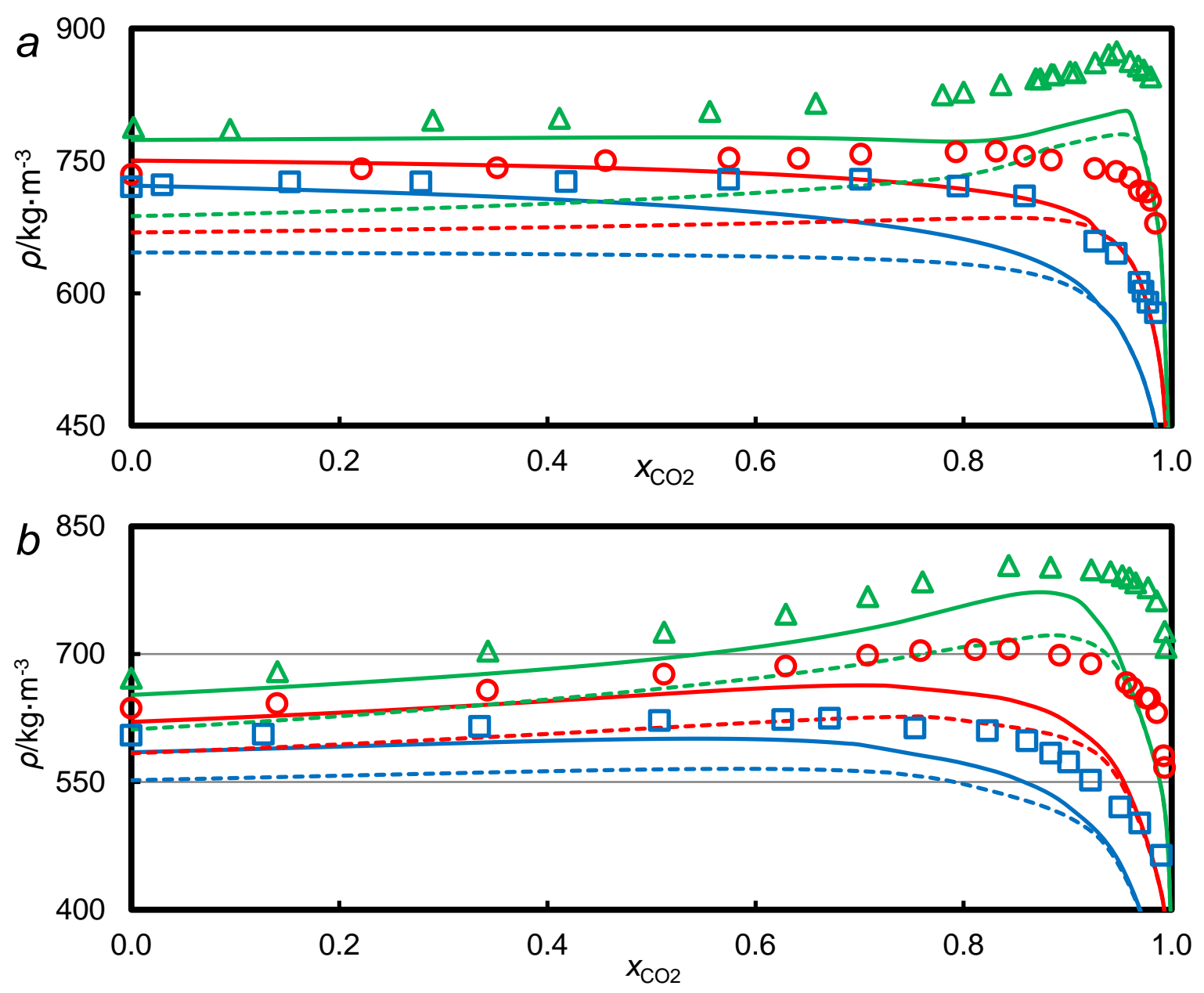

Figure 9. Saturated phase densities $\rho$ as a function of the mole fraction $\mathrm{X}_{\mathrm{CO}_{2}}$ of $\mathrm{CO}_{2}$ for (a) $\left(\mathrm{CO}_{2}+\right.$ dead oil $)$ and (b) $\left(\mathrm{CO}_{2}+\right.$ live oil 2): $\triangle, T=323.15 \mathrm{~K} ; \mathrm{O}, T=373.15$ and $\square, T=423.15$ $\mathrm{K}$. Curves show the predictions of the PPR78 EoS with the Soave alpha function and either no volume translation (dashed curve) or the Peneloux volume translation (solid curves). 


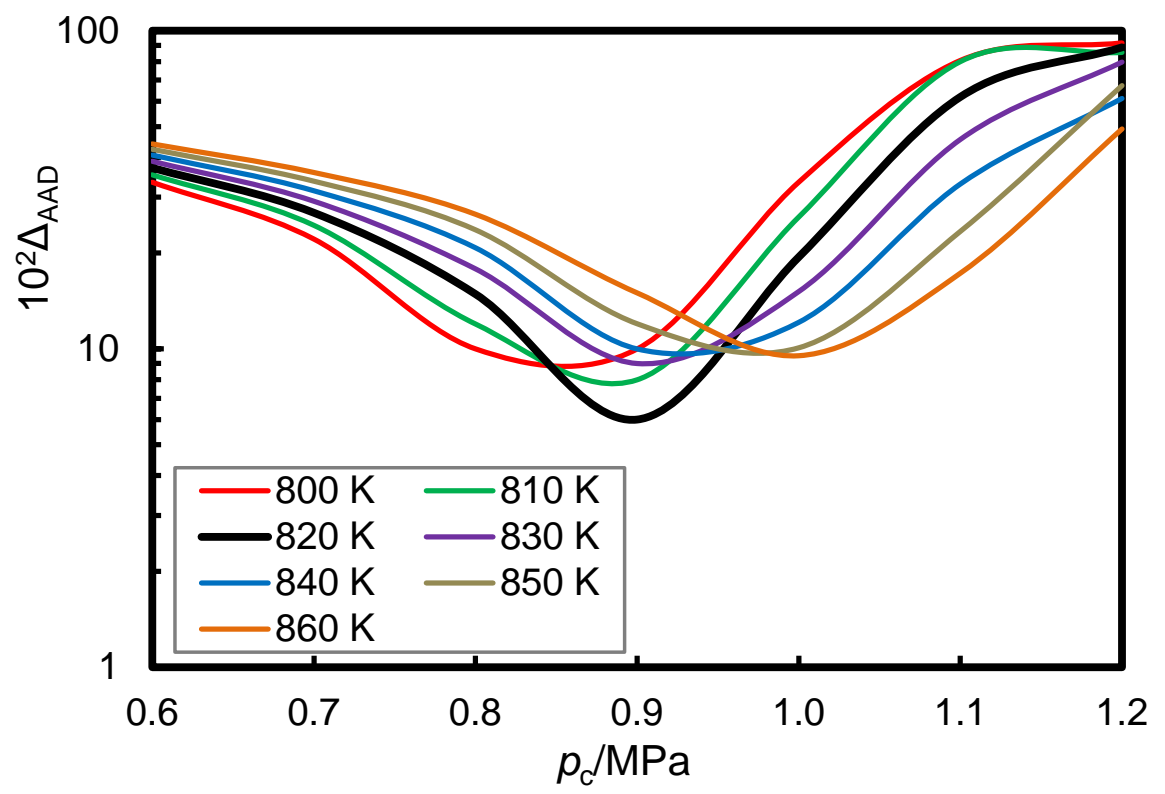

Figure 10. Absolute average deviation $\triangle_{\mathrm{AAD}}$ of experimental VLE data for $\left(\mathrm{CO}_{2}+\right.$ squalane $)$ and $\left(\mathrm{CH}_{4}+\right.$ squalane $)$ from the PPR78 EoS with different values of the critical temperature $T_{\mathrm{c}}$ and critical pressure $p_{\mathrm{c}}$ for squalane. 


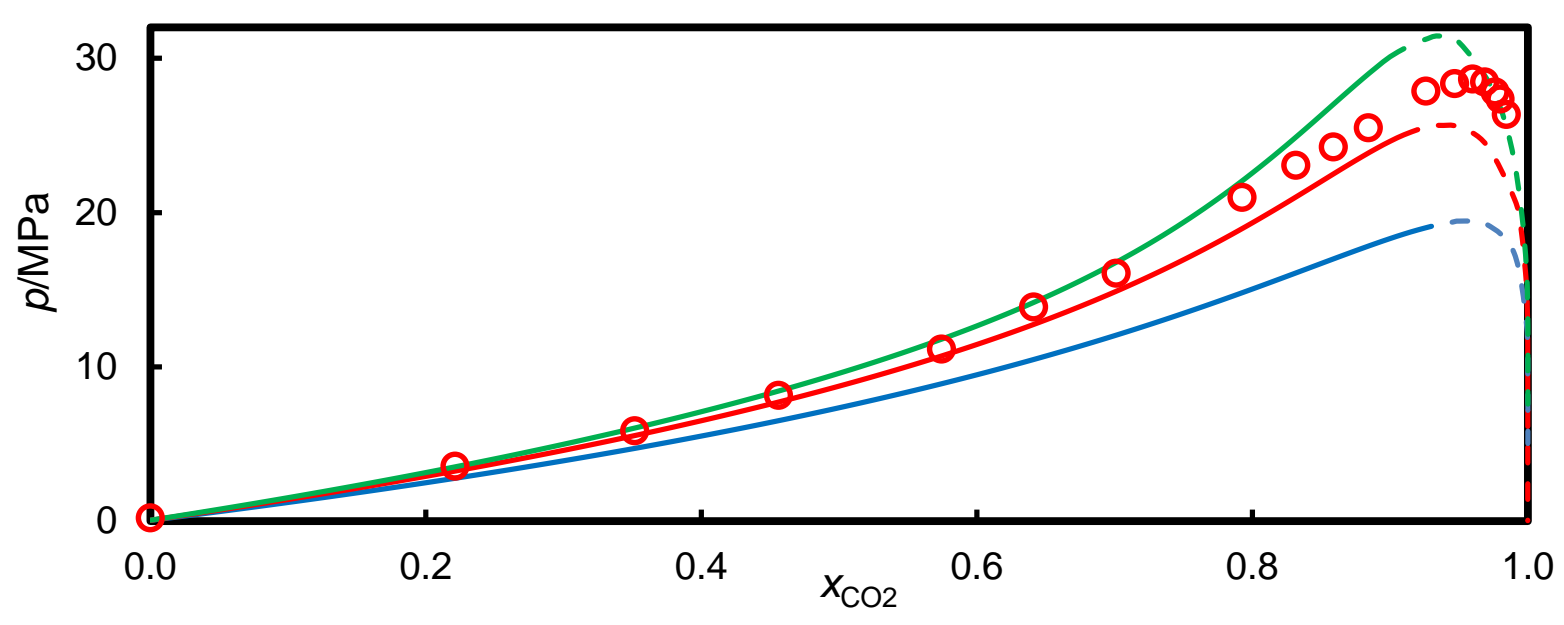

Figure 11. Bubble- and dew-point pressures $p$ as a function of the mole fraction $\mathrm{x}_{\mathrm{CO}_{2}}$ of $\mathrm{CO}_{2}$ for $\left(\mathrm{CO}_{2}+\right.$ dead oil) at $T=373.15 \mathrm{~K}: \mathrm{O}$, experimental data. Curves show the predictions of the PPR78 EoS with the Soave alpha function and different critical constants for squalane: blue curve, $T_{\mathrm{c}}=822 \mathrm{~K}$ and $p_{\mathrm{c}}=0.70 \mathrm{MPa}$ [86]; green curve, $T_{\mathrm{c}}=822.89 \mathrm{~K}$ and $p_{\mathrm{c}}=1.13 \mathrm{MPa}$ [45]; red curve $T_{\mathrm{c}}=820 \mathrm{~K}$ and $p_{\mathrm{c}}=0.90 \mathrm{MPa}$, determined in this work. 



Figure 12. Bubble- and dew-point pressures $p$ as a function of the mole fraction $\mathrm{X}_{\mathrm{CO}_{2}}$ of $\mathrm{CO}_{2}$ for (a) $\left(\mathrm{CO}_{2}+\right.$ dead oil $),\left(\right.$ b) $\left(\mathrm{CO}_{2}+\right.$ live oil 1$)$, (c) $\left(\mathrm{CO}_{2}+\right.$ live oil 2$): \triangle, T=323.15 \mathrm{~K} ; \mathrm{O}, T$ $=373.15$ and $\square, T=423.15 \mathrm{~K}$. Curves show the predictions of the PPR78 EoS with the BostonMathias alpha function and either no binary parameters adjusted (dashed curves) or $k_{\mathrm{CO}_{2}-\mathrm{CH}_{4}}$ fitted to the bubble pressures of the live oil 2 and $k_{\text {squalane- } \mathrm{CH}_{4}}$ fitted to the bubble pressure of the live oil 2 at $x_{\mathrm{CO}_{2}}=0$ (solid curves). 

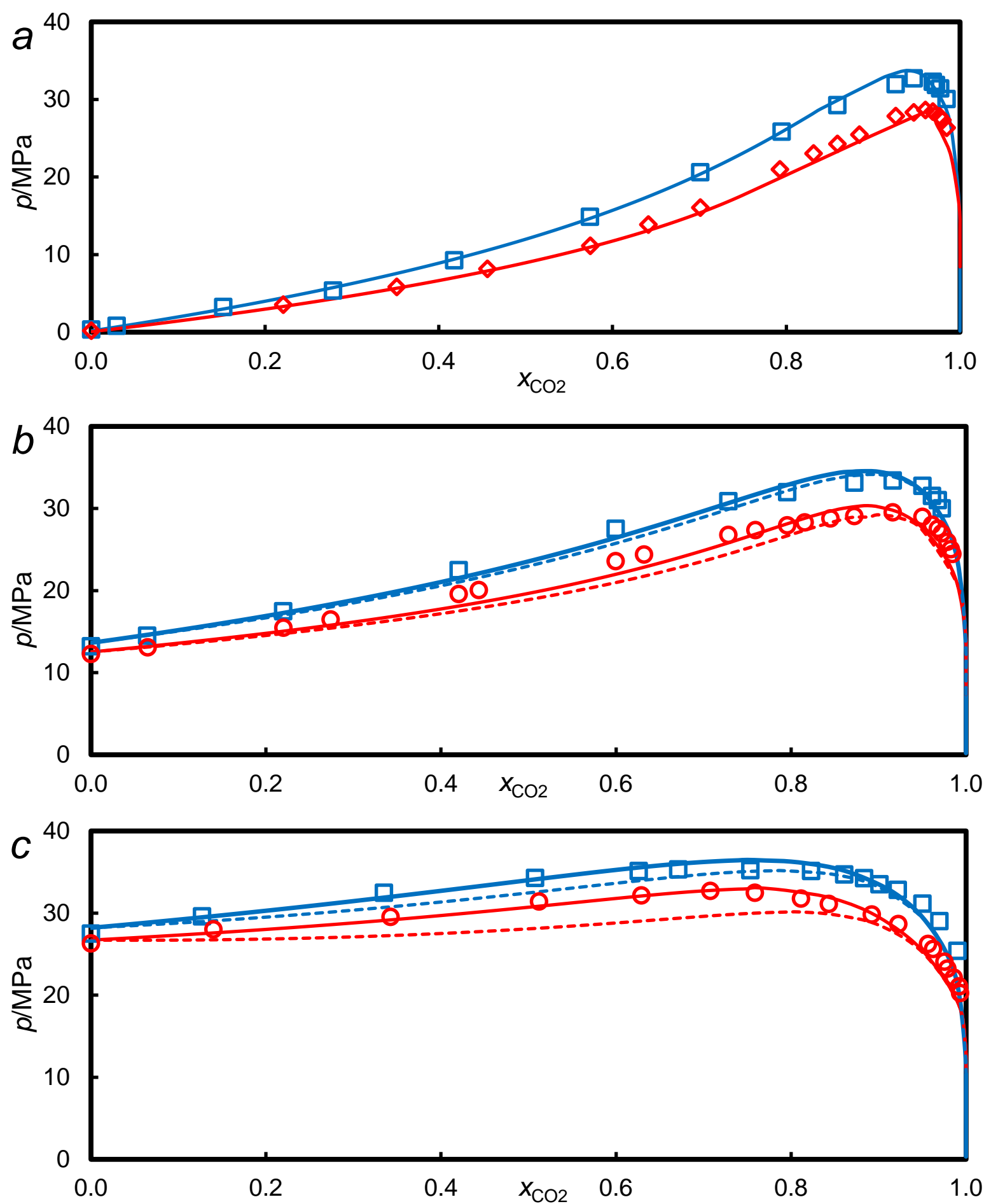

Figure 13. Bubble- and dew-point pressures $p$ as a function of the mole fraction $\mathrm{XCO}_{2}$ of $\mathrm{CO}_{2}$ for (a) $\left(\mathrm{CO}_{2}+\right.$ dead oil), (b) $\left(\mathrm{CO}_{2}+\right.$ live oil 1), (c) $\left(\mathrm{CO}_{2}+\right.$ live oil 2$): \triangle, T=323.15 \mathrm{~K} ; \mathrm{O}, T$ $=373.15$ and $\square, T=423.15 \mathrm{~K}$. Curves show the predictions of the $\mathrm{PP}_{2} \mathrm{SRK}$ EoS with the Soave alpha function and either no binary parameters adjusted (dashed curves) or $\mathrm{K}_{\mathrm{CO}_{2}-\mathrm{CH}_{4}}$ fitted to the bubble pressures of the live oil 2 (solid curves). 

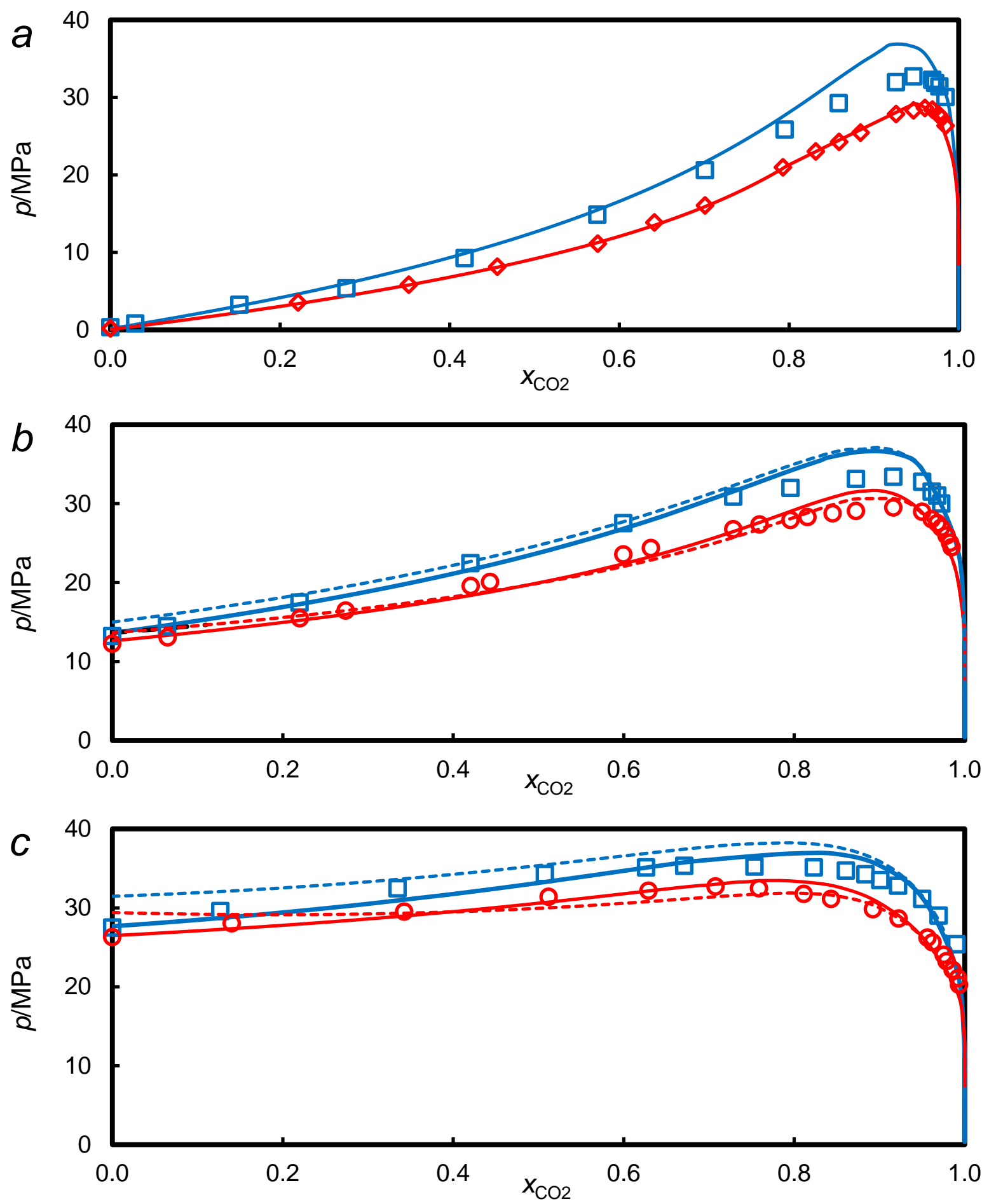

Figure 14. Bubble- and dew-point pressures $p$ as a function of the mole fraction $x_{\mathrm{CO}_{2}}$ of $\mathrm{CO}_{2}$ for (a) $\left(\mathrm{CO}_{2}+\right.$ dead oil $)$, (b) $\left(\mathrm{CO}_{2}+\right.$ live oil 1$)$, (c) $\left(\mathrm{CO}_{2}+\right.$ live oil 2$): \triangle, T=323.15 \mathrm{~K} ; \mathrm{O}, T$ $=373.15$ and $\square, T=423.15 \mathrm{~K}$. Curves show the predictions of the $\mathrm{PP}_{2} \mathrm{SRK}$ EoS with the Boston-Mathias alpha function and either no binary parameters adjusted (dashed curves) or $k_{\mathrm{CO}_{2}-\mathrm{CH}_{4}}$ fitted to the bubble pressures of the live oil 2 and $k_{\text {squalane- } \mathrm{CH}_{4}}$ fitted to the bubble pressure of the live oil 2 at $x_{\mathrm{CO}_{2}}=0$ (solid curves). 


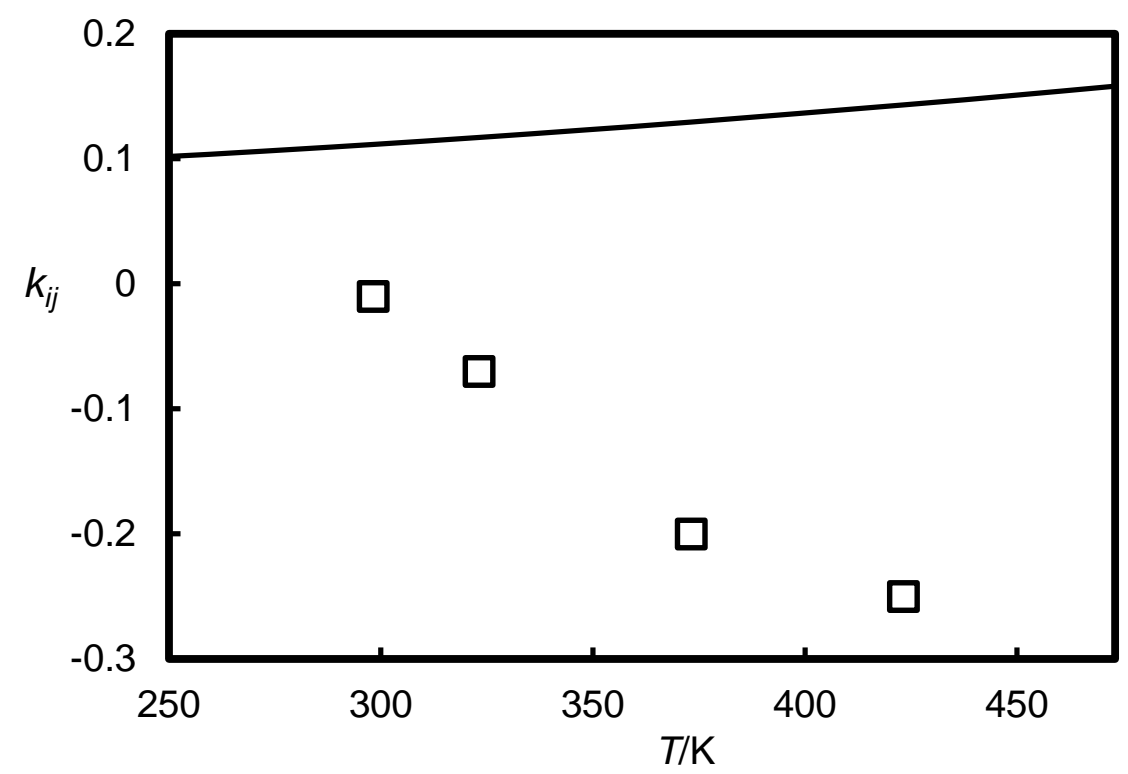

Figure 15. Binary interaction parameters for $\mathrm{CO}_{2}-\mathrm{CH}_{4}$ : $\square$, optimized in this work; solid curve, prediction of PPR78 with the Soave alpha function. 